\title{
Hormone-induced changes in the coagulation system
}

Citation for published version (APA):

Tchaikovski, S. N. (2009). Hormone-induced changes in the coagulation system. [Doctoral Thesis, Maastricht University]. Datawyse / Universitaire Pers Maastricht. https://doi.org/10.26481/dis.20091216st

Document status and date:

Published: 01/01/2009

DOI:

10.26481/dis.20091216st

Document Version:

Publisher's PDF, also known as Version of record

\section{Please check the document version of this publication:}

- A submitted manuscript is the version of the article upon submission and before peer-review. There can be important differences between the submitted version and the official published version of record.

People interested in the research are advised to contact the author for the final version of the publication, or visit the DOI to the publisher's website.

- The final author version and the galley proof are versions of the publication after peer review.

- The final published version features the final layout of the paper including the volume, issue and page numbers.

Link to publication

\footnotetext{
General rights rights.

- You may freely distribute the URL identifying the publication in the public portal. please follow below link for the End User Agreement:

www.umlib.nl/taverne-license

Take down policy

If you believe that this document breaches copyright please contact us at:

repository@maastrichtuniversity.nl

providing details and we will investigate your claim.
}

Copyright and moral rights for the publications made accessible in the public portal are retained by the authors and/or other copyright owners and it is a condition of accessing publications that users recognise and abide by the legal requirements associated with these

- Users may download and print one copy of any publication from the public portal for the purpose of private study or research.

- You may not further distribute the material or use it for any profit-making activity or commercial gain

If the publication is distributed under the terms of Article $25 \mathrm{fa}$ of the Dutch Copyright Act, indicated by the "Taverne" license above, 


\section{Hormone-induced Changes in the Coagulation System}




\section{Hormone-induced Changes in the Coagulation System}

ISBN 9789052788951

Layout and cover by Svetlana N. Tchaikovski

Printed by Datawyse BV । Universitaire Pers Maastricht

(C) S.N. Tchaikovski, Maastricht 2009 


\title{
Hormone-induced Changes in the Coagulation System
}

\author{
PROEFSCHRIFT
}

ter verkrijging van de graad van doctor aan de Universiteit Maastricht op gezag van de Rector Magnificus, Prof. mr. G.P.M.F. Mols, volgens het besluit van het College van Decanen, in het openbaar te verdedigen op woensdag 16 december 2009 om 12:00 uur

door

Svetlana Nikolayevna Tchaikovski

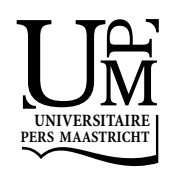




\section{Promotor}

Prof. dr. J. Rosing

\section{Copromotor}

Dr. G. Tans

\section{Beoordelingscommissie}

Prof. dr. J.G.R. de Mey (voorzitter)

Prof. dr. I. Pabinger (University of Vienna, Austria)

Dr. L.L.H. Peeters

Prof. dr. M.H. Prins

Prof. dr. C.D.A. Stehouwer

Financial support by Kordia, Rossix, Thrombinoscope BV, Nodia, Instrumentation laboratories and American Diagnostica for the publication of this thesis is gratefully acknowledged. 
"Science is wonderfully equipped to answer the question "How?" but it gets terribly confused when you ask the question "Why?"'" Erwin Chargaff 



\section{Contents}

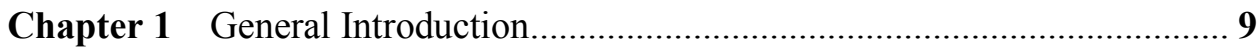

Chapter 2 Venous Thrombosis and Oral Contraceptives: Current Status....... 21

Chapter 3 Effect of Oral Contraceptives on Thrombin Generation Measured via Calibrated Automated Thrombography (CAT) ........................ 43

Chapter 4 Effect of Non-oral Hormonal Contraceptives on the Haemostatic

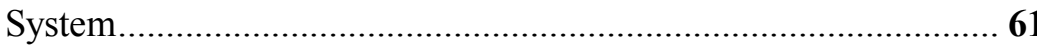

Chapter 5 Development of a Calibrated Automated Thrombography-based Thrombin Generation Test in Mouse Plasma

Chapter 6 Pregnancy-associated Changes in the Haemostatic System in Wild-type and Factor $\mathrm{V}_{\text {Leiden }}$ Mice

Chapter 7 Summary and General Discussion.............................................. 115

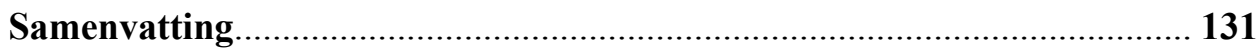

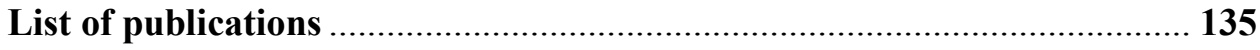

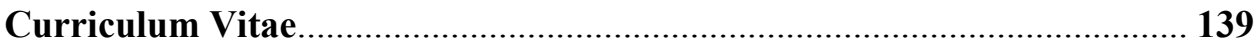

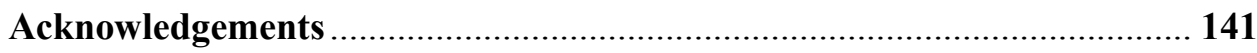





\section{Chapter 1}

General Introduction 


\section{Blood Coagulation}

The cardiovascular system carries out many vital functions in the human body, the major one of which is the transport of blood through a network of vessels to provide individual cells with oxygen and nutrients and to remove the metabolic waste. It is therefore essential for survival that blood flow is tightly regulated. The coagulation system is a specialized biological machinery that maintains blood in a fluid state under normal conditions and that responds to vessel injury by rapid formation of a clot to prevent blood loss. Haemostasis is a dynamic process in which blood coagulation is initiated and terminated in a rapid and tightly regulated fashion which requires coordinated interactions between tissue components, platelets and plasma proteins.

Primary haemostatic events are triggered in response to damage of the vascular wall by the exposure of blood to the subendothelial extracellular matrix. Platelets adhere to the injured vessel wall, become activated and subsequently recruit other platelets from flowing blood to form platelet aggregates. Platelet activation is accompanied by major morphological changes of the platelets including rearrangement of membrane phospholipids and exposure of negatively charged phosphatidylserine and release of the content of internal stores, which contributes to the regulation of haemostasis. The negatively charged phospholipids on the surface of the activated platelets increase the efficacy of a number of pro- and anticoagulant reactions.

At the same time, exposure of extravascular tissue factor (TF) to blood triggers the coagulation system. Coagulation comprises the sequential activation of coagulation factors in a cascade-like fashion (Fig. 1). Each coagulation factor acts as the substrate for the previous factor and once activated becomes the activator of the next coagulation factor one step down the cascade. Coagulation factors circulate in a non-active form (zymogen) and their activation occurs through limited proteolysis to form active proteases (thrombin, factors IXa, Xa, $\mathrm{XIa}$, etc.) or protease cofactors (factors Va, VIIIa). The coagulation cascade is initiated as a result of the interaction between factor VII and factor VIIa with exposed TF. The TF/factor VIIa complex activates factor $\mathrm{X}$ to factor $\mathrm{Xa}$, which subsequently converts prothrombin (factor II) into thrombin (factor IIa), a multifunction protease that promotes its own formation by a number of positive feedback loops. Small amounts of thrombin activate factors V, VIII and XI. Factor XIa converts factor IX into factor IXa, which assembles with its nonenzymatic cofactor factor VIIIa on the negatively charged phospholipid surface to form the so-called "intrinsic tenase", which efficiently generates factor Xa. Factor Xa assembles on the surface of activated platelets with factor Va to form 
the "prothrombinase complex", which exhibits greatly enhanced catalytic activity of prothrombin activation as compared to factor Xa alone. The positive feedback loops initiated by the first traces of thrombin result in a large burst of thrombin generation. Thrombin converts fibrinogen into fibrin, which polymerizes into fibrin strands that become cross-linked by factor XIIIa (also activated by thrombin) and which stabilizes the initially formed platelet thrombus.

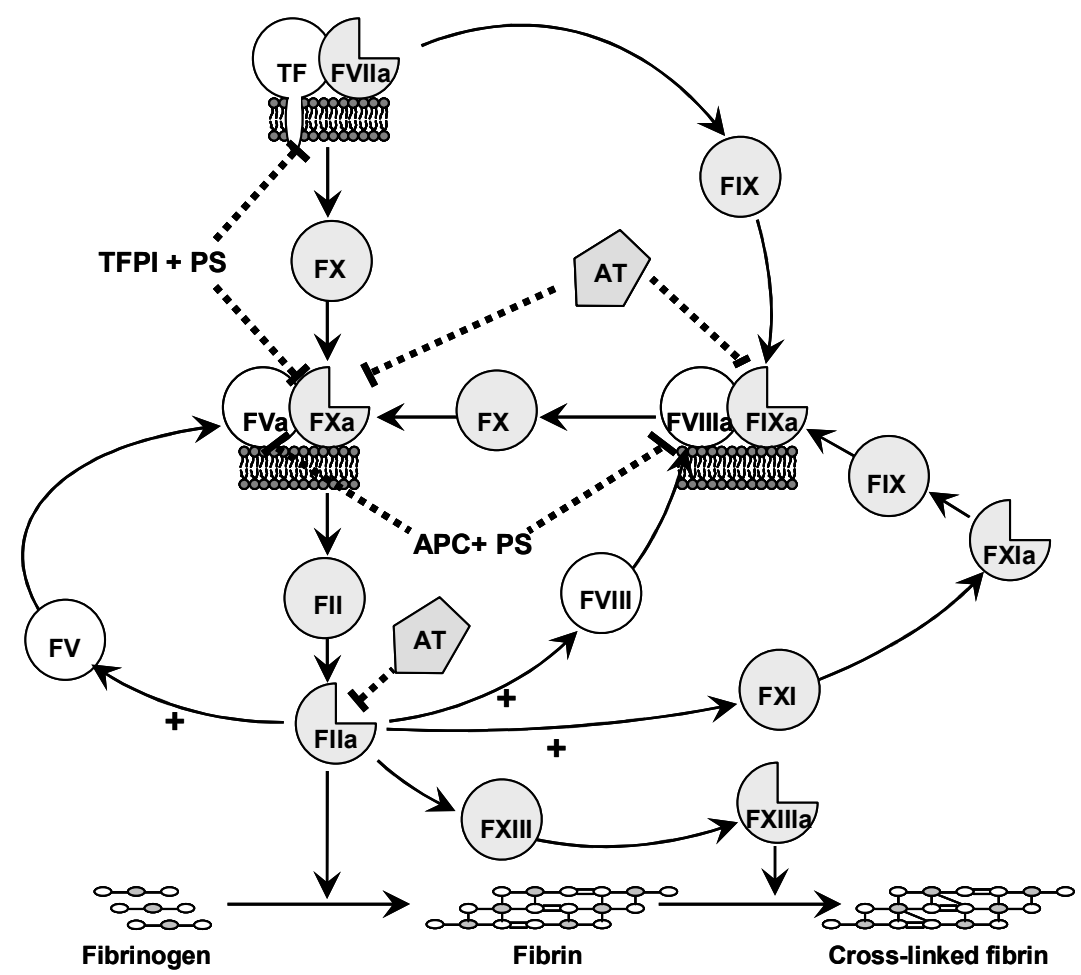

Fig. 1. Schematic Representation of the Coagulation Cascade

The sequential activation of coagulation factors (F), indicated with roman numbers, occurs in a cascade-like fashion and eventually leads to the formation of thrombin. Thrombin promotes its own formation by a number of positive feedback loops $(+)$ and cleaves fibrinogen to fibrin. Fibrin strands together with platelets form a thrombus. The coagulation cascade is down-regulated by the anticoagulant system at several levels (dashed lines). AT: antithrombin; APC: activated protein C; PS: protein S; TFPI: tissue factor pathway inhibitor.

Blood coagulation is limited spatially to the site of injury and excessive thrombin formation is prevented by the anticoagulant system that acts at several levels of the coagulation cascade. The inhibitors of blood coagulation are summarized in Table 1. 
Table 1. Anticoagulant Proteins Regulating Blood Coagulation

\begin{tabular}{|l|l|l|}
\hline Inhibitor / cofactor & Target protease & Reference \\
\hline Antithrombin / heparin & Thrombin, factors VIIa, IXa, Xa, XIa, XIIa & 1 \\
\hline$\alpha_{2}$-macroglobulin & Thrombin, plasmin & 2 \\
\hline $\begin{array}{l}\text { Tissue factor pathway inhibitor / } \\
\text { protein S }\end{array}$ & Factors VIIa, Xa & 3,4 \\
\hline Activated protein C/ protein S & Factors Va, VIIIa & $5-7$ \\
\hline $\begin{array}{l}\text { Protein Z-dependent protease inhibitor / } \\
\text { protein Z }\end{array}$ & Factors Xa, IXa & 8,9 \\
\hline Heparin cofactor II / heparin & Thrombin, Factor Xa & 10 \\
\hline Protein C inhibitor / heparin & Thrombin, activated protein C, t-PA & 11 \\
\hline$\alpha_{1}$-protease inhibitor & Thrombin & 12 \\
\hline
\end{tabular}

t-PA: tissue-type plasminogen activator.

The major anticoagulant proteins (systems) in plasma are:

1) Antithrombin, a serine protease inhibitor (serpin) that down-regulates coagulation by directly inhibiting activated coagulation factors (Table 1). The main targets of antithrombin are thrombin and factor $\mathrm{Xa}$ and its anticoagulant activity is greatly enhanced by heparin.

2) The protein $C$ system in which activated protein $C$ (APC), together with its non-enzymatic cofactor protein $\mathrm{S}$, inhibits thrombin formation via proteolytic inactivation of factor Va and factor VIIIa (Table 1).

3) The tissue factor pathway inhibitor (TFPI) system in which the Kunitztype protease inhibitor TFPI forms a complex with factor Xa that subsequently inhibits the TF pathway by forming a quaternary complex with TF/factor VIIa. The down-regulation of TF-mediated thrombin generation by TFPI is promoted by protein $\mathrm{S} .^{4}$

Under normal conditions, a delicate balance exists between the procoagulant and the anticoagulant pathways. However, a decrease of plasma levels or activity of procoagulant proteins due to inherited defects, liver diseases or anticoagulant treatment may lead to the development of a hemophilic phenotype and can ultimately cause bleeding. In contrast, an elevation of the plasma levels of procoagulant proteins or a decrease of the plasma levels or activity of anticoagulant proteins causes a pro-thrombotic state, which may result in excessive thrombin formation and the development of venous thrombosis (VT). 


\section{Venous Thrombosis}

VT is a condition in which a blood clot (thrombus) forms in a venous part of the cardiovascular system, which may embolise and enter the circulation until it lodges in a smaller blood vessel and obstructs the circulation, e.g. in lungs causing pulmonary embolism. VT occurs with an annual incidence of approximately 1 per 1000 in the adult population. ${ }^{13}$ About two-thirds of the thrombotic episodes manifest as deep vein thrombosis and one-third as pulmonary embolism with or without deep vein thrombosis. ${ }^{14}$ The major outcomes of VT are death, recurrence, post-thrombotic syndrome or major bleeding due to anticoagulant treatment.

Understanding of the pathogenesis of VT is crucial for the development of effective strategies for its prevention and treatment. In 1856 Rudolph Virchow outlined the so called Virchow's triad, which even to date still forms the basis of our understanding of VT. He postulated that development of thrombosis is the result of changes in the vessel wall, reduced blood flow and changes in blood composition. Examples of the pathophysiological factors that alter the vessel wall or slow down blood flow are trauma, surgery, malignancy, immobilization and infection. Whereas a vessel wall injury and stasis alone rarely result in the development of thromboembolism, (procoagulant) changes in blood composition appear to be the most important factor underlying many episodes of the disease. ${ }^{15}$ Prothrombotic changes in the coagulation system may occur due to either an elevation in the plasma levels of procoagulant proteins ${ }^{16-}$ ${ }^{19}$ or deficiencies in the anticoagulant proteins. ${ }^{20-22}$

A prothrombotic condition can be caused either by genetic alterations or by acquired factors ${ }^{23}$ such as obesity, ${ }^{24}$ pregnancy, ${ }^{25}$ puerperium, ${ }^{26,27}$ oral contraceptive (OC) use (see chapter 2 for an overview) or hormone replacement therapy (HRT). ${ }^{28}$ Hormonal changes during pregnancy, OC use or HRT increase the risk of VT ranging from 6 to 10, from 3 to 6 and from 2 to 4 times respectively (see review ${ }^{29}$ ). The OC- and HRT-induced increase in VT risk is dependent on the dose and the type of administrated hormones ${ }^{28}$ and it is more pronounced in the presence of inherited prothrombotic alterations such as the factor $\mathrm{V}_{\text {Leiden }}$ mutation. ${ }^{30}$ The mechanism of the increased risk of venous thrombosis during $\mathrm{OC}$ use was hypothesized to relate partly to the first-pass effect of the administrated hormones through the liver, ${ }^{31}$ and therefore, formulations with alternative routes of administration (i.e. transdermal, intravaginal and intrauterine) have been developed to increase the safety of birth control. 


\section{Current Tests for the Prediction of Venous Thrombosis}

Due to the multicausal nature of VT, prediction of the thrombosis development on the basis of changes in the concentrations of coagulation factors or anticoagulant proteins in plasma of an individual patient is very difficult. Coagulation factor assays can only identify specific defects and therefore, relate only to a part of "The puzzle of VT development". To assess the overall status of the coagulation system a global test(s) is (are) needed.

Traditional global coagulation tests, such as the prothrombin time and activated partial prothrombin time do not assess the whole coagulation system. These tests use clot formation as endpoint that already occurs when only a small fraction of the physiologically available prothrombin is converted into thrombin. ${ }^{32}$ It appears that neither the prothrombin time nor the activated partial prothrombin time is sensitive to prothrombotic states. ${ }^{33}$ Measurement of an individual's capacity to generate thrombin, however, captures the end result of the interaction between proteases and their inhibitors and is, therefore, potentially more useful as a reflection of a thrombotic or haemorrhagic phenotype compared to conventional coagulation tests. In recent years, it became feasible to determine the complete time course of thrombin generation in a calibrated automated fashion. ${ }^{34}$ The introduction of Calibrated Automated Thrombography (CAT) enabled measurement of thrombin generation parameters under various experimental circumstances simultaneously in a large number of plasma samples. Hence, the contribution of the extrinsic and the intrinsic coagulation pathways to thrombin generation can easily be assessed in individual plasma samples as well as the function of anticoagulant pathways, i.e. the efficacy by which the protein $\mathrm{C}$ or TFPI systems down-regulate coagulation.

The most important parameters of the thrombin generation curves (Fig. 2) are:

1) the lag time, representing the time before onset of the thrombin burst, which correlates with the clotting time,

2) the peak height, which corresponds to the maximum concentration of thrombin reached, and is a function of the rates of thrombin formation and inhibition;

3) the time to peak, which is the time required to reach the maximum thrombin concentration,

4) the endogenous thrombin potential (ETP), which represents the time integral of thrombin formed (the area under the thrombin generation curve), which is generally a measure for the total amount of "catalytic work" that can be done by thrombin in plasma. 


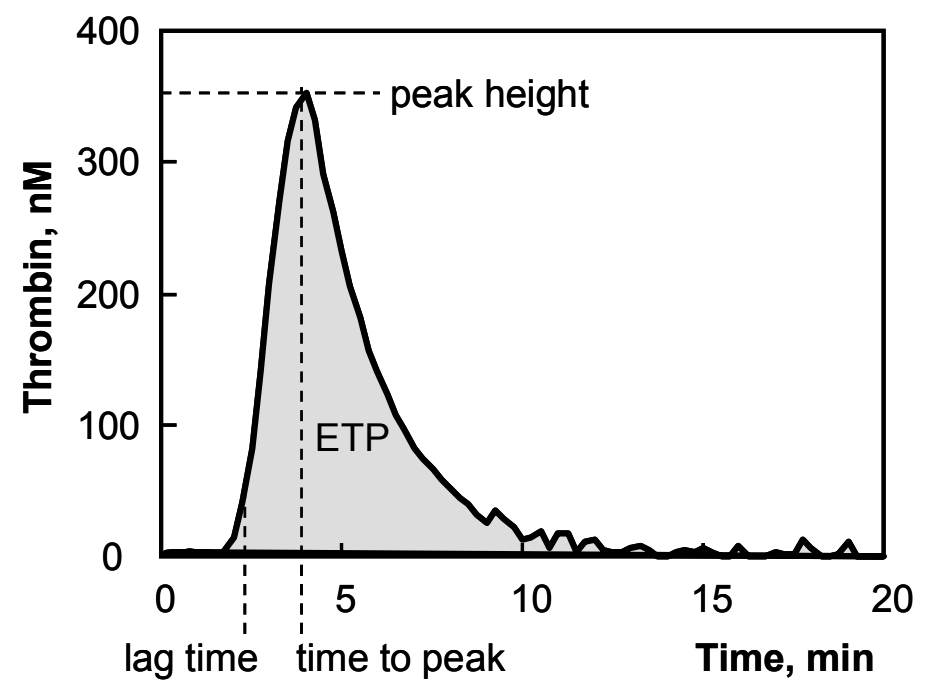

Fig. 2. Thrombin Generation Curve

The following parameters can be obtained from thrombin generation curves:

1) the lag time, representing the time before onset of the thrombin burst;

2) the peak height, which corresponds to the maximum concentration of thrombin reached;

3 ) the time to peak, which is the time required to reach the maximum thrombin concentration;

4) the endogenous thrombin potential (ETP), which represents the time integral of thrombin formed (the area under the thrombin generation curve).

Even though clinical and predictive values of CAT-based methods remain to be validated in large prospective multicenter studies with clinically relevant endpoints like bleeding or thrombosis, ${ }^{33}$ several studies suggested possible applications of CAT in routine clinical practice (see reference ${ }^{33}$ for overview).

Furthermore, a thrombin generation-based test was used for evaluation of an individual's resistance to activated protein C (APC resistance). ${ }^{35} \mathrm{APC}$ resistance was originally described to be associated with a point mutation in the factor $\mathrm{V}$ gene (factor $\mathrm{V}_{\text {Leiden }}$ ), ${ }^{36}$ but later was also shown to occur in the absence of factor $\mathrm{V}_{\text {Leiden }} \cdot{ }^{37}$ The thrombin generation-based APC resistance test was validated as a predictor of the risk of VT both in the absence ${ }^{38}$ and in the presence of factor $\mathrm{V}_{\text {Leiden }}{ }^{39}$ Since the outcome of this test was found to be very sensitive to the changes in the coagulation system induced by OC use, ${ }^{40} \mathrm{HRT}^{41}$ or pregnancy ${ }^{25}$ it has been suggested that this phenomenon, which is called acquired APC resistance, may explain the hormone-induced increased risk of VT. The mechanism by which APC resistance develops during pregnancy, OC use or HRT is, however, not completely understood. The multiple hormone- 
induced changes in the plasma levels of coagulation factors and anticoagulant proteins (for an overview see chapter 2 , references ${ }^{42,43}$ ) are thought to be responsible for this impairment in the function of the protein $\mathrm{C}$ system. However, it has to be established which coagulation factors or anticoagulant proteins play the most prominent role in hormone-induced APC resistance.

\section{Animal Models}

Development of a procoagulant state during OC use, HRT or pregnancy is a complex process, which most likely involves regulation by hormones of the synthesis of coagulation factors and anticoagulant proteins by liver, endothelium and possibly other tissues. Therefore, use of in vivo models is ultimately inevitable in studying the molecular and cellular mechanisms by which sex steroid hormones induce changes of the plasma levels of coagulation factors and anticoagulant proteins. Mouse models have become more and more popular in thrombosis research. This is due, amongst others, to the ease of breeding, the availability of the entire genome and the potential for generating genetically modified animals. The number of studies using thrombosis models in mice has substantially increased over the last decade. ${ }^{44}$ Mouse models are not only used to study the (patho)physiology of thrombus formation but also to generate preclinical information about varying pharmaceutical agents, including formulations used in oral contraceptives and hormone replacement therapy. ${ }^{45-47}$

\section{Aim of the Thesis}

The goal of this thesis was to investigate the changes in the coagulation system during hormonal contraceptive use and pregnancy in order to gain more insight in the mechanism via which these may lead to a (pro)thrombotic state. To this end we have used CAT and mouse models. In chapter 2 a systemic review of the literature on the changes in the coagulation system during the use of oral contraceptives is given.

In chapter 3 we applied CAT to compare the effects of OC, containing different progestogen compounds (levonorgestrel, drospirenone, or cyproterone acetate) on the thrombin generation parameters determined in the absence and in the presence of APC. The advantages of the newly introduced CAT-based APC resistance test over the previously described end-point method are discussed in detail in this chapter. In chapter 4 we summarize three studies, in which the thrombin generation-based method was used to compare the APC resistance changes introduced by OC or by hormonal contraceptives with 
alternative ways of administration, i.e. transdermal contraception (patch), the vaginal ring and the levonorgestrel-releasing intrauterine device.

To enable a study of hormone-induced changes on thrombin generation and APC resistance in a mouse model, in chapter 5 we developed a CAT-based assay for measurement of thrombin generation and APC resistance in mouse plasma. Whereas mouse models are widely used for preclinical investigation of in vivo effects of newly developed compounds of $\mathrm{OC}$ and hormone replacement therapy, there are little data available on hormone-induced changes in the mouse coagulation system. In chapter $\mathbf{6}$ we investigated whether elevation of hormones in pregnant mice modulates the plasma levels of coagulation factors and APC resistance in a similar way as in humans.

Chapter 7 contains a summary and a general discussion of the results presented in this thesis.

\section{References}

1. van 't Veer C, Mann KG. Regulation of tissue factor initiated thrombin generation by the stoichiometric inhibitors tissue factor pathway inhibitor, antithrombin-III, and heparin cofactor-II. J Biol Chem. 1997;272:4367-4377.

2. James K, Taylor FB, Jr., Fudenberg HH. The effect of alpha-2-macroglobulin in human serum on trypsin, plasmin, and thrombin activities. Biochim Biophys Acta. 1967;133:374376.

3. Girard TJ, Warren LA, Novotny WF, et al. Functional significance of the Kunitz-type inhibitory domains of lipoprotein-associated coagulation inhibitor. Nature. 1989;338:518520 .

4. Hackeng TM, Sere KM, Tans G, Rosing J. Protein S stimulates inhibition of the tissue factor pathway by tissue factor pathway inhibitor. Proc Natl Acad Sci U S A. 2006;103:3106-3111.

5. Eaton D, Rodriguez H, Vehar GA. Proteolytic processing of human factor VIII. Correlation of specific cleavages by thrombin, factor $\mathrm{Xa}$, and activated protein $\mathrm{C}$ with activation and inactivation of factor VIII coagulant activity. Biochemistry. 1986;25:505-512.

6. Walker FJ. Regulation of activated protein $\mathrm{C}$ by a new protein. A possible function for bovine protein S. J Biol Chem. 1980;255:5521-5524.

7. Walker FJ, Sexton PW, Esmon CT. The inhibition of blood coagulation by activated Protein C through the selective inactivation of activated Factor V. Biochim Biophys Acta. 1979;571:333-342.

8. Broze GJ, Jr. Protein Z-dependent regulation of coagulation. Thromb Haemost. 2001;86:813.

9. Heeb MJ, Cabral KM, Ruan L. Down-regulation of factor IXa in the factor Xase complex by protein Z-dependent protease inhibitor. J Biol Chem. 2005;280:33819-33825.

10. Tollefsen DM, Majerus DW, Blank MK. Heparin cofactor II. Purification and properties of a heparin-dependent inhibitor of thrombin in human plasma. J Biol Chem. 1982;257:21622169.

11. Suzuki K, Nishioka J, Kusumoto H, Hashimoto S. Mechanism of inhibition of activated protein C by protein C inhibitor. J Biochem. 1984;95:187-195.

12. Machovich R, Horvath I. Thrombin and haemostasis: regulation of the biological functions of thrombin. (Facts and perspectives). Haematologia (Budap). 1981;14:339-359.

13. White RH. The epidemiology of venous thromboembolism. Circulation. 2003;107:I4-8. 
14. Cushman M. Epidemiology and risk factors for venous thrombosis. Semin Hematol. 2007;44:62-69.

15. Meissner MH, Wakefield TW, Ascher E, et al. Acute venous disease: venous thrombosis and venous trauma. J Vasc Surg. 2007;46 Suppl S:25S-53S.

16. Meijers JC, Tekelenburg WL, Bouma BN, Bertina RM, Rosendaal FR. High levels of coagulation factor XI as a risk factor for venous thrombosis. N Engl J Med. 2000;342:696701.

17. Poort SR, Rosendaal FR, Reitsma PH, Bertina RM. A common genetic variation in the 3'untranslated region of the prothrombin gene is associated with elevated plasma prothrombin levels and an increase in venous thrombosis. Blood. 1996;88:3698-3703.

18. van Hylckama Vlieg A, Rosendaal FR. High levels of fibrinogen are associated with the risk of deep venous thrombosis mainly in the elderly. J Thromb Haemost. 2003;1:2677-2678.

19. van Hylckama Vlieg A, van der Linden IK, Bertina RM, Rosendaal FR. High levels of factor IX increase the risk of venous thrombosis. Blood. 2000;95:3678-3682.

20. Egeberg O. Inherited Antithrombin Deficiency Causing Thrombophilia. Thromb Diath Haemorrh. 1965;13:516-530.

21. Griffin JH, Evatt B, Zimmerman TS, Kleiss AJ, Wideman C. Deficiency of protein C in congenital thrombotic disease. J Clin Invest. 1981;68:1370-1373.

22. Lijfering WM, Mulder R, ten Kate MK, Veeger NJ, Mulder AB, van der Meer J. Clinical relevance of decreased free protein $S$ levels: results from a retrospective family cohort study involving 1143 relatives. Blood. 2009;113:1225-1230.

23. Rosendaal FR. Venous thrombosis: a multicausal disease. Lancet. 1999;353:1167-1173.

24. Abdollahi M, Cushman M, Rosendaal FR. Obesity: risk of venous thrombosis and the interaction with coagulation factor levels and oral contraceptive use. Thromb Haemost. 2003;89:493-498.

25. Curvers J, Thomassen MC, Rimmer J, et al. Effects of hereditary and acquired risk factors of venous thrombosis on a thrombin generation-based APC resistance test. Thromb Haemost. 2002;88:5-11.

26. Brenner B. Haemostatic changes in pregnancy. Thromb Res. 2004;114:409-414.

27. Hellgren M. Hemostasis during normal pregnancy and puerperium. Semin Thromb Hemost. 2003;29:125-130.

28. Bloemenkamp KW, Helmerhorst FM, Rosendaal FR, Vandenbroucke JP. Thrombophilias and gynaecology. Best Pract Res Clin Obstet Gynaecol. 2003;17:509-528.

29. Kujovich JL. Hormones and pregnancy: thromboembolic risks for women. Br J Haematol. 2004;126:443-454.

30. Bloemenkamp KW, Rosendaal FR, Helmerhorst FM, Buller HR, Vandenbroucke JP. Enhancement by factor V Leiden mutation of risk of deep-vein thrombosis associated with oral contraceptives containing a third-generation progestagen. Lancet. 1995;346:1593-1596.

31. Kuhl H. Pharmacology of estrogens and progestogens: influence of different routes of administration. Climacteric. 2005;8 Suppl 1:3-63.

32. Hemker HC, Beguin S. Thrombin generation in plasma: its assessment via the endogenous thrombin potential. Thromb Haemost. 1995;74:134-138.

33. van Veen JJ, Gatt A, Makris M. Thrombin generation testing in routine clinical practice: are we there yet? Br J Haematol. 2008;142:889-903.

34. Hemker HC, Giesen P, Al Dieri R, et al. Calibrated automated thrombin generation measurement in clotting plasma. Pathophysiol Haemost Thromb. 2003;33:4-15.

35. Nicolaes GA, Thomassen MC, Tans G, Rosing J, Hemker HC. Effect of activated protein C on thrombin generation and on the thrombin potential in plasma of normal and APC-resistant individuals. Blood Coagul Fibrinolysis. 1997;8:28-38.

36. Bertina RM, Koeleman BP, Koster $\mathrm{T}$, et al. Mutation in blood coagulation factor $\mathrm{V}$ associated with resistance to activated protein C. Nature. 1994;369:64-67. 
37. Castaman G, Tosetto A, Simioni M, Ruggeri M, Madeo D, Rodeghiero F. Phenotypic APC resistance in carriers of the A20210 prothrombin mutation is associated with an increased risk of venous thrombosis. Thromb Haemost. 2001;86:804-808.

38. de Visser MC, Rosendaal FR, Bertina RM. A reduced sensitivity for activated protein C in the absence of factor $\mathrm{V}$ Leiden increases the risk of venous thrombosis. Blood. 1999;93:1271-1276.

39. Tans G, van Hylckama Vlieg A, Thomassen MC, et al. Activated protein C resistance determined with a thrombin generation-based test predicts for venous thrombosis in men and women. Br J Haematol. 2003;122:465-470.

40. Rosing J, Tans G, Nicolaes GA, et al. Oral contraceptives and venous thrombosis: different sensitivities to activated protein $\mathrm{C}$ in women using second- and third-generation oral contraceptives. Br J Haematol. 1997;97:233-238.

41. Hoibraaten E, Mowinckel MC, de Ronde H, Bertina RM, Sandset PM. Hormone replacement therapy and acquired resistance to activated protein $\mathrm{C}$ : results of a randomized, double-blind, placebo-controlled trial. Br J Haematol. 2001;115:415-420.

42. Tikkanen MJ. The menopause and hormone replacement therapy: lipids, lipoproteins, coagulation and fibrinolytic factors. Maturitas. 1996;23:209-216.

43. Bremme KA. Haemostatic changes in pregnancy. Best Pract Res Clin Haematol. 2003;16:153-168.

44. Whinna HC. Overview of murine thrombosis models. Thromb Res. 2008;122 Suppl 1:S6469.

45. Abu-Fanne R, Brzezinski A, Golomb M, et al. Effects of estradiol and raloxifene on arterial thrombosis in ovariectomized mice. Menopause. 2008;15:98-104.

46. Geng H, Zhang H, Zhang W, Nieswandt B, Bray PF, Leng X. Transdermal 17-beta estradiol replacement therapy reduces megakaryocyte GPVI expression. Thromb Res. 2008;123:9399.

47. Leng XH, Zhang W, Nieswandt B, Bray PF. Effects of estrogen replacement therapies on mouse platelet function and glycoprotein VI levels. Circ Res. 2005;97:415-417. 



\section{Chapter 2}

\section{Venous Thrombosis and Oral Contraceptives:}

\section{Current Status}

S.N. Tchaikovski, G. Tans \& J. Rosing

Women's Health 2006; 2: 761-72 


\section{Summary}

The use of oral contraceptives is associated with an increased risk of venous thrombosis. It is now generally accepted that women who use oral contraceptives that contain so-called third-generation progestins (desogestrel or gestodene) are exposed to a twofold higher risk of venous thrombosis than women who use oral contraceptives that contain the second-generation progestin levonorgestrel. Coagulation studies demonstrated that oral contraceptives increase the plasma level of prothrombin, decrease the level of protein $\mathrm{S}$ and induce acquired activated protein $\mathrm{C}$ resistance. The changes of hemostatic parameters can explain why women who use oral contraceptives are exposed to an increased risk of venous thrombosis and why the risk is further increased in third-generation oral contraceptive users.

\section{Introduction}

The history of hormonal fertility control began in 1937, when Makepeace demonstrated that injections of progesterone could prevent ovulation in rabbits. ${ }^{1}$ The antiovulatory effect of progesterone was later used as the basis for hormonal contraception, although natural progesterone, due to its low bioavailability following oral administration, was replaced by synthetic progestins. The first large-scale clinical trials of oral contraceptives (OC) started in 1956 and 1957. The earliest preparations contained the progestin norethynodrel, which was accidentally contaminated with the estrogen compound mestranol. When the mestranol contamination was reduced, women experienced one of the most frequent side effects of progestin-only preparations, breakthrough bleeding. Therefore, the estrogen compound was retained for improved cycle control, establishing the principle of combined oral contraception. ${ }^{2}$

In 1959 the first OC were approved for birth control in the USA. Although OC were widely welcomed, it did not take long before concerns were raised regarding their side effects. The first case reports describing venous and arterial thromboembolic events in women using OC, including fatal cases, appeared shortly after the introduction of the pill. ${ }^{3-5}$ Initially, the estrogen component of OC was considered to be responsible for the prothrombotic effect of hormonal contraception. ${ }^{6}$ Compared with nonusers, the risk of venous thrombosis (VT) was estimated to be four- to ten-times increased in users of the early contraceptive formulations (containing over $50 \mu \mathrm{g}$ of ethinylestradiol) ${ }^{7,8}$ and the death rate attributable to OC was considered to be approximately $3 / 100,000$ users. ${ }^{9}$ Subsequent reductions in the amount of estrogen in pills to the lowest dose necessary for effective cycle control (15-35 $\mu \mathrm{g}$ of ethinylestradiol) resulted 
in a decreased risk of thromboembolic events. However, the risk of VT is still reported to be increased for 'low-dose' OC by three- to six-fold in healthy young women without other risk factors. Consequently, an incidence of approximately $1 / 10,000$ women-years in nonusers is increased to $3-4 / 10,000$ women-years during contraceptive use. ${ }^{10}$ In spite of the low absolute risk, oral contraceptives are responsible for most of the VT cases in young women. The highest risk occurs during the first year of use and the increased risk persists until, but not beyond, discontinuation of the OC intake. ${ }^{11,12}$

Further efforts to improve OC formulation were aimed at minimizing the androgenicity and the adverse metabolic effects of the progestin compound. Since progestin prevents ovulation and, as a result, provides the contraceptive effect, the changes in this compound concerned the chemical composition rather than the dose. In the early 1980 s, OC containing so-called third generation progestins (gestodene or desogestrel) were introduced on the market. Gestodene and desogestrel were expected to eventually replace the previous progestin generation (levonorgestrel) owing to their higher biological effectiveness, lower androgenicity and minimal adverse metabolic effects. However, in 1995, the thrombogenicity of OC again became a topic of debate when a number of casecontrol studies indicated that both gestodene- and desogestrel-containing OC (third-generation OC) might further increase the risk of VT 1.5- to 3-fold compared with levonorgestrel-containing OC (second-generation OC). ${ }^{11,13-15}$ These findings were questioned in later publications, in which the difference in the risk of VT was attributed to bias and confounding. ${ }^{16,17}$ Potential sources of bias mentioned where:

- Selective prescription of third-generation OC to women with a higher risk of venous thrombosis;

- The tendency that women with suspected VT who use newer formulations of $\mathrm{OC}$ will be more likely referred for diagnostic testing than women taking other formulations;

- So-called 'attrition of susceptibles', meaning that the group of users of older formulations of OC might be relatively healthier and free of side effects since individuals susceptible to VT were gradually eliminated from the group due to thrombotic complications. ${ }^{18}$

The conflict in the interpretation of the data initiated a large number of comparative epidemiological studies. Most of these studies confirmed that women who use third-generation OC are exposed to a higher risk of VT than users of second-generation OC, ${ }^{12,19,20}$ although some did not. ${ }^{21,22}$ In a number of consecutive reports by Heinemann and colleagues, ${ }^{23-25}$ it was argued that study design, prescription and referral bias, as well as diagnostic suspicion, may have 
led to an overestimation of the increase in the risk of VT among users of newer OC compared with those who use previous generation OC.

However, careful reanalysis of the original studies with appropriate stratification for risk factors, such as smoking, obesity and duration of use, executed by independent experts, led to the conclusion that bias and confounding could not explain the consistent epidemiological findings of an increased risk of VT during use of third generation OC. ${ }^{10,26}$ An effect of diagnostic suspicion and referral bias was excluded in the additional case-control study, in which patients and controls were subjected to the same referral and diagnostic procedures. ${ }^{27}$ Thus, it is now generally accepted by major national and international drug regulatory authorities that third generation $\mathrm{OC}$ are more thrombogenic than second-generation OC, although the absolute risk of VT among OC users remains very low. In this respect, the European Agency for the Evaluation of Medicinal Products (EMEA) issued position statements ${ }^{101}$ and information for women using oral contraceptives, ${ }^{102}$ in which the Committee for the Proprietary of Medicinal Products (CPMP) concluded that "users of combined OC containing desogestrel or gestodene with $30 \mu \mathrm{g}$ of ethinylestradiol (mono-, bi- or triphasic formulation) have a small increased risk of venous thromboembolism compared to women using combined OC containing levonorgestrel with less than $50 \mu \mathrm{g}$ of ethinylestradiol" and "while in users of levonorgestrel-containing products the frequency of venous thromboembolism is estimated to be approximately 20 cases per 100,000 women-years of use it is estimated to be approximately 30-40 cases per 100,000 women-years of use of desogestrel- or gestodene-containing products with $30 \mu \mathrm{g}$ of ethinylestradiol". Furthermore, a number of recent studies indicated that the risk of VT in women taking a cyproterone acetate-containing OC preparation was significantly higher (fourfold) than the risk of women using levonorgestrel- containing OC. ${ }^{28}$

Ever since VT was established as one of the most serious side effects of OC use, there have been investigations into the influence of estrogens and progestins on the hemostatic system in an attempt to provide a biological explanation for pill-induced thrombosis. It appeared that OC affect the plasma levels of almost all proteins involved in coagulation and since, at the time of these studies, there was limited knowledge concerning the etiology of VT, these investigations did not provide a mechanistic basis for the thrombotic effect of OC. However, the discovery of a large number of hereditary risk factors of VT in the 1990s enabled a better interpretation of the relation between the OC effects on hemostatic parameters and the risk of VT. 


\section{Risk Factors of Venous Thrombosis}

Under normal conditions, the hemostatic system (Fig. 1) is in a delicate balance, which is the result of the complex interaction between the procoagulant and anticoagulant pathways. However, increased levels of procoagulant proteins or defects in the anticoagulant system may disturb this balance and lead to a socalled prothrombotic state which, under certain conditions, may result in excessive thrombin formation and the development of VT.

The occurrence of thrombosis is not just a matter of chance, but can often be associated with the presence of one or more risk factors that can be either of acquired or genetic origin (Table 1).

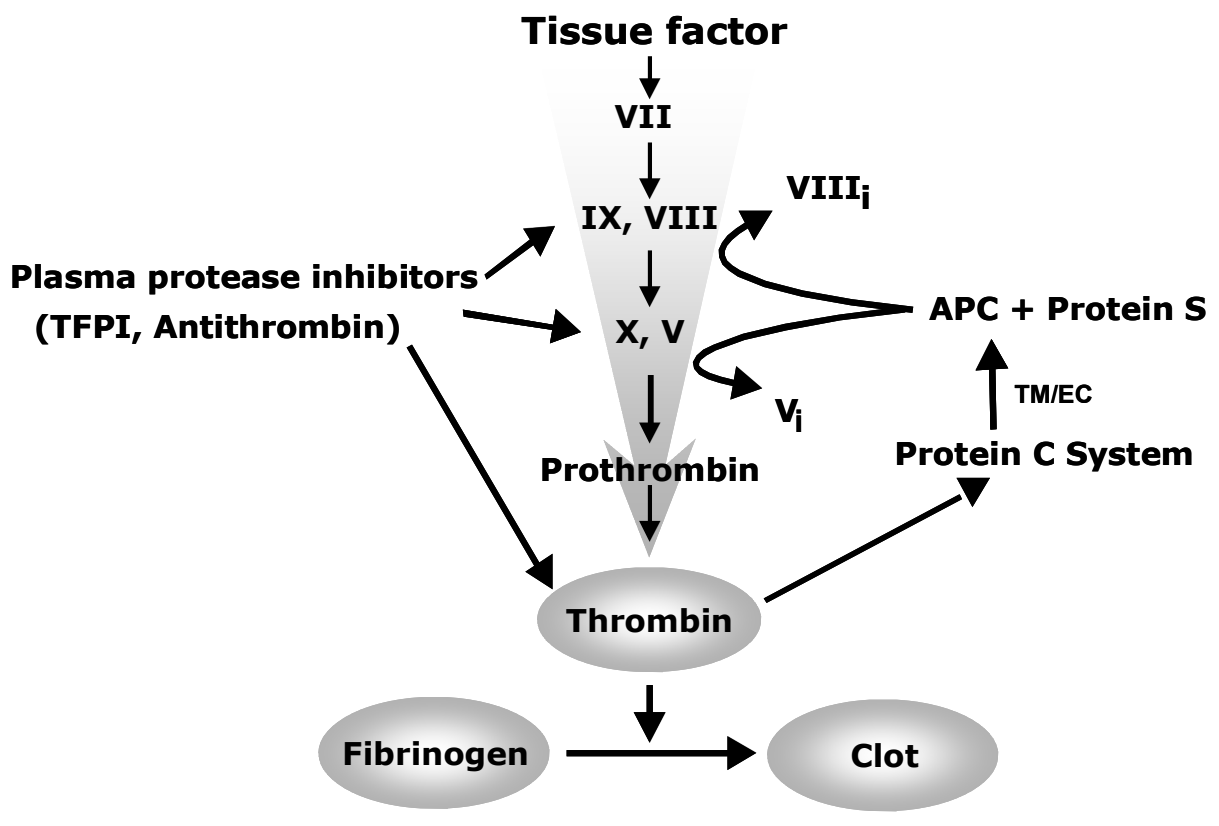

Fig. 1. Regulation of the Coagulation Cascade

Coagulation is initiated by the tissue factor (TF)-factor VIIa complex, which is formed when TF becomes exposed to blood. The TF-factor VIIa complex activates factor IX and factor X, followed by the activation of prothrombin to thrombin. Subsequently, thrombin converts fibrinogen into fibrin, which polymerizes and forms a blood clot. Thrombin also activates factors V and VIII, whose active forms exhibit cofactor activity amplifying thrombin formation by three to four orders of magnitude. Thrombin formation is down-regulated by the anticoagulant system, which consists of plasma protease inhibitors antithrombin, TFPI, $\alpha_{2}$-macroglobulin and the protein C system. APC is formed after activation of protein $\mathrm{C}$ by thrombin-thrombomodulin on the surface of endothelial cells (TM/EC). APC, together with its non-enzymatic cofactor protein S inactivates factors $\mathrm{Va}$ and VIIIa, which leads to the down-regulation of thrombin formation. APC: Activated protein C; TFPI: Tissue factor pathway inhibitor. 
Table 1. Major Risk Factors for Venous Thrombosis

\begin{tabular}{|c|c|}
\hline Hereditary risk factors & Genetic alteration \\
\hline \multicolumn{2}{|l|}{ Procoagulant factors: } \\
\hline$\uparrow$ Prothrombin ${ }^{65}$ & G20210A mutation ${ }^{65}$ \\
\hline$\uparrow$ Fibrinogen ${ }^{66,67}$ & Two polymorphisms in fibrinogen gene ${ }^{82}$ \\
\hline Dysfibrinogenemia ${ }^{68}$ & Several mutations in the fibrinogen gene ${ }^{68,83}$ \\
\hline$\uparrow$ Factor VIII ${ }^{69,70}$ & Non-O blood group, $\uparrow v W F{ }^{69}$ \\
\hline$\uparrow$ Factor IX ${ }^{71}$ & Unknown \\
\hline$\uparrow$ Factor XI ${ }^{72}$ & Unknown \\
\hline \multicolumn{2}{|l|}{ Anticoagulant factors: } \\
\hline$\downarrow$ Antithrombin III ${ }^{73}$ & Antithrombin deficiency ${ }^{84}$ \\
\hline$\downarrow$ Protein $\mathrm{C}^{73}$ & Protein $\mathrm{C}$ deficiency ${ }^{85}$ \\
\hline$\downarrow$ Protein $\mathrm{S}^{73}$ & Proten S deficiency ${ }^{86}$ \\
\hline$\downarrow$ TFPI $^{74,75}$ & V264M mutation ${ }^{87}$ \\
\hline \multirow[t]{2}{*}{ APC resistance $^{81}$} & R506Q (Factor V Leiden) ${ }^{41}$ \\
\hline & G20210A mutation ${ }^{88}$ \\
\hline \multicolumn{2}{|l|}{ Acquired risk factors } \\
\hline \multicolumn{2}{|l|}{$\begin{array}{l}\text { Malignancy } \\
\text { Pregnancy } \\
\text { Trauma } \\
\text { Puerperium } \\
\text { OC use } \\
\text { Hormone replacement therapy } \\
\text { Surgery } \\
\text { Immobilization }\end{array}$} \\
\hline
\end{tabular}

OC: Oral contraception; TFPI: Tissue factor pathway inhibitor; vWF: von Willebrand factor

The plasma levels and activity of proteins involved in blood coagulation and the anticoagulant pathways are determined by a genetic background and environmental influence. The G20210A prothrombin mutation (which is associated with elevated prothrombin levels), the factor $\mathrm{V}$ Leiden mutation (which results in a decreased sensitivity of factor Va for APC [see later]), and deficiencies of antithrombin (AT), proteins $\mathrm{C}$ and $\mathrm{S}$ are the most well known hereditary risk factors of VT (Table 1). A combination of two or more genetic defects leads to an interaction and synergistically increases the thrombosis risk. ${ }^{29}$ In addition, acquired risk factors, such as pregnancy, puerperium, malignancy, surgery, OC use and hormone-replacement therapy, greatly enhance the risk of VT introduced by a genetic background. For instance, it has been reported that $\mathrm{OC}$ use further increases the risk of VT in women heterozygous for deficiencies of $\mathrm{AT}$, protein $\mathrm{C}$ and protein $\mathrm{S}^{30}$ in heterozygous and homozygous carriers of the 
G20210A prothrombin ${ }^{31}$ and the factor V Leiden mutations ${ }^{32}$. Combination of acquired risk factors, such as obesity and $\mathrm{OC}$ use, are furthermore associated with a greater risk of VT than would be expected on the basis of their individual effects. ${ }^{33,34}$ The synergistic effect on the risk of VT can possibly be explained by additive effects of obesity ${ }^{34-36}$ on the changes of coagulation parameters that occur during $\mathrm{OC}$ use (see later). ${ }^{37-39}$

A prothrombotic condition may not only be caused by changes in the plasma levels of clotting factors and anticoagulant proteins, but may also be a result of qualitative alterations. In 1993, a hereditary prothrombotic condition was described that appeared to be associated with resistance to the anticoagulant protein, activated protein C (APC). ${ }^{40} \mathrm{APC}$, together with its cofactor protein S, inhibits coagulation by inactivating the activated forms of coagulation factors $\mathrm{V}$ and VIII (factors Va and VIIIa) by limited proteolysis (Fig. 1). One year after the discovery of APC resistance, its molecular basis was identified as a single point mutation in the factor $\mathrm{V}$ gene (factor $\mathrm{V}$ Leiden), which renders the factor Va molecule less susceptible to inactivation by APC. ${ }^{41}$ Later, APC resistance was also shown to occur in the absence of the mutation. This condition which, in the majority of cases, was associated with increased plasma levels of procoagulant proteins (prothrombin and factor VIII) or decreased levels of the anticoagulant protein, protein $\mathrm{S},{ }^{42,43}$ appeared to be an independent risk factor of VT. ${ }^{44}$

Knowledge regarding hereditary risk factors of VT and their influence on the coagulation system sheds new light on the relation between the effects of OC on hemostatic parameters and the increased risk of VT during pill use.

\section{Effects of OC on the Procoagulant System}

The effects of $\mathrm{OC}$ on parameters of the procoagulant, anticoagulant and fibrinolytic systems and differences in effects between second- and thirdgenerations are summarized in Table 2. These data were obtained in a well designed randomized cycle-controlled cross-over study ${ }^{37-39,45}$ and were later confirmed in a large study initiated by the EMEA. ${ }^{45,46}$ These studies demonstrated that the plasma levels of the coagulation factors VII, VIII and X, fibrinogen and prothrombin are increased and that the factor $\mathrm{V}$ level is decreased during OC use (Table 2). Moreover, the increase in prothrombin and factor VII (both antigen and activity) ${ }^{45}$ and the decrease in factor $\mathrm{V}$ levels were significantly more pronounced during the use of desogestrel-containing OC than during the use of levonorgestrel-containing OC. ${ }^{37}$ The changes in the concentrations of coagulation factors $\mathrm{V}$, VII and $\mathrm{X}$ may not have clinical implications since they are not considered to be risk factors for VT; however, the 
elevated plasma levels of fibrinogen, prothrombin and factor VIII are more likely to contribute to the increased risk of VT associated with OC use. However, since the difference between the plasma prothrombin levels during the use of third- and second-generation OC are small, it is unlikely that changes in prothrombin level alone can fully explain the difference in the risk of VT between these OC.

\section{Effects of OC on the Anticoagulant System}

OC use considerably affects the anticoagulant system (Table 2), decreasing the plasma level of the major inhibitor of several activated coagulation factors, AT and the concentration and activity of tissue factor pathway inhibitor (TFPI). ${ }^{38,47}$

Table 2. Effects of $O C$ on Hemostatic Parameters

\begin{tabular}{|c|c|c|c|c|c|}
\hline & \multicolumn{2}{|c|}{ Levonorgestrel (Lev) } & \multicolumn{2}{|c|}{ Desogestrel (Des) } & \multirow{2}{*}{$\begin{array}{c}\text { Difference } \\
\text { Lev/ Des } \\
\text { p-value }\end{array}$} \\
\hline & $\begin{array}{l}\text { Before OC, } \\
\text { mean } \pm \mathrm{SD}\end{array}$ & $\begin{array}{l}\text { Increase, } \\
\text { mean } \pm \mathrm{SD}\end{array}$ & $\begin{array}{l}\text { Before OC, } \\
\text { mean } \pm \mathrm{SD}\end{array}$ & $\begin{array}{l}\text { Increase, } \\
\text { mean } \pm \mathrm{SD}\end{array}$ & \\
\hline \multicolumn{6}{|l|}{ Coagulation factors $^{a}$} \\
\hline Prothrombin, act, $\%$ & $97 \pm 7$ & $12.0 \pm 8.0$ & $95 \pm 4$ & $16.0 \pm 6.0$ & 0.048 \\
\hline Fibrinogen, g/l & $2.7 \pm 0.4$ & $0.5 \pm 0.4$ & $2.7 \pm 0.1$ & $0.5 \pm 0.3$ & 0.89 \\
\hline Factor $\mathrm{V}$, act, $\%$ & $105 \pm 21$ & $-3.0 \pm 12.0^{*}$ & $106 \pm 35$ & $-11.0 \pm 8.0$ & 0.010 \\
\hline Factor VII, act, \% & $99 \pm 40$ & $12.0 \pm 15.0$ & $100 \pm 17$ & $32.0 \pm 10.0$ & 0.0001 \\
\hline Factor VIII, act, \% & $103 \pm 4$ & $6.0 \pm 25.0^{*}$ & $108 \pm 23$ & $10.0 \pm 23.0$ & 0.89 \\
\hline Factor $\mathrm{X}$, act, $\%$ & $105 \pm 25$ & $22.0 \pm 14.0$ & $104 \pm 15$ & $25.0 \pm 12.0$ & 0.42 \\
\hline \multicolumn{6}{|c|}{ Anticoagulant system ${ }^{b}$} \\
\hline AT, act, $\%$ & $111 \pm 9$ & $-1.3 \pm 8.0^{*}$ & $112 \pm 11$ & $-3.1 \pm 7.8$ & 0.43 \\
\hline$\alpha_{2}-\mathrm{M}$, act, $\%$ & $119 \pm 32$ & $8.9 \pm 14.9$ & $114 \pm 31$ & $14.1 \pm 14.6$ & 0.09 \\
\hline$\alpha_{1}-\mathrm{AT}$, act, $\%$ & $94 \pm 22$ & $31.8 \pm 13.8$ & $92 \pm 20$ & $36.1 \pm 11.0$ & 0.08 \\
\hline PCI, Ag, \% & $83 \pm 18$ & $0.3 \pm 11.4^{*}$ & $82 \pm 13$ & $6.6 \pm 12.0$ & 0.07 \\
\hline Protein C, Ag, \% & $84 \pm 14$ & $9.1 \pm 13.2$ & $85 \pm 17$ & $9.8 \pm 12.1$ & 0.83 \\
\hline Protein $\mathrm{C}$, act, $\%$ & $89 \pm 15$ & $7.6 \pm 10.3$ & $89 \pm 16$ & $11.0 \pm 9.6$ & 0.12 \\
\hline Protein $\mathrm{S}_{\text {total }}, \mathrm{Ag}, \%$ & $99 \pm 13$ & $5.0 \pm 20.4^{*}$ & $99 \pm 10$ & $-11.4 \pm 9.7$ & 0.0012 \\
\hline Protein $\mathrm{S}_{\text {free }}, \mathrm{Ag}, \%$ & $94 \pm 14$ & $4.3 \pm 17.9^{*}$ & $94 \pm 12$ & $-12.1 \pm 9.3$ & $<0.0001$ \\
\hline APCsr (aPTT-based) & $0.83 \pm 0.11$ & $0.0 \pm 0.1^{*}$ & $0.83 \pm 0.11$ & $-0.04 \pm 0.08$ & 0.02 \\
\hline APCsr (ETP-based) & $1.39 \pm 0.49$ & $0.77 \pm 0.33$ & $1.40 \pm 0.55$ & $1.29 \pm 0.44$ & $<0.0001$ \\
\hline \multicolumn{6}{|l|}{ Fibrinolytic system ${ }^{c}$} \\
\hline $\mathrm{tPA}, \mathrm{Ag}, \mathrm{ng} / \mathrm{ml}$ & $3.35 \pm 0.95$ & $-1.08 \pm 0.98$ & $3.08 \pm 0.96$ & $-0.84 \pm 0.81$ & 0.33 \\
\hline $\mathrm{tPA}$, act, $\mathrm{U} / \mathrm{ml}$ & $0.64 \pm 0.28$ & $0.22 \pm 0.29$ & $0.62 \pm 0.24$ & $0.30 \pm 0.34$ & 0.38 \\
\hline PAI-1, Ag, ng/ml & $7.4 \pm 3.8$ & $-3.6 \pm 4.1$ & $7.4 \pm 4.1$ & $-4.1 \pm 3.6$ & 0.67 \\
\hline PAI-1, act, U/ml & $6.7 \pm 3.8$ & $-3.6 \pm 3.4$ & $6.6 \pm 3.9$ & $-3.4 \pm 3.2$ & 0.83 \\
\hline Plasminogen, act, \% & $108.6 \pm 13.4$ & $40.7 \pm 12.3$ & $107.3 \pm 13.5$ & $40.3 \pm 10.6$ & 0.80 \\
\hline TAFI, Ag, $\%$ & $87.8 \pm 18.2$ & $8.4 \pm 8.2$ & $86.1 \pm 14.1$ & $12.7 \pm 9.1$ & 0.005 \\
\hline
\end{tabular}

* Not significant $(\mathrm{p}>0.05)$. AT: antithrombin; $\alpha_{2}-\mathrm{M}$ : $\alpha_{2}$-macroglobulin; $\alpha_{1}$-AT: $\alpha_{1}$-antitrypsin; PCI: protein C Inhibitor; APCsr: activated protein C sensitivity ratio; aPTT: activated partial prothrombin time; ETP: endogenous thrombin potential; PAI: plasminogen activator-inhibitor; TAFI: thrombin-activatable fibrinolysis inhibitor; tPA: tissue-type plasminogen activator; Ag: antigen; act: activity; SD: standard deviation. ${ }^{\mathrm{a}}$ Ref. $37^{\mathrm{b}}$ Ref. 38 ; $^{\mathrm{c}}$ Ref. 39. 
However, the most pronounced changes occur in the protein $\mathrm{C}$ pathway. $\mathrm{OC}$ induce a small increase in concentration and activity of protein $\mathrm{C}$, which is presumably counterbalanced by elevated levels of the major protein $\mathrm{C}$ inhibitors, protein $\mathrm{C}$ inhibitor (PCI), $\alpha_{1}$-antitrypsin and $\alpha_{2}$-macroglobulin. ${ }^{38,48}$ By contrast, the total and free protein $\mathrm{S}$ concentration, as well as the APC-independent anticoagulant activity of protein $\mathrm{S}$ are considerably reduced during $\mathrm{OC}$ use. ${ }^{38,48,49}$ Furthermore, the concentration of total and free protein S and its APCindependent anticoagulant activity are significantly lower in women using thirdgeneration OC than in users of second-generation OC. ${ }^{38,48,49}$

An interesting phenomenon related to the protein $\mathrm{C}$ system was observed in OC users: they were shown to be more resistant to the anticoagulant effect of APC than nonusers. Acquired APC resistance during pill use was demonstrated by measuring the effect of APC on the activated partial thromboplastin time (aPTT) ${ }^{50}$ and on thrombin generation. ${ }^{51}$ These tests have been validated clinically as predictors of risk of VT development both in the presence and the absence of the factor V Leiden mutation. ${ }^{44,52,53}$ However, the difference in the sensitivity to APC between non-pill users and users of different OC formulations, determined with the aPTT-based assay, is subtle and does not always reach the level of statistical significance. By contrast, the thrombin generation-based APC resistance test demonstrates substantially higher APC resistance in all pill users compared with non-pill users and in users of third-generation compared with users of second-generation OC (Fig. 2). ${ }^{54}$ Furthermore, an amplification of genetically determined APC resistance in carriers of the factor $\mathrm{V}$ Leiden mutation by OC use was observed with the thrombin generation-based APC resistance test (Fig. 2) but not with the aPTT-based assay. ${ }^{54}$

The different results obtained with the two assays can be explained by the differences in the determinants of the assays. ${ }^{42}$ The clotting of plasma, which is used as an end point in the aPTT-based assay, occurs when only a small amount of thrombin is generated. Thus, the outcome of the test mainly probes the initiation phase of thrombin generation. By contrast, the thrombin generationbased assay mainly depends on the propagation and termination phases of thrombin generation, which results in a higher sensitivity to defects of anticoagulant components, such as AT, TFPI and the proteins of the protein C pathway. For instance, total and free protein $\mathrm{S}$ levels appear to be the major determinants of the thrombin generation-based APC resistance test, whereas they have only a small influence on the aPTT-based assay. ${ }^{42}$

In the thrombin generation-based APC resistance test, the response to APC is expressed as an APC sensitivity ratio (APCsr), which is obtained by dividing the result of the measurement in the presence of APC, the endogenous thrombin 


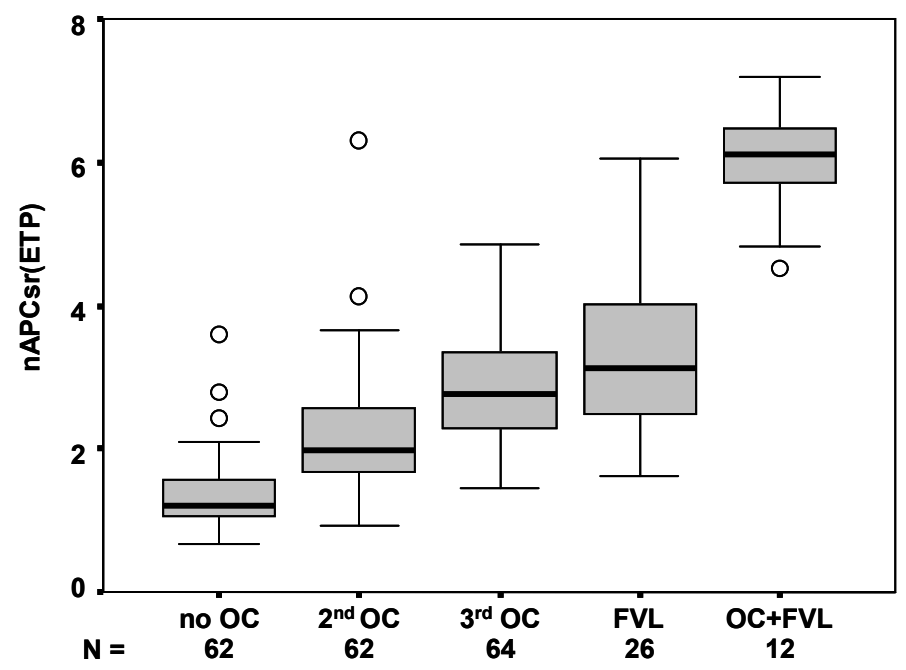

Fig. 2. Effect of Oral Contraceptive Use and Factor V Leiden Mutation on Activated Protein C Resistance

Effect of OC use on APC resistance was determined with the thrombin generation-based APC resistance test. ${ }^{45}$ Normalized APC sensitivity ratios (nAPCsr) were measured in women not using OC (no OC), using second generation OC (2nd OC) or third-generation OC (3rd OC). Separately depicted women who were heterozygous carriers of the factor $\mathrm{V}$ Leiden mutation who were not using OC (FVL) or who were using OC $(\mathrm{OC}+\mathrm{FVL})$. The lines in the boxes indicate the median. The lower and upper edges correspond to 25 th and 75 th percentiles, respectively. The whiskers show the minimum and maximum values that do not extend more than 1.5-times the interquartile range. The points outside of the ends of the whiskers are suspected outliers.

potential $\left(\mathrm{ETP}_{+\mathrm{APC}}\right)$, by the result of the measurement in the absence of APC $\left(\mathrm{ETP}_{-\mathrm{APC}}\right)$. This mathematical operation, which provides a correction for nonAPC-related changes of the ETP, raised a question regarding the influence of the components of the equation $\left(\mathrm{ETP}_{-\mathrm{APC}}\right.$ and $\mathrm{ETP}_{{ }_{\mathrm{APC}}}$ ) on the final result and on the clinical relevance of an increased APCsr. ${ }^{55,56}$ It appears that ETP $_{-\mathrm{APC}}$ and $\mathrm{ETP}_{+\mathrm{APC}}$ are elevated in users of OC, compared with nonusers. It was noticed by Gris and colleagues ${ }^{55}$ that, in one of the original studies, ${ }^{51}$ the absolute differences between the $\mathrm{ETP}_{-\mathrm{APC}}$ and the $\mathrm{ETP}_{+\mathrm{APC}}$ in pooled plasma from users of second- and third-generation OC were identical. This led to a debate as to whether the elevation of APCsr in OC users is caused by changes in basal

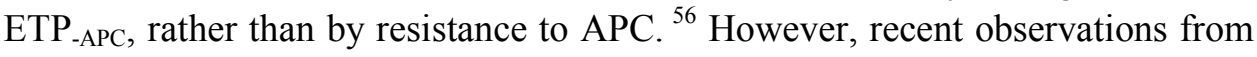
our laboratory in a large population of second- and third-generation OC users and users of cyproterone acetate- and drospirenone-containing OC indicated that all 
OC significantly increase the $\mathrm{ETP}_{-\mathrm{APC}}$, but that there is no significant difference between the effects of the various OC on the ETP-APC (Chapter 3). Multiple regression analysis showed that the main determinant of the APCsr is the $\mathrm{ETP}_{+\mathrm{APC}}$ and that there is no significant influence by the ETP ${ }_{-\mathrm{APC}}$ on the APCsr value. Thus, these observations support the hypothesis that elevated APCsr in OC users reflect an impaired response to APC and that the higher APCsr values of users of third-generation OC are indicative of a more APC-resistant phenotype compared with users of second-generation OC.

At present, acquired resistance to APC is believed to explain the increased risk of VT during OC use, as well as the differential risk in users of second- and third- generation OC. Yet, the molecular basis of acquired APC resistance in pill users remains uncertain. The differences in plasma protein $\mathrm{S}$ and prothrombin levels between non-users and users of second- or third-generation OC cannot fully explain the differences in sensitivity to APC, which implies that other hemostatic parameters, that were not included in the regression analysis, contribute to acquired APC resistance during pill use. ${ }^{42}$

\section{Effects of OC on the Fibrinolytic System}

For a long time, it was believed that the procoagulant changes in plasma during OC use were at least partially compensated by an enhanced fibrinolytic activity. Particularly, the decreased concentration and activity of plasminogen activator inhibitor (PAI)-1 and the increased plasma levels of tissue plasminogen activator (tPA) and plasminogen during OC use were considered to counteract the prothrombotic effects of the pill. ${ }^{39}$ However, it is not clear whether these findings have clinical implications, since changes in the fibrinolytic system have not been demonstrated to affect the risk of VT. Moreover, the increased activity of the fibrinolytic system during OC use is counteracted by elevated thrombinactivatable fibrinolysis inhibitor (TAFI), the plasma level of which has been shown to be higher in women taking desogestrel-containing OC than in users of levonorgestrel-containing pills. ${ }^{39}$

\section{Differentiation between the Effects of Progestins \& Estrogens on Hemostatic Parameters}

Presently, it is not clear whether the more pronounced effect of third-generation OC on coagulation is determined by a difference in the modulating effect of the progestin components on the ethinylestradiol-promoted changes of the hemostatic system or an independent effect of the progestins. It is hypothesized that overall effects of OC are dependent on their so-called 'estrogenicity', which 
rises with increasing dose of estrogen, but decreases with increasing antiestrogenic capacity of progestin. ${ }^{57}$ Sex hormone binding globulin (SHBG), which is up-regulated by estrogens ${ }^{58}$ and down-regulated by progestins, ${ }^{59}$ is considered to be one of the most sensitive indicators of the 'estrogenicity' of hormone preparations. ${ }^{57}$ The SHBG level during OC use correlates with the risk of VT and, furthermore, there appears to be an inverse correlation between the SHBG level and the concentrations of free protein S and the APC sensitivity ratios in OC users. ${ }^{60}$ Considerably higher plasma concentrations of SHBG are observed in users of more thrombogenic formulations of OC. ${ }^{57}$ Thus, OC containing the less androgenic progestins CPA, gestodene or desogestrel are considered to be more estrogenic, which is explained by a weaker antiestrogenic effect of these progestin compounds.

The newest OC containing drospirenone have an estrogenic potential comparable with that of third-generation OC, which suggests that they may increase the risk of VT to the same extent as gestodene- and desogestrelcontaining OC. In this respect, it is interesting to note that the increase in SHBG plasma level and resistance to APC in users of drospirenone-containing OC has been shown to be similar to the increase observed for desogestrel-, gestodeneand CPA-containing OC. ${ }^{61}$

Comparison of progestin-only preparations with combined oral contraceptives may provide an answer to the question of why OC with thirdgeneration progestins are more thrombotic than second-generation OC and why they have more pronounced effects on hemostatic parameters. It has been reported that progestin-only preparations used to treat menstrual disorders increase the risk of VT. ${ }^{62}$ However, there is no evidence that progestin-only pills, when used for contraception in the general population, are associated with an increased VT risk. ${ }^{63,64}$ Although there is no information on the risk of VT in thrombophilic women using progestin-only preparations, many clinicians prescribe progestin- only preparations (pills, implants, injections or progestinbearing intra-uterine devices) for women with a personal or family history of venous thromboembolism.

Unfortunately, the effects of progestin-only pills on the coagulation system have been studied to a much lesser extent. It has been shown that they exert an influence on the anticoagulant system opposite to combined OC. Progestin-only pills decreased the plasma levels of protein $\mathrm{C}$, elevated the levels of total and free protein $\mathrm{S}$ and increased the sensitivity of plasma towards APC with more pronounced effects in women who used levonorgestrel-only preparations compared with users of desogestrel-only preparations. ${ }^{48}$ Thus, it was hypothesized that the progestin component in the combined OC has an 
antithrombotic effect that counteracts the estrogen-induced prothrombotic changes. The data on the effects of progestin-only preparations on hemostatic parameters further indicate that levonorgestrel has a more potent antithrombotic effect than desogestrel. These observations can explain the more pronounced changes of hemostatic parameters in women using third-generation $\mathrm{OC}$ and the higher risk of VT in third-generation pill users.

\section{Overall Hemostatic Effects of OC}

Although the OC-induced thrombophilic alterations are rather small and the levels of coagulation factors mostly stay within the normal range, $\mathrm{OC}$ appears to have a net prothrombotic effect that can explain the increased risk of VT in OC users, demonstrated in numerous epidemiological studies. For several years, it was argued that changes of coagulation parameters during pill use are too small to explain the thrombotic effect of OC. However, currently, it is known that a small increase in the plasma levels of coagulation factors or relatively small decreases in the levels of anticoagulant proteins increase the risk of VT. ${ }^{65-75}$ For instance, the prothrombin G20210A mutation, which, in the heterozygous state, is associated with approximately a $20 \%$ increase of the plasma prothrombin level, increases the risk of VT two- to threefold. ${ }^{65}$ Therefore, although the mean prothrombin level of heterozygous carriers of this mutation $(\sim 120 \%)$ is well within the normal range, it is still associated with a two- to threefold increase of the thrombotic risk.

The homeostasis of the coagulation system is maintained by complex mechanisms that allow compensation for the effects of unfavorable environmental factors. Recently, it has been shown that in the healthy population the plasma level of prothrombin correlates with that of protein S. ${ }^{76}$ Although the mechanism of the prothrombotic effect of elevated prothrombin levels is not yet fully understood, evidence has been provided that at least part of this effect may be explained by inhibition of the APC-mediated factor Va inactivation by prothrombin ${ }^{77}$ and APC resistance. ${ }^{78}$ Protein $\mathrm{S}$ was demonstrated to reduce prothrombin-induced APC resistance. ${ }^{76}$ Thus, the effect of elevated prothrombin, which is an independent risk factor of VT, is modulated by an opposite effect of protein $\mathrm{S}$ which, in normal individuals, simultaneously increases with prothrombin. Interestingly, in OC users, the correlation between these two proteins disappears since during pill use the level of prothrombin is increased, whereas the plasma level of protein $\mathrm{S}$ is decreased. As a result of the shift in the prothrombin/protein $\mathrm{S}$ ratio, the elevated level of prothrombin in OC users is not counterbalanced by an increase in protein S. Thus, women using OC, are exposed 
to a higher risk of VT than non-pill users, with an equally elevated concentration of prothrombin owing to the presence of the prothrombin G20210A mutation. ${ }^{76}$

Some investigators dispute whether changes to hemostatic parameters determined during $\mathrm{OC}$ use via in vitro tests provide reliable information regarding VT risks and differences in risks between various OC preparations. ${ }^{79,80}$ However, it appears that elevated levels of for example prothrombin, ${ }^{65}$ factor VIII ${ }^{69,70}$ and, factor IX ${ }^{71}$ and decreased levels of protein $\mathrm{S}^{73}$ and AT ${ }^{73}$, determined via in vitro assays as well as APC resistance, ${ }^{81}$ are well established as risk factors of VT, even in the absence of thrombotic polymorphisms/mutations. ${ }^{65,81}$ This also applies to acquired APC resistance resulting from OC use, which, when determined via the ETP-based assay, predicts an increased risk for VT independent of factor $\mathrm{V}$ Leiden. ${ }^{53}$ In summary, the multiple changes of the hemostatic parameters that occur during pill use, which amplify each other, can very well explain the increased risk of VT in OC users and the risk differences between second- and third-generation OC.

\section{Conclusions}

Resistance to APC is likely to be a pathophysiological basis for OC-induced thrombosis. The decreased sensitivity to the natural anticoagulant APC is at least partially caused by the multiple effects of OC on the hemostatic system, for instance, decreased plasma levels of protein S and TFPI and increased plasma prothrombin concentrations. ${ }^{37,38,42}$ In the absence of hereditary risk factors of VT, these alterations lead to an APC-resistant phenotype, the severity of which is comparable with that observed in heterozygous carriers of the factor $\mathrm{V}$ Leiden mutation. ${ }^{48,54}$ Nevertheless, the overall risk/benefit ratio for OC use remains favorable. The rare side effects are at least partially counterbalanced by advantages of OC use, including not only prevention of undesired pregnancies and negative health consequences of the induced terminations of such pregnancies, but also their therapeutic effects. Worldwide, more than 100 million women use OC for birth control and/or treatment of premenstrual syndrome, dysmenorrhea, endometriosis, menorrhagia and iron-deficiency anemia, and only relatively few of them experience any serious side effects. Moreover, among those who develop VT, most have additional thrombotic risk factors, such as an impaired genetic background or acquired risk factors such as obesity, malignancy or trauma. 


\section{Future Prospective}

In the past 10 years, great advances have been made in the understanding of the underlying mechanisms of the prothrombotic effects of OC. This progress will facilitate the design of safer OC formulations and aid a prudent prescription of OC. Physicians who prescribe OC should consider the specific benefits and adverse effects of the formulation and other personal risk factors for each individual patient. OC that cause a higher risk of VT should be administered with precaution in women who already have a high baseline risk of VT due to inherited or acquired disorders.

\section{Executive Summary}

\section{Oral Contraceptives \& Risk of Venous Thrombosis}

- The association between the use of oral contraceptives (OC) and an increased risk of venous thrombosis (VT) was recognized soon after the introduction of OC in the 1960s.

- Despite a lowering of the estrogen component in OC, an elevated thrombotic risk remained, which, compared with nonusers, was estimated to be three- to sixfold higher in women who used so-called second-generation OC containing 30-50 $\mu \mathrm{g}$ ethinylestradiol and the progestin levonorgestrel.

- Surprisingly, the risk of VT increased again 1.5- to twofold when the progestin component of OC was changed from levonorgestrel to the so-called thirdgeneration progestins, desogestrel or gestodene.

- The biological basis of pill-induced VT has remained obscure for a long time.

\section{Risk Factors of Venous Thrombosis}

- In the 1990s, several risk factors of venous thrombosis (VT), such as elevated plasma prothrombin levels, decreased plasma levels of the anticoagulant proteins antithrombin, protein $\mathrm{C}$ and protein $\mathrm{S}$, and resistance to activated protein $\mathrm{C}$ (APC), were identified.

- The discovery of these risk factors shed new light on the association between the effects of OC on the hemostatic system and the increased risk of VT in pill users.

\section{Effects of OC on Hemostatic Parameters}

- It is now generally accepted that the OC use increases the plasma level of prothrombin, decreases the level of protein S and overall, induces acquired APC resistance.

- Together, these changes can explain why women who use OC are exposed to an increased risk of VT. 
- Compared with second-generation OC, third-generation OC caused more pronounced changes in the plasma levels of prothrombin and protein $\mathrm{S}$ and in APC resistance.

\section{Effects of Progestins \& Estrogens on Hemostatic Parameters}

- Progestin-only preparations change several hemostatic parameters in a direction that is opposite to that observed with combined oral contraceptives.

- It is hypothesized that ethinylestradiol has a thrombotic effect and progestins have a counterbalancing antithrombotic effect, the magnitude of which depends on the type of progestin.

- Differences in the antithrombotic effects between desogestrel/gestodene and levonorgestrel can explain the more pronounced effects of third-generation OC on hemostatic parameters.

\section{Conclusions}

- Insight in the biological basis of pill thrombosis and the discovery of new risk factors of VT will facilitate the development of safer OC formulations with an improved risk/benefit ratio and guide the choice of a proper method of contraception. 


\section{References}

1. Makepeace AW, Weinstein GL, Friedman MH: The effect of progestin and progesterone on ovulation in the rabbit. Am. J. Physiol. 119, 512-516 (1937).

2. Connell EB: Contraception in the prepill era. Contraception 59, 7S-10S (1999).

3. Jordan WM: Pulmonary embolism. Lancet 18, 1146-1147 (1961).

4. McWilliam RS, Macdonald AJ, Lindsay I: Thrombophlebitis following the use of norethynodren (Enovid). Can. Med. Assoc. J. 88, 1032-1033 (1963).

5. Schatz IJ, Smith RF, Breneman GM, Bower GC: Thromboembolic disease associated with norethynodrel: report of six cases. JAMA 188, 493-495 (1964).

6. Inman WH, Vessey MP, Westerholm B, Engelund A: Thromboembolic disease and the steroidal content of oral contraceptives. A report to the Committee on Safety of Drugs. Br. Med. J. 2, 203-209 (1970).

7. Stadel BV: Oral contraceptives and cardiovascular disease (second of two parts). N. Engl. J. Med. 305, 672-677 (1981).

8. Burkman RT: Current controversies: hormone replacement therapy and breast cancer. Obstet. Gynecol. Surv. 58, 633-635 (2003).

9. Oral contraceptives and thromboembolism. IPPF Med. Bull. 1, 4 (1967).

10. Farley TM, Meirik O, Collins J: Cardiovascular disease and combined oral contraceptives: reviewing the evidence and balancing the risks. Hum. Reprod. Update 5, 721-735 (1999).

11. Effect of different progestagens in low oestrogen oral contraceptives on venous thromboembolic disease. World Health Organization Collaborative Study of Cardiovascular Disease and Steroid Hormone Contraception. Lancet 346, 1582-1588 (1995).

12. Herings RM, Urquhart J, Leufkens HG: Venous thromboembolism among new users of different oral contraceptives. Lancet 354, 127-128 (1999).

13. Bloemenkamp KW, Rosendaal FR, Helmerhorst FM, Buller HR, Vandenbroucke JP: Enhancement by factor V Leiden mutation of risk of deep vein thrombosis associated with oral contraceptives containing a third-generation progestagen. Lancet 346, 1593-1596 (1995).

14. Jick H, Jick SS, Gurewich V, Myers MW, Vasilakis C: Risk of idiopathic cardiovascular death and nonfatal venous thromboembolism in women using oral contraceptives with differing progestagen components. Lancet 346, 1589-1593 (1995).

15. Spitzer WO, Lewis MA, Heinemann LA, Thorogood M, MacRae KD: Third generation oral contraceptives and risk of venous thromboembolic disorders: an international case-control study. Transnational Research Group on Oral Contraceptives and the Health of Young Women. BMJ 312, 83-88 (1996).

16. Spitzer WO: The 1995 pill scare revisited: anatomy of a non-epidemic. Hum. Reprod. 12, 2347-2357 (1997).

17. Farmer RD, Lawrenson RA, Thompson CR, Kennedy JG, Hambleton IR: Populationbased study of risk of venous thromboembolism associated with various oral contraceptives. Lancet 349, 83-88 (1997).

18. Ory HW: Epidemiology of venous thromboembolic disease and $\mathrm{OC}$ use. Dialogues Contracept. 5, 4-7, 10 (1996).

19. Andersen BS, Olsen J, Nielsen GL et al.: Third generation oral contraceptives and heritable thrombophilia as risk factors of non-fatal venous thromboembolism. Thromb. Haemost. 79, 28-31 (1998).

20. Lidegaard O, Edstrom B, Kreiner S: Oral contraceptives and venous thromboembolism: a fiveyear national case-control study. Contraception 65, 187-196 (2002).

21. Farmer RD, Todd JC, Lewis MA, MacRae KD, Williams TJ: The risks of venous thromboembolic disease among German women using oral contraceptives: a database study. Contraception 57, 67-70 (1998).

22. Martinelli I, Taioli E, Bucciarelli P, Akhavan S, Mannucci PM: Interaction between the G20210A mutation of the prothrombin gene and oral contraceptive use in deep vein thrombosis. Arterioscler. Thromb. Vasc. Biol. 19, 700-703 (1999). 
23. Lewis MA, MacRae KD, Kuhl-Habichl D, Bruppacher R, Heinemann LA, Spitzer WO: The differential risk of oral contraceptives: the impact of full exposure history. Hum. Reprod. 14, 1493-1499 (1999).

24. Heinemann LA, Garbe E, Farmer R, Lewis MA: Venous thromboembolism and oral contraceptive use: a methodological study of diagnostic suspicion and referral bias. Eur. J. Contracept. Reprod. Health Care 5, 183-191 (2000).

25. Heinemann LA, Lewis MA, Assmann A, Thiel C: Case-control studies on venous thromboembolism: bias due to design? A methodological study on venous thromboembolism and steroid hormone use. Contraception 65, 207-214 (2002).

26. Walker AM: Newer oral contraceptives and the risk of venous thromboembolism. Contraception 57, 169-181 (1998).

27. Bloemenkamp KW, Rosendaal FR, Buller HR, Helmerhorst FM, Colly LP, Vandenbroucke JP: Risk of venous thrombosis with use of current low-dose oral contraceptives is not explained by diagnostic suspicion and referral bias. Arch. Intern. Med. 159, 65-70 (1999).

28. Vasilakis-Scaramozza C, Jick H: Risk of venous thromboembolism with cyproterone or levonorgestrel contraceptives. Lancet 358, 1427-1429 (2001).

29. Rosendaal FR: Venous thrombosis: a multicausal disease. Lancet 353, 1167-1173 (1999).

30. Pabinger I, Schneider B: Thrombotic risk of women with hereditary antithrombin III-, protein C- and protein S-deficiency taking oral contraceptive medication. The GTH Study Group on Natural Inhibitors. Thromb. Haemost. 71, 548-552 (1994).

31. Legnani C, Palareti G, Guazzaloca G et al.: Venous thromboembolism in young women; role of thrombophilic mutations and oral contraceptive use. Eur. Heart J. 23, 984-990 (2002).

32. Vandenbroucke JP, Koster T, Briet E, Reitsma PH, Bertina RM, Rosendaal FR: Increased risk of venous thrombosis in oralcontraceptive users who are carriers of factor $\mathrm{V}$ Leiden mutation. Lancet 344, 1453-1457 (1994).

33. Nightingale AL, Lawrenson RA, Simpson EL, Williams TJ, MacRae KD, Farmer RD: The effects of age, body mass index, smoking and general health on the risk of venous thromboembolism in users of combined oral contraceptives. Eur. J. Contracept. Reprod. Health Care 5, 265-274 (2000).

34. Abdollahi M, Cushman M, Rosendaal FR: Obesity: risk of venous thrombosis and the interaction with coagulation factor levels and oral contraceptive use. Thromb. Haemost. 89, 493-498 (2003).

35. Cushman M, Yanez D, Psaty BM et al.: Association of fibrinogen and coagulation factors VII and VIII with cardiovascular risk factors in the elderly: the Cardiovascular Health Study. Cardiovascular Health Study Investigators. Am. J. Epidemiol. 143, 665-676 (1996).

36. De Pergola G, De Mitrio V, Giorgino F et al.: Increase in both pro-thrombotic and antithrombotic factors in obese premenopausal women: relationship with body fat distribution. Int. J. Obes. Relat. Metab. Disord. 21, 527-535 (1997).

37. Middeldorp S, Meijers JC, van den Ende AE et al.: Effects on coagulation of levonorgestreland desogestrel-containing low dose oral contraceptives: a cross-over study. Thromb. Haemost. 84, 4-8 (2000).

38. Tans G, Curvers J, Middeldorp S et al.: A randomized cross-over study on the effects of levonorgestrel- and desogestrelcontaining oral contraceptives on the anticoagulant pathways. Thromb. Haemost. 84, 15-21 (2000).

39. Meijers JC, Middeldorp S, Tekelenburg W et al.: Increased fibrinolytic activity during use of oral contraceptives is counteracted by an enhanced factor XI-independent down regulation of fibrinolysis: a randomized cross-over study of two low-dose oral contraceptives. Thromb. Haemost. 84, 9-14 (2000).

40. Dahlback B, Carlsson M, Svensson PJ: Familial thrombophilia due to a previously unrecognized mechanism characterized by poor anticoagulant response to activated protein C: prediction of a cofactor to activated protein C. Proc. Natl Acad. Sci. USA 90, 1004-1008 (1993). 
41. Bertina RM, Koeleman BP, Koster T et al.: Mutation in blood coagulation factor V associated with resistance to activated protein C. Nature 369, 64-67 (1994).

42. de Visser MC, van Hylckama Vlieg A, Tans G et al.: Determinants of the APTT- and ETPbased APC sensitivity tests. J. Thromb. Haemost. 3, 1488-1494 (2005).

43. Gennari LC, Blanco AN, Dominguez MP, Grosso SH, Lazzari MA: Endogenous or exogenous coagulation factor level and the response to activated protein C. Thromb. Res. (2005).

44. de Visser MC, Rosendaal FR, Bertina RM: A reduced sensitivity for activated protein $C$ in the absence of factor V Leiden increases the risk of venous thrombosis. Blood 93, 1271-1276 (1999).

45. The effects of seven monophasic oral contraceptive regimens on hemostatic variables: conclusions from a large randomized multicenter study. Contraception 67, 173-185 (2003).

46. An open label, randomized study to evaluate the effects of seven monophasic oral contraceptive regimens on hemostatic variables. Outline of the protocol. Oral Contraceptive and Hemostasis Study Group. Contraception 59, 345-355 (1999).

47. Harris GM, Stendt CL, Vollenhoven BJ, Gan TE, Tipping PG: Decreased plasma tissue factor pathway inhibitor in women taking combined oral contraceptives. Am. J. Hematol. 60, 175180 (1999).

48. Kemmeren JM, Algra A, Meijers JC et al.: Effect of second- and third-generation oral contraceptives on the protein $\mathrm{C}$ system in the absence or presence of the factor VLeiden mutation: a randomized trial. Blood 103, 927-933 (2004).

49. Koenen RR, Christella M, Thomassen LG, Tans G, Rosing J, Hackeng TM: Effect of oral contraceptives on the anticoagulant activity of protein $\mathrm{S}$ in plasma. Thromb. Haemost. 93, 853-859 (2005).

50. Olivieri $\mathrm{O}$, Friso $\mathrm{S}$, Manzato $\mathrm{F}$ et al.: Resistance to activated protein $\mathrm{C}$ in healthy women taking oral contraceptives. Br. J. Haematol. 91, 465-470 (1995).

51. Rosing J, Tans G, Nicolaes GA et al.: Oral contraceptives and venous thrombosis: different sensitivities to activated protein $\mathrm{C}$ in women using second- and third-generation oral contraceptives. Br. J. Haematol. 97, 233-238 (1997).

52. Rodeghiero F, Tosetto A: Activated protein $\mathrm{C}$ resistance and factor $\mathrm{V}$ Leiden mutation are independent risk factors for venous thromboembolism. Ann. Intern. Med. 130, 643-650 (1999).

53. Tans G, van Hylckama Vlieg A, Thomassen MC et al.: Activated protein $\mathrm{C}$ resistance determined with a thrombin generation-based test predicts for venous thrombosis in men and women. Br. J. Haematol. 122, 465-470 (2003).

54. Curvers J, Thomassen MC, Nicolaes GA et al.: Acquired APC resistance and oral contraceptives: differences between two functional tests. Br. J. Haematol. 105, 88-94 (1999).

55. Gris JC, Jamin C, Benifla JL, Quere I, Madelenat P, Mares P: APC resistance and thirdgeneration oral contraceptives: acquired resistance to activated protein $\mathrm{C}$, oral contraceptives and the risk of thromboembolic disease. Hum. Reprod. 16, 3-8 (2001).

56. Gris JC, Nouvellon-Cochery E, Mares P: Increased resistance to activated protein C in women taking third-generation oral contraceptives? Blood 104, 1908-1909 (2004).

57. Odlind V, Milsom I, Persson I, Victor A: Can changes in sex hormone binding globulin predict the risk of venous thromboembolism with combined oral contraceptive pills? Acta Obstet. Gynecol. Scand. 81, 482-490 (2002).

58. Mashchak CA, Lobo RA, Dozono-Takano R et al.: Comparison of pharmacodynamic properties of various estrogen formulations. Am. J. Obstet. Gynecol. 144, 511-518 (1982).

59. Mainwaring R, Hales HA, Stevenson $\mathrm{K}$ et al.: Metabolic parameter, bleeding, and weight changes in U.S. women using progestin only contraceptives. Contraception 51, 149-153 (1995).

60. van Rooijen M, Silveira A, Hamsten A, Bremme K: Sex hormone-binding globulin - a surrogate marker for the prothrombotic effects of combined oral contraceptives. Am. J. Obstet. Gynecol. 190, 332-337 (2004). 
61. van Vliet HA, Frolich M, Christella $\mathrm{M}$ et al.: Association between sex hormone-binding globulin levels and activated protein $\mathrm{C}$ resistance in explaining the risk of thrombosis in users of oral contraceptives containing different progestogens. Hum. Reprod. 20, 563-568 (2005).

62. Poulter NR, Chang CL, Farley TM, Meirik O: Risk of cardiovascular diseases associated with oral progestogen preparations with therapeutic indications. Lancet 354, 1610 (1999).

63. Gerstman BB, Piper JM, Freiman JP et al.: Oral contraceptive oestrogen and progestin potencies and the incidence of deep venous thromboembolism. Int. J. Epidemiol. 19, 931-936 (1990).

64. Vasilakis C, Jick H, del Mar Melero-Montes M: Risk of idiopathic venous thromboembolism in users of progestagens alone. Lancet 354, 1610-1611 (1999).

65. Poort SR, Rosendaal FR, Reitsma PH, Bertina RM: A common genetic variation in the 3'untranslated region of the prothrombin gene is associated with elevated plasma prothrombin levels and an increase in venous thrombosis. Blood 88, 3698-3703 (1996).

66. Doutremepuich F, Aguejouf O, Belougne-Malfatti E, Doutremepuich C: Fibrinogen as a factor of thrombosis: experimental study. Thromb. Res. 90, 57-64 (1998).

67. van Hylckama Vlieg A, Rosendaal FR: High levels of fibrinogen are associated with the risk of deep venous thrombosis mainly in the elderly. J Thromb. Haemost. 1, 2677-2678 (2003).

68. Uitte de Willige S, de Visser MC, Houwing-Duistermaat JJ, Rosendaal FR, Vos HL, Bertina RM: Genetic variation in the fibrinogen gamma gene increases the risk for deep venous thrombosis by reducing plasma fibrinogen gamma levels. Blood 106, 4176-4183 (2005).

69. Koster T, Blann AD, Briet E, Vandenbroucke JP, Rosendaal FR: Role of clotting factor VIII in effect of von Willebrand factor on occurrence of deep-vein thrombosis. Lancet 345, 152 155 (1995).

70. Tsai AW, Cushman M, Rosamond WD et al.: Coagulation factors, inflammation markers, and venous thromboembolism: the longitudinal investigation of thromboembolism etiology (LITE). Am. J. Med. 113, 636-642 (2002).

71. van Hylckama Vlieg A, van der Linden IK, Bertina RM, Rosendaal FR: High levels of factor IX increase the risk of venous thrombosis. Blood 95, 3678-3682 (2000).

72. Meijers JC, Tekelenburg WL, Bouma BN, Bertina RM, Rosendaal FR: High levels of coagulation factor XI as a risk factor for venous thrombosis. N. Engl. J. Med. 342, 696-701 (2000).

73. Martinelli I, Mannucci PM, De Stefano V et al.: Different risks of thrombosis in four coagulation defects associated with inherited thrombophilia: a study of 150 families. Blood 92, 2353-2358 (1998).

74. Dahm A, Van Hylckama Vlieg A, Bendz B, Rosendaal F, Bertina RM, Sandset PM: Low levels of tissue factor pathway inhibitor (TFPI) increase the risk of venous thrombosis. Blood 101, 4387-4392 (2003).

75. Amini-Nekoo A, Futers TS, Moia M, Mannucci PM, Grant PJ, Ariens RA: Analysis of the tissue factor pathway inhibitor gene and antigen levels in relation to venous thrombosis. Br. J. Haematol. 113, 537-543 (2001).

76. Brugge JM, Tans G, Rosing J, Castoldi E: Protein S levels modulate the activated protein C resistance phenotype induced by elevated prothrombin levels. Thromb. Haemost. 95, 236-242 (2006).

77. Smirnov MD, Safa O, Esmon NL, Esmon CT: Inhibition of activated protein C anticoagulant activity by prothrombin. Blood 94, 3839-3846 (1999).

78. Tripodi A, Chantarangkul V, Mannucci PM: Hyperprothrombinemia may result in acquired activated protein C resistance. Blood 96, 3295-3296 (2000).

79. Winkler UH: Hemostatic effects of third- and second-generation oral contraceptives: absence of a causal mechanism for a difference in risk of venous thromboembolism. Contraception 62, 11S-20S (2000).

80. Kluft C: Renewed interest in haemostasis changes induced by oral contraceptives (OC). Thromb. Haemost. 84, 1-3 (2000). 
81. Svensson PJ, Dahlback B: Resistance to activated protein C as a basis for venous thrombosis. N. Engl. J. Med. 330, 517-522 (1994).

82. Humphries SE, Cook M, Dubowitz M, Stirling Y, Meade TW: Role of genetic variation at the fibrinogen locus in determination of plasma fibrinogen concentrations. Lancet 1, 1452-1455 (1987).

83. Haverkate F, Samama M: Familial dysfibrinogenemia and thrombophilia. Report on a study of the SSC Subcommittee on Fibrinogen. Thromb. Haemost. 73, 151-161 (1995).

84. Lane DA, Bayston T, Olds RJ et al.: Antithrombin mutation database: $2^{\text {nd }}$ (1997) update. For the Plasma Coagulation Inhibitors Subcommittee of the Scientific and Standardization Committee of the International Society on Thrombosis and Haemostasis. Thromb. Haemost. 77, 197-211 (1997).

85. Reitsma PH: Protein C deficiency: summary of the 1995 database update. Nucleic Acids Res. 24, 157-159 (1996).

86. Gandrille S, Borgel D, Sala $\mathrm{N}$ et al.: Protein $\mathrm{S}$ deficiency: a database of mutations - summary of the first update. Thromb. Haemost. 84, 918 (2000).

87. Moatti D, Seknadji P, Galand C et al.: Polymorphisms of the tissue factor pathway inhibitor (TFPI) gene in patients with acute coronary syndromes and in healthy subjects: impact of the V264M substitution on plasma levels of TFPI. Arterioscler. Thromb. Vasc. Biol. 19, 862-869 (1999).

88. Castaman G, Tosetto A, Simioni M, Ruggeri M, Madeo D, Rodeghiero F: Phenotypic APC resistance in carriers of the A20210 prothrombin mutation is associated with an increased risk of venous thrombosis. Thromb. Haemost. 86, 804-808 (2001).

\section{Websites}

101. The European Agency for the Evaluation of Medicinal Products: position statement. CPMP concludes its assessment of 'third-generation' combined oral contraceptives and the risk of venous thromboembolism. www.emea.europa.eu.int/pdfs/human/regaffair/0225001 en.pdf

102. The European Agency for the Evaluation of Medicinal Products: information for women using oral contraceptives. www.emea.europa.eu.int/pdfs/human/regaffair/0225901 en.pdf 



\section{Chapter 3}

\section{Effect of Oral Contraceptives on Thrombin}

Generation Measured via Calibrated

\section{Automated Thrombography (CAT)}

S.N. Tchaikovski, H.A.A.M. van Vliet, M.C.L.G.D. Thomassen, R.M. Bertina,

F.R. Rosendaal, P.M. Sandset, F.M. Helmerhorst, G. Tans, J. Rosing

Thrombosis and Haemostasis 2007; 98(6): 1350-6 


\section{Summary}

In a study population consisting of healthy men $(\mathrm{n}=8)$, women not using oral contraceptives (OC) $(n=28)$ and women using different kinds of OC $(n=187)$ we used calibrated automated thrombography (CAT) in the absence and presence of added activated protein $\mathrm{C}$ (APC) to compare parameters that can be obtained from thrombin generation curves i.e. the lag time, time to peak, peak height and endogenous thrombin potential (ETP).

Both with and without APC, plasmas of OC users exhibited the shortest lag time and time to peak, and the highest peak height and ETP. In the absence of APC none of these parameters differed between users of OC containing different progestogens. In contrast, in the presence of APC shorter lag times and time to peak, and higher peak height and ETP were observed in plasma of users of gestodene-, desogestrel-, drospirenone- and cyproterone acetate-containing OC than in plasma of users of levonorgestrel-containing OC.

The ETP determined in the absence of APC (ETP-APC) had no predictive value for the $\mathrm{APCsr}\left(\mathrm{r}=0.11\right.$; slope $0.9 \times 10^{-3} ; 95 \% \mathrm{CI}:-0.1 \times 10^{-3}$ to $\left.2.0 \times 10^{-3}\right)$ whereas the ETP measured in the presence of APC $\left(\mathrm{ETP}_{+\mathrm{APC}}\right)$ showed an excellent correlation with the APCsr ( $\mathrm{r}=0.95$; slope $6.6 \times 10^{-3} ; 95 \% \mathrm{CI}: 6.3 \times 10^{-3}$ to $6.9 \times 10^{-3}$ ) indicating that the APCsr is entirely determined by the $\mathrm{ETP}_{+\mathrm{APC}}$.

In conclusion, OC use increases thrombin generation, but differential effects of second and third generation OCs on the protein $\mathrm{C}$ system likely determine the differences in the risk of venous thrombosis between these kinds of OC. 


\section{Introduction}

Oral contraceptive (OC) use increases risk of venous thrombosis (VT) two- to six-fold. ${ }^{1}$ The thrombosis risk is $\sim$ two-fold higher in users of so-called third generation $\mathrm{OC}$, containing desogestrel or gestodene as compared to users of second generation OC, containing levonorgestrel. ${ }^{2}$ This risk increase is associated with OC-induced changes in the plasma levels of many coagulation factors. Because these changes are often modest and may have synergistic or opposing effects, assessment of an individual's risk for VT on the basis of changes of coagulation factor concentrations is rather difficult. Evaluation of thrombin generation in plasma provides an over-all measure for the state of the coagulation system that may be indicative for the risk of VT. ${ }^{3,4}$ Indeed, compared to non-users, plasmas of OC users show increased thrombin generation (endogenous thrombin potential or ETP) upon initiation of the extrinsic coagulation pathway with tissue factor (TF) ${ }^{5}$ but no differences were reported for $\mathrm{OC}$ preparations containing different progestogens. We have developed a thrombin generation assay that quantifies the effect of activated protein C (APC) on the total amount of thrombin generated in plasma upon initiation of coagulation with TF. ${ }^{6}$ This assay appeared to be particularly sensitive for hormone use ${ }^{7}$ and it was demonstrated that plasma from third generation OC users was significantly more APC resistant than that of second generation OC users. ${ }^{8}$

An impaired response to APC (APC resistance) is most commonly caused by a single point mutation in the factor $\mathrm{V}$ gene, known as factor $\mathrm{V}_{\text {Leiden }}$ $\left(\mathrm{FV}_{\text {Leiden }}\right),{ }^{9,10}$ but can also result from elevated levels of prothrombin ${ }^{11}$ or factor VIII, ${ }^{12}$ or from acquired conditions such as pregnancy, ${ }^{13,14}$ OC use, ${ }^{15,16}$ hormone replacement therapy ${ }^{17}$ or the presence of lupus anticoagulants. ${ }^{18}$ APC resistance in the presence ${ }^{19,20}$ as well as in the absence of $\mathrm{FV}_{\text {Leiden }}{ }^{21,22}$ is associated with an increased risk of VT.

In the thrombin generation-based APC resistance test developed by Nicolaes et al. ${ }^{6}$ the ratio of the final plateaus of thrombin amidolytic activity trapped in complex with $\alpha_{2}$-macroglobulin $\left(\alpha_{2} \mathrm{M}\right.$-IIa) determined in the presence and absence of added APC was used as a measure for the effect of APC on the ETP. However, measurements of the final plateau of $\alpha_{2} \mathrm{M}$-IIa do not yield information about the complete time course of thrombin formation nor do they allow evaluation of the separate measurements since the final plateau of amidolytic activity strongly depends on the amount of $\alpha_{2}$-macroglobulin present in an individual's plasma. 
In recent years, it has become feasible to determine the time course of thrombin formation in a calibrated automated fashion in a plate reader using a low affinity fluorescent thrombin substrate. ${ }^{23}$ Besides the ETP values, calibrated automated thrombography (CAT) provides additional information on thrombin generation such as lag time, time to peak and peak height of thrombin generation which can readily be obtained with the proper software. ${ }^{23}$

In the current paper we determined parameters of thrombin generation measured by CAT in the absence and in the presence of APC in plasmas of women using different formulations of OC. Furthermore, we analyzed the APC sensitivity ratios in terms of the individual thrombin generation measurements.

\section{Materials \& Methods}

\section{Collection of Plasma Samples}

This investigation was performed with plasma collections from two studies, the design of which has been previously described. ${ }^{24-26}$ Available for analysis from the study of Koenen et al. ${ }^{24}$ were 94 samples obtained from healthy men $(n=8$; mean age 25 years), women not using OC ( $\mathrm{n}=28$; mean age 27 years, including one $\mathrm{FV}_{\text {Leiden }}$ heterozygote), women using first generation $\mathrm{OC}(\mathrm{n}=2$; mean age 28.5 years), women using second generation $\mathrm{OC}(\mathrm{n}=27$; mean age 25 years), women using third generation OC $(n=27$; mean age 24 years, including one $\mathrm{FV}_{\text {Leiden }}$ heterozygote) and women using cyproterone acetate (CPA)-containing OC ( $\mathrm{n}=2$; mean age 22 years).

In the study of van Vliet et al. ${ }^{25,26}$ plasma samples were obtained from 158 women, two of whom were excluded because of diabetes mellitus $(n=1)$ or a history of VT $(n=1)$ and from two women no samples were available. The remaining samples were from healthy women, using first generation $\mathrm{OC}(\mathrm{n}=2$; mean age 30 years), second generation $\mathrm{OC}(\mathrm{n}=59$; mean age 28 years, including $4 \mathrm{FV}_{\text {Leiden }}$ heterozygotes), third generation $\mathrm{OC}(\mathrm{n}=45$; mean age 29 years, including $4 \mathrm{FV}_{\text {Leiden }}$ and 3 prothrombin $\mathrm{G} 20210 \mathrm{~A}$ heterozygotes), norgestimatecontaining $\mathrm{OC}\left(\mathrm{n}=4\right.$, mean age 27 years, including $3 \mathrm{FV}_{\text {Leiden }}$ heterozygotes), CPA-containing OC $(\mathrm{n}=21$, mean age 27 years, including one prothrombin G20210A heterozygote) and drospirenone (DRSP)-containing OC $(\mathrm{n}=23$, mean age 28 years, including $3 \mathrm{FV}_{\text {Leiden }}$ and one prothrombin G20210A heterozygotes). All women had been using their respective preparation of OC for at least four cycles. Furthermore, after a first blood donation, users of DRSP- and CPA-containing OC were asked to switch to second generation OC, whereas users of second or third generation OC were asked to switch to DRSP- 
containing pills. In total 194 samples were available for analysis (154 first donations and 40 second donations).

In both studies exclusion criteria were a personal history of VT, a chronic or intercurrent disease or use of a medication known to interfere with blood coagulation. The OC classification is based on the progestogen component. Lynestrenol- or norethisterone-containing OC were defined as first generation, levonorgestrel-containing $\mathrm{OC}$ as second generation and $\mathrm{OC}$ containing desogestrel or gestodene as third generation. Norgestimate-, CPA- and DRSPcontaining OC were classified as independent groups. The studies were approved by the Medical Ethics committees of the Maastricht ${ }^{24}$ and Leiden University Medical Centers. ${ }^{25,26}$ All volunteers gave written informed consent.

\section{Laboratory Methods}

Blood samples were taken and processed as described elsewhere. ${ }^{24,25}$ All participants were screened for $\mathrm{FV}_{\text {Leiden }}$. ${ }^{24,25}$ The prothrombin G20210A mutation was determined only in the study of van Vliet et al. ${ }^{25,26}$

Prothrombin concentrations were determined as described before ${ }^{27}$ after complete activation of the prothrombin present in plasma with Ecarin (Pentapharm Ltd, Basel, Switzerland). Antithrombin concentrations were measured with the Coamatic ${ }^{\circledR}$ antithrombin kit (Chromogenix, Milano, Italy). TFPI activity (TFPI ${ }_{\text {activity }}$ ) was determined with an in-house chromogenic substrate assay, whereas free TFPI antigen (TFPI free $_{\text {) }}$ and total TFPI antigen

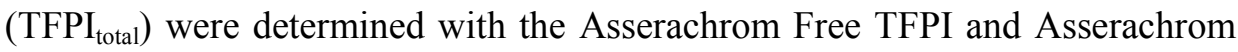
Total TFPI ELISA kits (Stago, Asniere, France) respectively, as described before. ${ }^{28}$ Protein $\mathrm{S}$ total antigen (protein $\mathrm{S}_{\text {total }}$ ) was measured as described earlier ${ }^{29}$ and protein $\mathrm{S}$ free antigen (protein $\mathrm{S}_{\text {free }}$ ) was determined with an ELISA according to Giri et al. ${ }^{30}$ with minor modifications.

Thrombin generation in the absence and in the presence of APC was monitored by CAT. ${ }^{23,31}$ The APC sensitivity ratio $\left(\mathrm{APCsr}_{\mathrm{ETP}}\right)$ for each plasma sample was calculated as previously described. ${ }^{31}$

Single ETPs were corrected for day-to-day variation by 1) division through the ETP of pooled normal plasma (PNP) determined in the same experiment $\left(\mathrm{ETP}_{\mathrm{PNP}-\mathrm{APC}}\right)$ followed by 2$)$ multiplication with the reference value $\left(\mathrm{ETP}_{\text {ref-APC }}\right)$ which is defined as the average of all ETP values of PNP determined within the study. Because the APC concentration in the experiments was chosen to set the $\mathrm{ETP}_{\mathrm{PNP}+\mathrm{APC}}$ at $\sim 10 \%$ of the $\mathrm{ETP}_{\mathrm{PNP}-\mathrm{APC}}$, the reference value for the $\mathrm{ETP}_{+\mathrm{APC}}$ was $0.1 * \mathrm{ETP}_{\text {ref-APC }}$. 
Thus,

$$
\begin{aligned}
& \mathrm{ETP}_{-\mathrm{APC}}=\left(\mathrm{ETP}_{\text {sample-APC }} / \mathrm{ETP}_{\mathrm{PNP}-\mathrm{APC}}\right) * \mathrm{ETP}_{\text {ref-APC }} \\
& \mathrm{ETP}_{+\mathrm{APC}}=\left(\mathrm{ETP}_{\text {sample }+\mathrm{APC}} / \mathrm{ETP}_{\mathrm{PNP}+\mathrm{APC}}\right) * 0.1 * \mathrm{ETP}_{\text {ref-APC }}
\end{aligned}
$$

The intra- and inter-assay coefficients of variation were $4 \%$ and $7 \%$ for the $\mathrm{ETP}_{-\mathrm{APC}}, 10 \%$ and $14 \%$ for the $\mathrm{ETP}_{+\mathrm{APC}}$ and $7 \%$ and $14 \%$ for the APCsr, respectively. All other parameters of thrombin generation curves (lag time, peak height, time to peak) were normalized for day-to-day variations in a similar way.

All laboratory tests were performed in random blinded order without knowledge of OC use or any other personal information.

\section{Statistical Analysis}

Statistical analysis was performed using SPSS 11.0 for Windows (SPSS, Chicago, IL). Correlations were evaluated by linear regression analysis and the Pearson coefficient and the slope with $95 \%$ confidence interval $(95 \% \mathrm{CI})$ are given.

Effects of sex and OC use on the APCsr ${ }_{\mathrm{ETP}}$ and parameters of thrombin generation were evaluated by multiple linear regression analysis with $\mathrm{APCsr}_{\mathrm{ETP}}$, $\mathrm{ETP}_{-\mathrm{APC}}, \mathrm{ETP}_{+\mathrm{APC}}$, peak height ${ }_{-\mathrm{APC}}$, peak height ${ }_{+\mathrm{APC}}$, lag time -APC $_{\text {and }}$ ag time $_{+\mathrm{APC}}$ as dependent variables and with sex $($ male $=0$, female $=1)$ and groups of $\mathrm{OC}$ as independent variables. To control for an effect of the center where the plasma samples were collected (Leiden or Maastricht) the analysis was performed including the center as an additional independent variable. To assess the determinants of the $\mathrm{APCSr}_{\mathrm{ETP}}$ and the ETPS, multiple linear regression analysis was performed, with $\mathrm{APCsr}_{\mathrm{ETP}}, \mathrm{ETP}_{-\mathrm{APC}}, \mathrm{ETP}_{+\mathrm{APC}}$ as dependent variables and putative determinants (prothrombin, antithrombin, protein $\mathrm{S}_{\text {total }}$ and protein $\mathrm{S}_{\text {free }}, \mathrm{TFPI}_{\text {total }}, \mathrm{TFPI}_{\text {free }}$ and $\mathrm{TFPI}_{\text {activity }}$ ) as independent variables.

\section{Results}

\section{Correlation between Two Thrombin Generation-Based APC Resistance Assays}

In the thrombin generation-based APC resistance test developed earlier ${ }^{6}$ the APC sensitivity ratio $\left(\mathrm{APCsr}_{\alpha 2 \mathrm{M}-\mathrm{II}}\right)$ was calculated from the ratio of the final levels of amidolytic activity of thrombin trapped in complex with $\alpha_{2}$ macroglobulin in the presence and absence of APC. In the current study the APCsr was calculated from the ETP's, obtained via semi-automated measurement of the complete thrombin generation time courses (APCsr $\mathrm{ATP}_{\mathrm{EP}}$ ). There appeared to be a good correlation $(\mathrm{r}=0.92$; slope $1.34 ; 95 \% \mathrm{CI}$ : 1.22 to 
1.46) between the APCsr ${ }_{\text {ETP }}$ and the $\mathrm{APCsr}_{\alpha 2 \mathrm{M}-\mathrm{II}}$ determined previously ${ }^{24}$ in the same plasma samples with the end point assay (see Chapter 7, Fig. 1).

\section{Contribution of ETP ${ }_{-A P C}$ and $E T P_{+A P C}$ to $A P C s r_{E T P}$}

In order to gain insight into the contribution of the individual ETP measurements $\left(\mathrm{ETP}_{+\mathrm{APC}}\right.$ and $\left.\mathrm{ETP}_{-\mathrm{APC}}\right)$ to the $\mathrm{APCsr}_{\mathrm{ETP}}$, the $\mathrm{APCsr}_{\mathrm{ETP}}$ was determined in 248 first donation samples available from the studies of Koenen ${ }^{24}$ and van Vliet ${ }^{25,26}$ and plotted as a function of the ETP-APC $($ Fig. 1A) and the $\mathrm{ETP}_{+\mathrm{APC}}\left(\right.$ Fig. 1B), respectively. The sample collection included $16 \mathrm{FV}_{\text {Leiden }}$ heterozygotes (semi-closed circles) and 5 prothrombin G20210A heterozygotes (semi-closed triangles). The APCsr ${ }_{\text {ETP }}$ did not correlate with the $\mathrm{ETP}_{\text {-APC }}$ (Fig. $1 \mathrm{~A}, \mathrm{r}=0.11$; slope $0.9 \times 10^{-3} ; 95 \% \mathrm{CI}:-0.1 \times 10^{-3}$ to $2.0 \times 10^{-3}$ ), whereas an excellent correlation was observed between the $\mathrm{APCsr}_{\mathrm{ETP}}$ and the $\mathrm{ETP}_{+\mathrm{APC}}$ (Fig. 1B, $\mathrm{r}=0.95$; slope $6.6 \times 10^{-3} ; 95 \% \mathrm{CI}$ : $6.3 \times 10^{-3}$ to $6.9 \times 10^{-3}$ ). This correlation remained $(\mathrm{r}=0.94)$ after exclusion of carriers of the $\mathrm{FV}_{\text {Leiden }}$ or prothrombin $\mathrm{G} 20210 \mathrm{~A}$ mutations.

\section{Effect of OC use on ETP ${ }_{-A P C}, E_{T P_{+A P C}}$ and APCSr ${ }_{E T P}$}

In order to determine whether the APCsr ${ }_{\mathrm{ETP}}$ showed the same sensitivity for hormonal status (e.g. in women using second or third generation OC) as reported earlier for the $\mathrm{APCsr}_{\alpha 2 \mathrm{M}-\mathrm{II} a}{ }^{16,32}$ and whether this effect of OC was caused by altering the $\mathrm{ETP}_{-\mathrm{APC}}$ or the $\mathrm{ETP}_{+\mathrm{APC}}$ or both, the data were
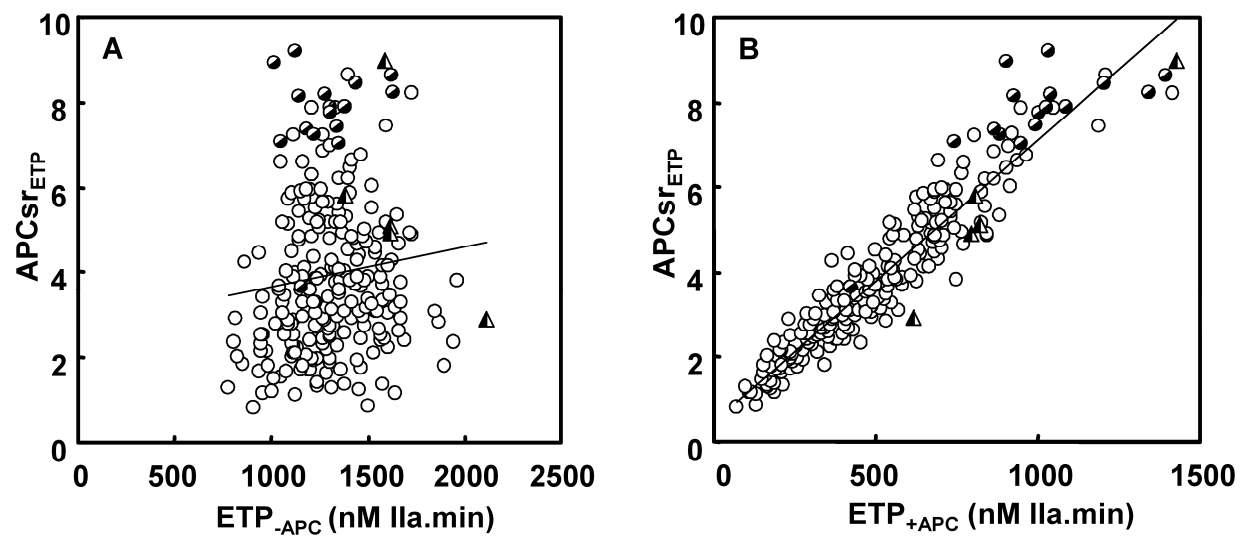

Fig. 1. Correlation of the APCsr ${ }_{E T P}$ with the $E T P_{+A P C}$ and the ETP ${ }_{-A P C}$

The $\mathrm{APCsr}_{\mathrm{ETP}}$ for each individual's plasma $(\mathrm{n}=248)$ are plotted as a function of the $\mathrm{ETP}_{-\mathrm{APC}}(\mathrm{A})$ or the $\mathrm{ETP}_{+\mathrm{APC}}(\mathrm{B})$. To minimize day-to-day variation, the individual $\mathrm{ETP}_{+\mathrm{APC}}$ and $\mathrm{ETP}_{-\mathrm{APC}}$ were normalized as described under Materials and Methods. Semi-closed circles represent $\mathrm{FV}_{\text {Leiden }}$ heterozygotes $(\mathrm{n}=16)$ and semi-closed triangles represent prothrombin $\mathrm{G} 20210$ A heterozygotes $(\mathrm{n}=5)$. 


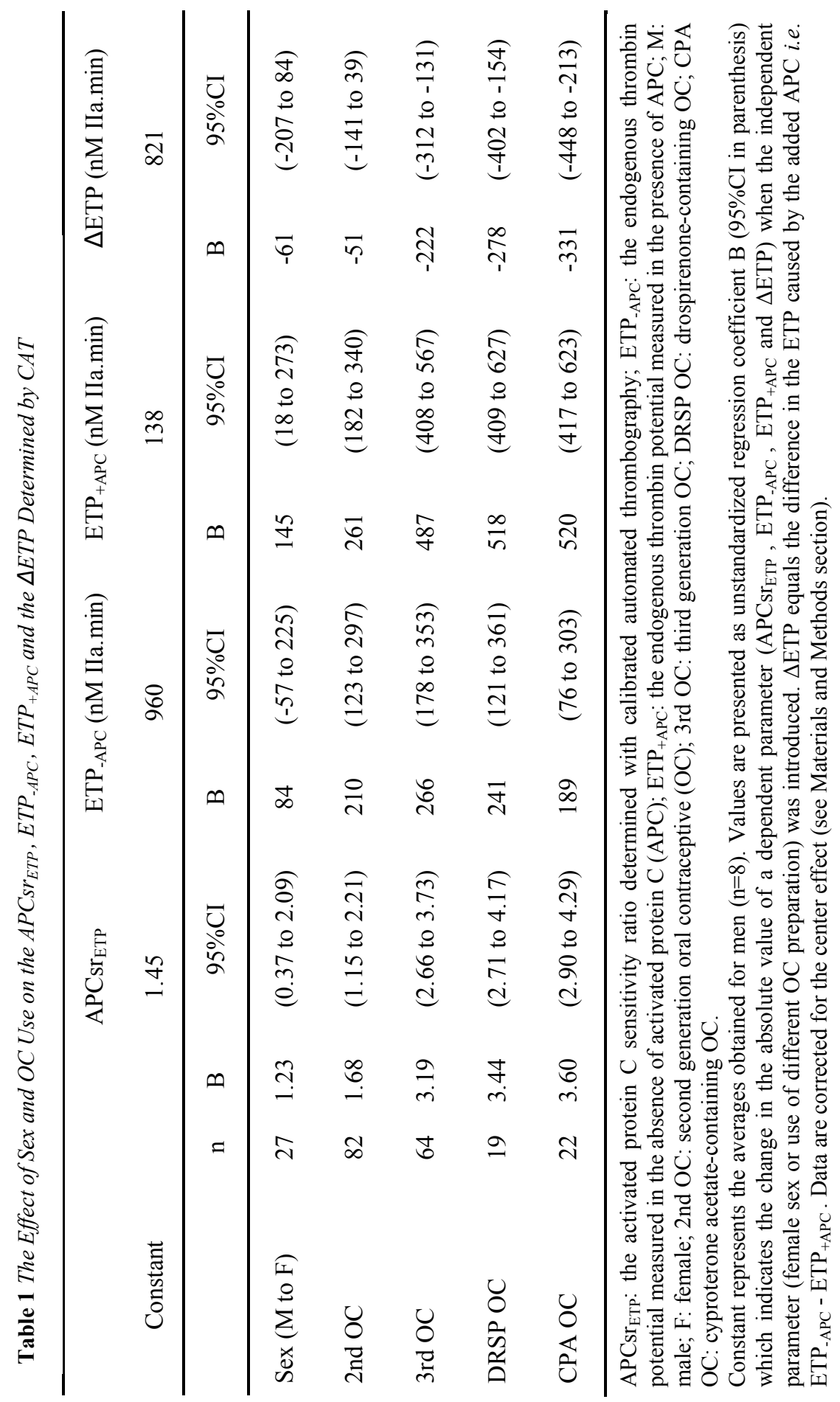


further analyzed by multiple regression analysis. We excluded from this analysis: $\mathrm{FV}_{\text {Leiden }}$ and prothrombin $\mathrm{G} 20210 \mathrm{~A}$ carriers, users of first generation or norgestimate-containing OC (norgestimate is converted in vivo into levonorgestrel ${ }^{33}$ ). This resulted in a total of 222 first donation plasma samples available for analysis. The results are summarized in Table 1. The well documented differences in the $\mathrm{APCsr}_{\alpha 2 \mathrm{M}-\mathrm{II} a}$ between the various groups ${ }^{16,32}$ were also observed for the APCsr ${ }_{\mathrm{ETP}}$ which increased in the order of men $<$ women not using $\mathrm{OC}<$ women using second generation $\mathrm{OC}<$ women using third generation OC or OC containing DRSP or CPA. Considering the correlation between the $\mathrm{APCsr}_{\mathrm{ETP}}$ and the $\mathrm{ETP}_{+\mathrm{APC}}$ (Fig. 1B), it is not surprising that the $\mathrm{ETP}_{+\mathrm{APC}}$ showed similar differences between the various groups (Table 1, Fig. 2D).

The $\mathrm{ETP}_{-\mathrm{APC}}$ of OC-using women were $\sim 25 \%$ higher than the $\mathrm{ETP}_{\text {-APC }}$ of men or of women not using OC. In contrast to the $\mathrm{ETP}_{+\mathrm{APC}}$, the $\mathrm{ETP}_{-\mathrm{APC}}$ of users of different $\mathrm{OC}$ preparations were approximately the same.

An increase of the $\mathrm{APCsr}_{\mathrm{ETP}}$ as well as the $\mathrm{ETP}_{+\mathrm{APC}}$ but not of the ETP-APC was observed when women switched from second generation to DRSPcontaining OC (Table 2). The switch from third generation OC to DRSPcontaining OC caused much smaller changes, whereas the switch from DRSPor CPA-containing OC to second generation OC caused changes of the $\mathrm{APCsr}_{\mathrm{ETP}}$ and $\mathrm{ETP}_{+\mathrm{APC}}$ that were opposite from those that occurred in women who switched from second to DRSP-containing OC.

\section{Effect of OC Use on other Parameters Derived from Thrombin Generation Curves}

We also analyzed the effects of gender and OC use on other parameters that can be obtained from thrombin generation curves, such as the lag time, time to peak, peak height (Table 3 and Fig. 2). The lag time and time to peak were shorter in women using OC than in men or women not using OC both in the absence and presence of APC. Compared to second generation OC, third generation and DRSP- or CPA-containing OC caused a more pronounced shortening of the lag time and time to peak in the presence of APC.

Between groups differences in the peak height (Table 3, Fig. 2C) were similar to the respective differences in the ETP (Table 3, Fig. 2D), which is explained by the good correlation between peak height and ETP (peak height ${ }_{-\mathrm{APC}}$ versus $\mathrm{ETP}_{\text {-APC }} \mathrm{r}=0.89$, slope $2.95,95 \% \mathrm{CI} 2.76$ to 3.14 and peak height ${ }_{+\mathrm{APC}}$ versus $\mathrm{ETP}_{+\mathrm{APC}} \mathrm{r}=0.97$, slope 3.11 , 95\%CI 3.01 to 3.21 ). Correspondingly, in the absence of APC peak heights were lower in men or 

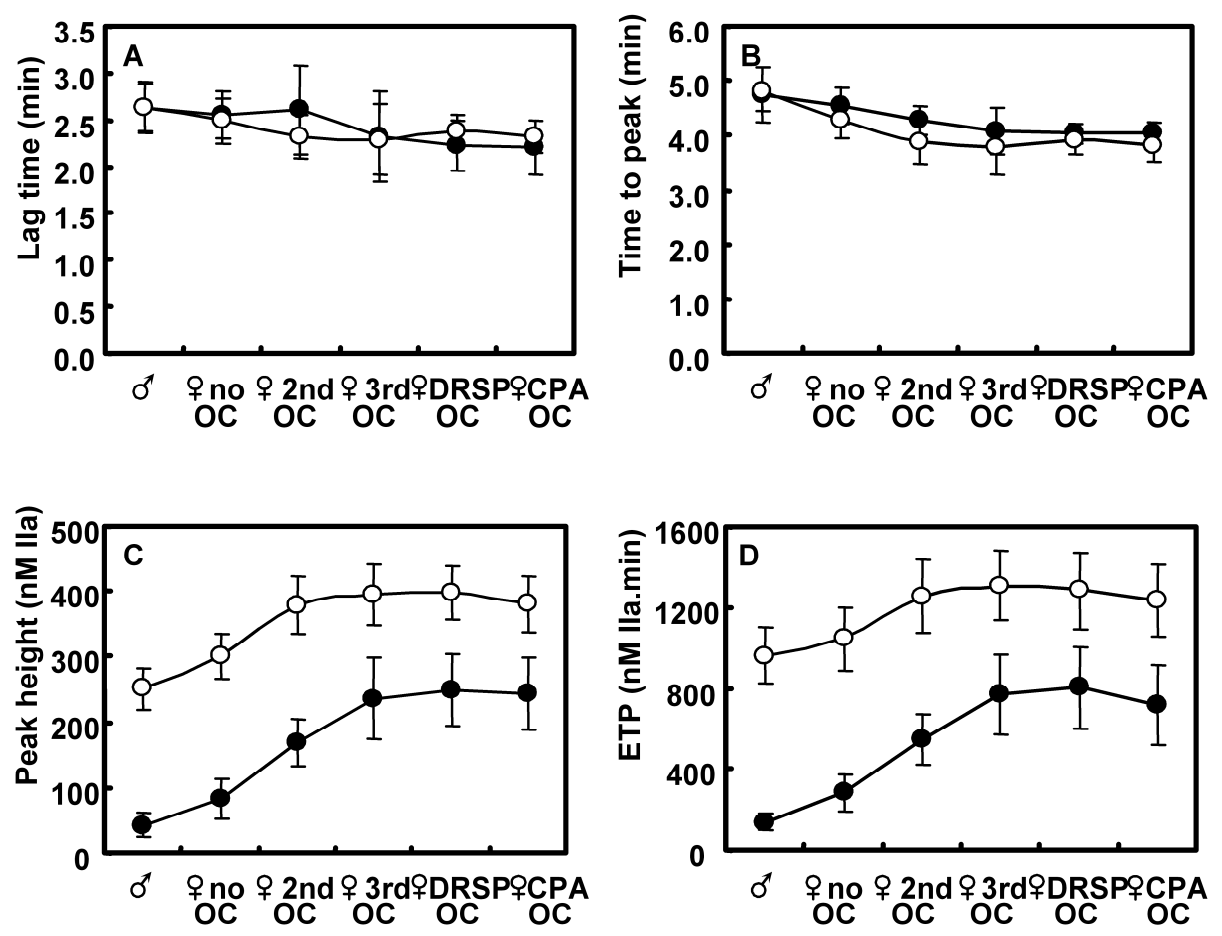

Fig. 2. Effect of Sex and OC Use on the Parameters Obtained from Thrombin Generation Curves The lag time (A), time to peak (B), peak height (C) and ETP (D) were obtained from thrombin generation curves determined in the absence $(0)$ and in the presence of APC $(\bullet)$ in plasma from men $(n=8)$ or women not using OC $(n=27)$, using second generation OC $(n=82)$, third generation OC $(n=64)$, drospirenone-(DRSP, $n=19)$ or cyproterone acetate-containing OC (CPA, $n=22)$. All parameters were corrected for day-to-day variations (see Materials and Methods). Each point represents mean value of the group with error bars corresponding to standard deviation.

Table 2 Change of the APCSr $r_{E T P}, E T P_{-A P C}$, and ETP ${ }_{+A P C}$ in Women upon Switching to another OC Formulation

\begin{tabular}{ccccc}
\hline $\begin{array}{c}\text { Phase 2 minus } \\
\text { Phase 1 }\end{array}$ & $\begin{array}{c}\text { 2nd } \rightarrow \text { DRSP OC } \\
\mathrm{n}=12\end{array}$ & $\begin{array}{c}\text { 3rd } \rightarrow \text { DRSP OC } \\
\mathrm{n}=10\end{array}$ & $\begin{array}{c}\text { DRSP OC } \rightarrow 2 \mathrm{nd} \\
\mathrm{n}=4\end{array}$ & $\begin{array}{c}\text { CPA } \rightarrow 2 \mathrm{nd} \\
\mathrm{n}=5\end{array}$ \\
\hline$\Delta \mathrm{ETP}_{-\mathrm{APC}}$ & 56 & 12 & -30 & -50 \\
& $(-21$ to 133$)$ & $(-35$ to 59$)$ & $(-197$ to 137$)$ & $(-280$ to 181$)$ \\
$\Delta$ ETP $_{+\mathrm{APC}}$ & 206 & 48 & -117 & -224 \\
& $(135$ to 278$)$ & $(-43$ to 138$)$ & $(-391$ to 157$)$ & $(-341$ to -106$)$ \\
$\Delta$ APCsr $_{\mathrm{ETP}}$ & 1.32 & 0.33 & -0.77 & -1.53 \\
& $(0.91$ to 1.74$)$ & $(-0.30$ to 0.95$)$ & $(-2.58$ to 1.04$)$ & $(-2.05$ to -1.0$)$ \\
\hline
\end{tabular}

2nd: second generation oral contraceptive (OC); 3rd: third generation OC; DRSP OC: drospirenone-containing OC; CPA: cyproterone acetate-containing OC. Values are given as mean in change with $95 \% \mathrm{CI}$ in parenthesis. $\triangle \mathrm{ETP}_{-\mathrm{APC}}$ and $\Delta \mathrm{ETP}_{+\mathrm{APC}}$ are expressed as $\mathrm{nM}$ IIa.min. 


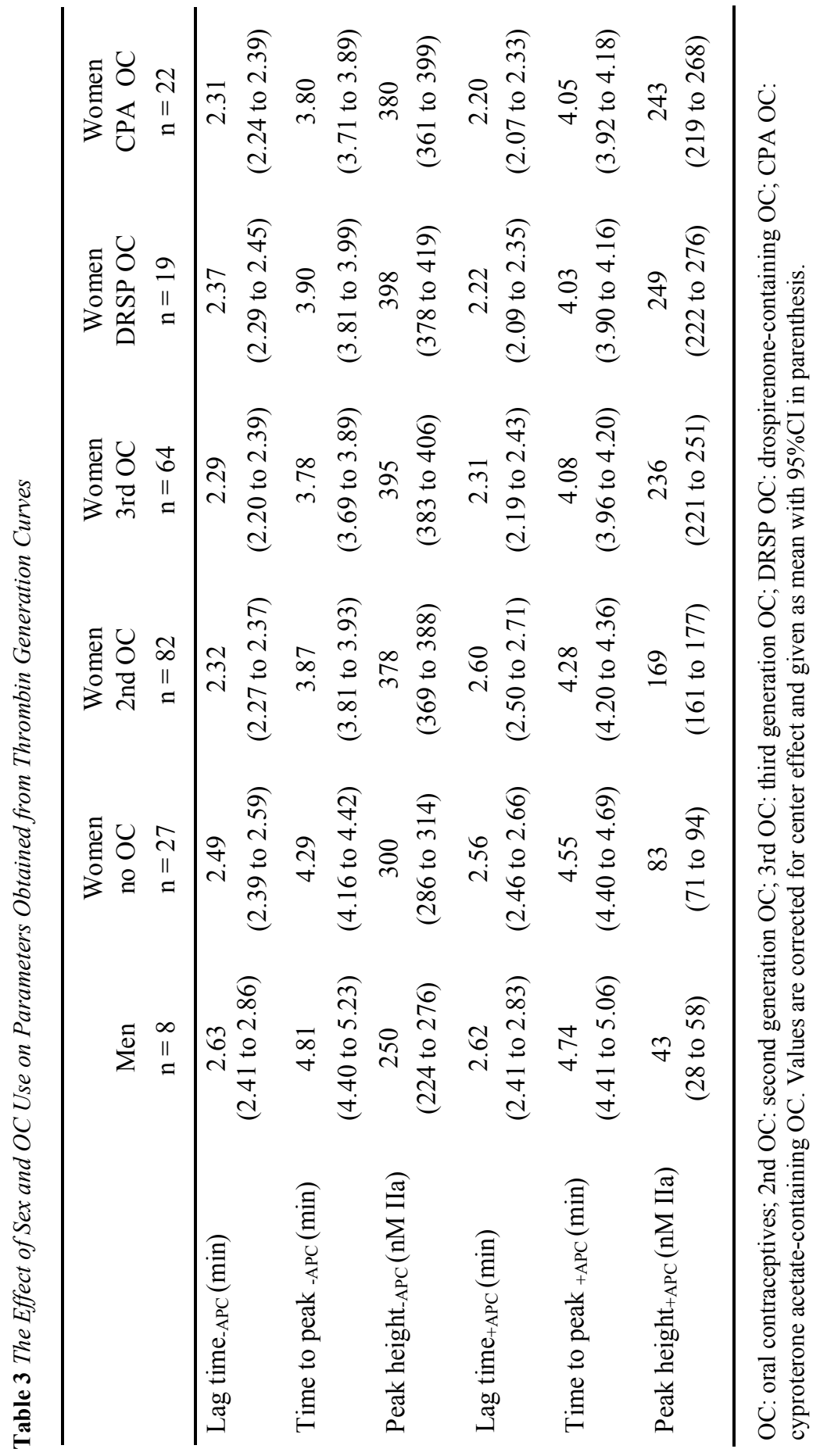


women not using $\mathrm{OC}$ than in $\mathrm{OC}$ using women, but there were no clear differences between users of different OC preparations. In the presence of APC the peak height was lower in men and in women not using OC than in OC users. Like the $\mathrm{ETP}_{+\mathrm{APC}}$, the peak height ${ }_{\mathrm{APC}}$ was much higher in the plasma samples of women using third generation OC (236 nM thrombin) than in women using second generation OC (169 nM thrombin) and not using OC ( $83 \mathrm{nM}$ thrombin). None of the thrombin generation parameters differed between users of third generation and DRSP- or CPA-containing OC preparations.

\section{Determinants of the $A P C s r_{E T P}, E_{T P}{ }_{+A P C}$ and $E T P_{+A P C}$}

The APCsr is determined by the ability of APC to down-regulate plasma FVa (or $\mathrm{FVa}_{\text {Leiden }}$ ) activity and is influenced by other plasma components that either directly or indirectly modulate the anticoagulant activity of APC. ${ }^{34}$ In the current study plasma levels of prothrombin, antithrombin, protein $\mathrm{S}_{\text {total }}$ and protein $\mathrm{S}_{\text {free }}, \mathrm{TFPI}_{\text {total }}, \mathrm{TFPI}_{\text {free }}$ and $\mathrm{TFPI}_{\text {activity }}$ were determined in the plasma collection of van Vliet et al. ${ }^{25,26}$ For the analysis one blood sample per individual (first donation) was used and $\mathrm{FV}_{\text {Leiden }}(\mathrm{n}=14)$, prothrombin $20210 \mathrm{~A}$ carriers $(\mathrm{n}=5)$ and one woman for whom no AT and prothrombin levels were available were excluded, resulting in a total of 134 plasma samples. Multiple linear regression analysis (Table 4) indicated that major determinants of both the APCsr $\mathrm{ETP}_{\mathrm{EP}}$ and the $\mathrm{ETP}_{+\mathrm{APC}}$ were protein $\mathrm{S}_{\text {free }}$ and prothrombin followed by TFPI $_{\text {free }}$. In contrast, the major determinants of the ETP-APC were prothrombin and antithrombin followed by protein $\mathrm{S}_{\text {free }}$ whereas $\mathrm{TFPI}_{\text {free }}$ was not a determinant of the ETP-APC (Table 4). Inclusion of a dummy variable depicting OC use as an independent variable did not substantially change the results.

\section{Discussion}

We demonstrated that the APCsr $\mathrm{ETP}_{\mathrm{ET}}$ obtained via CAT correlates very well with the $\mathrm{APCsr}_{\text {o2-M-IIa }}$ determined with the original clinically validated ${ }^{22}$ thrombin generation-based APC resistance assay. The slope of the regression line was 1.34 which indicates that $\mathrm{APCsr}_{\mathrm{ETP}}$ are about $30 \%$ higher than $\mathrm{APCsr}_{\text {o2-M-IIa }}$, a phenomenon that might be caused by an effect of fibrinogen or fibrin (the APCsr $r_{\text {22-M-IIa }}$ is determined in defibrinated plasma) on thrombin generation or on the activity of APC. In line with the good correlation between the $\mathrm{APCsr}_{\alpha 2-\mathrm{M}-\mathrm{II}}$ and the $\mathrm{APCsr}_{\mathrm{ETP}}$, we observed that, like the $\mathrm{APCsr}_{\text {a2-M-IIa }},{ }^{16}$ the $\mathrm{APCsr}_{\mathrm{ETP}}$ gradually increases in the order men $<$ women not using $\mathrm{OC}<$ women using second $<$ women using third generation OC. 


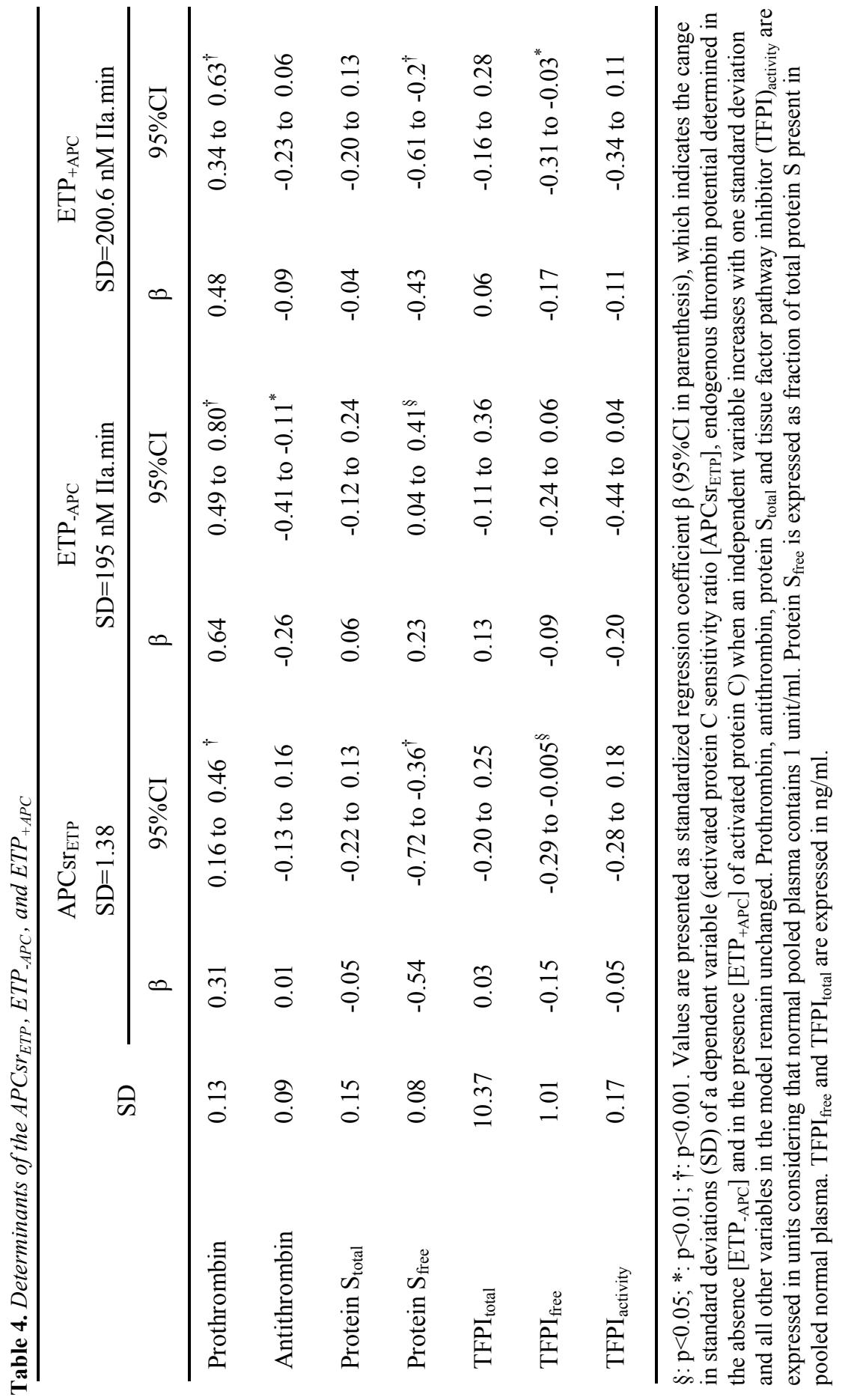


One of the disadvantages of the original end-point APC resistance test was that final amidolytic levels of $\alpha_{2} \mathrm{M}$-IIa which are used to calculate the APCsr do not offer information about the time course of thrombin generation and about the actual values of the ETP in the absence and presence of APC. This disadvantage does not apply to the semi-automated thrombin generation measurement (CAT) in which the presence of a low-affinity fluorogenic substrate for thrombin in non-defibrinated clotting plasma allows continuous monitoring of thrombin generation and calculation of the parameters that describe the thrombin generation curve, i.e. the real ETP values, lag time, time to peak and peak height of thrombin generation.

In agreement with literature, we observed that $\mathrm{OC}$ use results in an increased ETP in the absence of APC. ${ }^{5}$ However, there were no significant

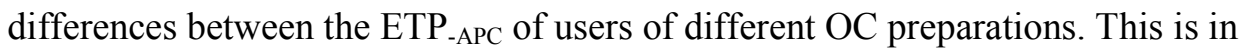
contrast to an earlier published experiment in which the $\mathrm{ETP}_{-\mathrm{APC}}$ in a defibrinated pooled plasma from women using third generation OC was reported to be higher than the $\mathrm{ETP}_{-\mathrm{APC}}$ determined in a plasma pool of second generation OC users. ${ }^{16}$ In this earlier experiment the absolute decrease of the ETP resulting from the addition of APC was approximately the same in both plasma pools. Based on this observation Gris et al. ${ }^{35,36}$ argued that the net anticoagulant effect of APC in plasma of second and third generation OC users was the same and that the differences between the APCsr of second and third generation OC users resulted from the mathematical division of two numbers and not from different sensitivities of plasma for APC. The data presented here indicate, however, that this earlier observation in defibrinated pooled plasma must have been a chance finding because in the current population study the ETP $_{\text {-APC }}$ did not differ between women using second or third generation OC. Similar ETP $_{\text {-APC }}$ values can be explained by the fact that second and third generation OC hardly differ in their effect on prothrombin and antithrombin levels, ${ }^{37,38}$ the main determinants of the ETP-APC .

The different APCsr of third and second generation OC users is completely attributable to differences in the $\mathrm{ETP}_{+\mathrm{APC}}$, which was higher in third generation $\mathrm{OC}$ users than in second generation $\mathrm{OC}$ users and in non-OC users. This observation is further supported by the excellent correlation between the $\mathrm{APCsr}_{\mathrm{ETP}}$ and the $\mathrm{ETP}_{+\mathrm{APC}}$ and by the results of the multiple regression analysis, which yielded plasma levels of protein $\mathrm{S}_{\text {free }}, \mathrm{TFPI}_{\text {free }}$ and prothrombin as the major determinants of both the APCsr and the $\mathrm{ETP}_{+\mathrm{APC}}$. These data are in good agreement with earlier reports in which determinants of thrombin generationbased APC-sr obtained with the end-point method were established. ${ }^{17,34}$ 
The perfect correlation between the $\mathrm{APCsr}_{\mathrm{ETP}}$ and the $\mathrm{ETP}_{+\mathrm{APC}}$ and their common determinants indicate that measurement of the $\mathrm{ETP}_{+\mathrm{APC}}$ may suffice to determine an individual's APC resistance. However, the ETP-APC and other parameters of thrombin generation curves provide additional information on the state of the coagulation system, and enables differentiation between different causes of APC resistance such as $\mathrm{FV}_{\text {Leiden }}$ (unchanged $\mathrm{ETP}_{\text {-APC }}$, shortening of lag time and time to peak in the presence of APC) or the prothrombin mutation (increased $\mathrm{ETP}_{-\mathrm{APC}}$, longer lag time and time to peak). ${ }^{39}$

In our study we observed procoagulant changes in thrombin generation both in the absence and in the presence of APC in plasma of OC users as compared to men and to women, who did not use OC. Compared to non-OC users, it was demonstrated that, besides an increase in the ETP, OC users had shorter lag time and time to peak, higher peak height both in the presence and in the absence of APC. However, none of the thrombin generation parameters, measured in the absence of APC differed between users of different OC. In contrast, thrombin generation in the presence of APC had shorter lag time and time to peak, higher peak height and the ETP in plasma of users of gestodene-, desogestrel-, drospirenone- and cyproterone acetate-containing OC, as compared to users of levonorgestrel-containing OC. Our results indicate that although OC use causes overall procoagulant changes, differential effects of OC on the protein $\mathrm{C}$ system are probably the main determinant for the differences in the risk of venous thrombosis between second and third generation OC.

\section{Acknowledgements}

We thank Rosemiek Cupers for technical assistance with the determination of free protein $\mathrm{S}$ antigen.

\section{References}

1. Rosendaal FR, Helmerhorst FM, Vandenbroucke JP. Female hormones and thrombosis. Arterioscler Thromb Vasc Biol 2002; 22: 201-10

2. Kemmeren JM, Algra A, Grobbee DE. Third generation oral contraceptives and risk of venous thrombosis: meta-analysis. Bmj 2001; 323: 131-4

3. Dargaud Y, Trzeciak MC, Bordet JC, et al. Use of calibrated automated thrombinography +/thrombomodulin to recognise the prothrombotic phenotype. Thromb Haemost 2006; 96: 5627

4. Hemker HC, Al Dieri R, De Smedt E, et al. Thrombin generation, a function test of the haemostatic-thrombotic system. Thromb Haemost 2006; 96: 553-61

5. Rotteveel RC, Roozendaal KJ, Eijsman L, et al. The influence of oral contraceptives on the time-integral of thrombin generation (thrombin potential). Thromb Haemost 1993; 70: 95962 
6. Nicolaes GA, Thomassen MC, Tans G, et al. Effect of activated protein $\mathrm{C}$ on thrombin generation and on the thrombin potential in plasma of normal and APC-resistant individuals. Blood Coagul Fibrinolysis 1997; 8: 28-38

7. Curvers J, Thomassen MC, Nicolaes GA, et al. Acquired APC resistance and oral contraceptives: differences between two functional tests. Br J Haematol 1999; 105: 88-94

8. Rosing J, Middeldorp S, Curvers J, et al. Low-dose oral contraceptives and acquired resistance to activated protein C: a randomised cross-over study. Lancet 1999; 354: 2036-40

9. Dahlback B, Carlsson M, Svensson PJ. Familial thrombophilia due to a previously unrecognized mechanism characterized by poor anticoagulant response to activated protein C: prediction of a cofactor to activated protein C. Proc Natl Acad Sci U S A 1993; 90: 10048

10. Bertina RM, Koeleman BP, Koster $\mathrm{T}$, et al. Mutation in blood coagulation factor $\mathrm{V}$ associated with resistance to activated protein C. Nature 1994; 369: 64-7

11. Tripodi A, Chantarangkul V, Mannucci PM. Hyperprothrombinemia may result in scquired activated protein C reistance. Blood 2000; 96: 3295-6

12. Laffan MA, Manning R. The influence of factor VIII on measurement of activated protein $\mathrm{C}$ resistance. Blood Coagul Fibrinolysis 1996; 7: 761-5

13. Curvers J, Thomassen MC, Rimmer J, et al. Effects of hereditary and acquired risk factors of venous thrombosis on a thrombin generation-based APC resistance test. Thromb Haemost 2002; 88: 5-11

14. Shu H, Wramsby $\mathrm{M}$, Bokarewa $\mathrm{M}$, et al. Decrease in protein $\mathrm{C}$ inhibitor activity and acquired APC resistance during normal pregnancy. J Thromb Thrombolysis 2000; 9: 277-81

15. Olivieri $\mathrm{O}$, Friso $\mathrm{S}$, Manzato $\mathrm{F}$, et al. Resistance to activated protein $\mathrm{C}$ in healthy women taking oral contraceptives. Br J Haematol 1995; 91: 465-70

16. Rosing J, Tans G, Nicolaes GA, et al. Oral contraceptives and venous thrombosis: different sensitivities to activated protein $\mathrm{C}$ in women using second- and third-generation oral contraceptives. Br J Haematol 1997; 97: 233-8

17. Hoibraaten E, Mowinckel MC, de Ronde H, et al. Hormone replacement therapy and acquired resistance to activated protein $\mathrm{C}$ : results of a randomized, double-blind, placebocontrolled trial. Br J Haematol 2001; 115: 415-20

18. Ehrenforth S, Radtke KP, Scharrer I. Acquired activated protein C-resistance in patients with lupus anticoagulants. Thromb Haemost 1995; 74: 797-8

19. Koster T, Rosendaal FR, de Ronde H, et al. Venous thrombosis due to poor anticoagulant response to activated protein C: Leiden Thrombophilia Study. Lancet 1993; 342: 1503-6

20. Svensson PJ, Dahlback B. Resistance to activated protein $\mathrm{C}$ as a basis for venous thrombosis. N Engl J Med 1994; 330: 517-22

21. de Visser MC, Rosendaal FR, Bertina RM. A reduced sensitivity for activated protein C in the absence of factor V Leiden increases the risk of venous thrombosis. Blood 1999; 93: 1271-6

22. Tans G, van Hylckama Vlieg A, Thomassen MC, et al. Activated protein C resistance determined with a thrombin generation-based test predicts for venous thrombosis in men and women. Br J Haematol 2003; 122: 465-70

23. Hemker HC, Giesen P, Al Dieri R, et al. Calibrated automated thrombin generation measurement in clotting plasma. Pathophysiol Haemost Thromb 2003; 33: 4-15

24. Koenen RR, Christella M, Thomassen LG, et al. Effect of oral contraceptives on the anticoagulant activity of protein $\mathrm{S}$ in plasma. Thromb Haemost 2005; 93: 853-9

25. van Vliet HA, Frolich M, Christella M, et al. Association between sex hormone-binding globulin levels and activated protein $\mathrm{C}$ resistance in explaining the risk of thrombosis in users of oral contraceptives containing different progestogens. Hum Reprod 2005; 20: 563-8

26. van Vliet HA, Winkel TA, Noort I, et al. Prothrombotic changes in users of combined oral contraceptives containing drospirenone and cyproterone acetate. J Thromb Haemost 2004; 2: $2060-2$ 
27. Bertina RM, van der Marel-van Nieuwkoop W, Loeliger EA. Spectrophotometric assays of prothrombin in plasma of patients using oral anticoagulants. Thromb Haemost 1979; 42: 1296-305

28. Dahm A, Van Hylckama Vlieg A, Bendz B, et al. Low levels of tissue factor pathway inhibitor (TFPI) increase the risk of venous thrombosis. Blood 2003; 101: 4387-92

29. Koster T, Rosendaal FR, Briet E, et al. Protein C deficiency in a controlled series of unselected outpatients: an infrequent but clear risk factor for venous thrombosis (Leiden Thrombophilia Study). Blood 1995; 85: 2756-61

30. Giri TK, Hillarp A, Hardig Y, et al. A new direct, fast and quantitative enzyme-linked ligandsorbent assay for measurement of free protein S antigen. Thromb Haemost 1998; 79: 767-72

31. Brugge JM, Tans G, Rosing J, et al. Protein S levels modulate the activated protein $\mathrm{C}$ resistance phenotype induced by elevated prothrombin levels. Thromb Haemost 2006; 95: 236-42

32. Kemmeren JM, Algra A, Meijers JC, et al. Effect of second- and third-generation oral contraceptives on the protein $\mathrm{C}$ system in the absence or presence of the factor VLeiden mutation: a randomized trial. Blood 2004; 103: 927-33

33. Newton JR. Classification and comparison of oral contraceptives containing new generation progestogens. Hum Reprod Update 1995; 1: 231-63

34. de Visser MC, van Hylckama Vlieg A, Tans G, et al. Determinants of the APTT- and ETPbased APC sensitivity tests. J Thromb Haemost 2005; 3: 1488-94

35. Gris JC, Jamin C, Benifla JL, et al. APC resistance and third-generation oral contraceptives: Acquired resistance to activated protein $\mathrm{C}$, oral contraceptives and the risk of thromboembolic disease. Hum Reprod 2001; 16: 3-8

36. Gris JC, Nouvellon-Cochery E, Mares P. Increased resistance to activated protein C in women taking third-generation oral contraceptives? Blood 2004; 104: 1907; author reply 8-9

37. Tans G, Curvers J, Middeldorp S, et al. A randomized cross-over study on the effects of levonorgestrel- and desogestrel-containing oral contraceptives on the anticoagulant pathways. Thromb Haemost 2000; 84: 15-21

38. Middeldorp S, Meijers JC, van den Ende AE, et al. Effects on coagulation of levonorgestreland desogestrel-containing low dose oral contraceptives: a cross-over study. Thromb Haemost 2000; 84: 4-8

39. Hezard N, Bouaziz-Borgi L, Remy MG, et al. Utility of thrombin-generation assay in the screening of factor V G1691A (Leiden) and prothrombin G20210A mutations and protein S deficiency. Clin Chem 2006; 52: 665-70 



\section{Chapter 4}

\section{Effect of Non-oral Hormonal Contraceptives on the Haemostatic System}

Based on:

Effects of Oral and Transdermal Hormonal Contraception on Vascular Risk Markers. J.V. Johnson, J. Lowell, G.J. Badger, J. Rosing, S.N. Tchaikovski, and M. Cushman. Obstetrics \& Gynecology, 2008; 111(2 Pt 1):278-84

Effects of the Contraceptive Patch, the Vaginal Ring and an Oral Contraceptive on APC Resistance and SHBG: A Cross-over Study. K. Fleischer, H.A. van Vliet, F.R. Rosendaal, J. Rosing, S.N. Tchaikovski, F.M. Helmerhorst. Thrombosis Research, 2009; 123(3):429-35

The Effect of the Levonorgestrel-releasing Intrauterine System on the Resistance to Activated Protein C. H.A.A.M. van Vliet, S.N. Tchaikovski, F.R. Rosendaal, J. Rosing, F.M. Helmerhorst. Thrombosis and Haemostasis, 2009; 101(4):691-5 


\section{Summary}

INTRODUCTION: The use of combined oral contraceptives (OC) is associated with an increased risk of venous thrombosis. To improve safety of hormonal contraception, formulations with alternative routes of administration have been developed.

OBJECTIVE: We conducted three clinical studies to compare the effects of oral and non-oral contraceptives on risk markers of venous and arterial thrombosis.

METHODS: In study 1 we investigated the effect of oral and transdermal contraceptives containing the same hormones on the plasma levels of D-dimer, von Willebrand factor, factor VIII, total and free protein S, antithrombin, fibrinogen, C-reactive protein, and the APC sensitivity ratio (APCsr) determined with two thrombin generation-based assays: the $\alpha_{2}$ macroglobulinthrombin end point method ( $\left.\mathrm{APCsr}_{\alpha 2 \mathrm{M}-\mathrm{II}}\right)$ and calibrated automated thrombography (APCsr $\mathrm{CAT}_{\mathrm{C}}$ ). In study 2 we compared the effect of transdermal and vaginal contraceptives containing a third-generation progestin and of $\mathrm{OC}$ containing a second-generation progestin on the $\mathrm{APCsr}_{\alpha 2 \mathrm{M}-\mathrm{II}}$ and on plasma levels of sex hormone-binding globulin (SHBG). In study 3 we compared the effects of a levonorgestrel-releasing and of a copper-containing intrauterine device on the APCsr $\mathrm{CAT}_{\mathrm{CAT}}$.

RESULTS: In study 1 both transdermal and oral contraceptives decreased free $(19 \%, 11 \%)$ and total $(19 \%, 13 \%)$ protein $\mathrm{S}$ and antithrombin $(13 \%, 10 \%)$; and elevated fibrinogen $(8 \%, 10 \%)$, C-reactive protein $(220 \%, 292 \%), \mathrm{APCsr}_{\alpha 2 \mathrm{M}-\mathrm{II}}$ $(81 \%, 61 \%)$, and $\mathrm{APCsr}_{\mathrm{CAT}}(102 \%, 68 \%)$. Transdermal contraceptives had a greater effect than $\mathrm{OC}$ on free protein $\mathrm{S}(\mathrm{P}=0.07), \mathrm{APCsr}_{\mathrm{\alpha} 2 \mathrm{M}-\mathrm{II}}(\mathrm{P}=0.06)$, and $\mathrm{APCsr}_{\mathrm{CAT}}(\mathrm{P}=0.03)$.

Study 2 showed that transdermal, vaginal and oral contraceptives increase the $\mathrm{APCsr}_{\alpha 2 \mathrm{M}-\mathrm{II}} 87.5 \%, 46.3 \%$ and $14 \%$, respectively and the SHBG plasma levels $384 \%, 287 \%$ and $57 \%$, respectively.

In study 3, the APCsr decreased in three months after insertion of the levonorgestrel-releasing intrauterine device by $10 \%$ in women who did not use hormonal contraception before the study and by $31 \%$ in those who switched from OC. With the copper-containing intrauterine device a decrease in the APCsr was only observed when women switched from OC (36\%).

CONCLUSIONS: Oral and transdermal contraception containing the same hormones had similar adverse effects on thrombotic risk markers. This suggests that women using either contraceptive are exposed to a similar thrombosis risk. The activity of the protein $\mathrm{C}$ system in plasma was impaired more by the 
transdermal and vaginal contraceptives than by an OC containing a secondgeneration progestin. The levonorgestrel-releasing intrauterine system decreases resistance to APC, which suggests that it does not exert a prothrombotic effect.

\section{Introduction}

The use of oral contraceptives (OC) increases the risk of venous thrombosis (VT) two- to three-fold. ${ }^{1}$ Although the absolute risk is low (2-3 per 10,000 women annually), it is important for women to understand the potential risk associated with contraceptives because VT can be fatal. There is also an increased risk of atherosclerotic events, with a recent meta-analysis reporting that use of low-dose OC is associated with a two-fold increased risk of myocardial infarction and stroke. ${ }^{2}$

Unlike OC, there is limited data on the risk of adverse vascular outcomes of non-oral hormonal contraception. Two epidemiologic studies have examined the effect of transdermal contraceptives on venous and arterial thrombosis with varied results. ${ }^{3,4}$ The United States Prescribing Information was recently updated to state that women using transdermal hormonal contraceptives are exposed to higher steady state ethinylestradiol (EE) concentrations compared to an OC containing the same estrogen and progestin. However, it remains unclear whether non-oral contraceptives, such as the transdermal patch and the vaginal ring have the same risk of thrombosis as OC.

Furthermore, little is known about the effects of non-oral progestin-only contraceptives, such as the levonorgestrel-releasing intrauterine device, on the coagulation system. Case-control studies on the risk of thrombosis in women using progestin-only pills or injectables suggest that there is little or no increased risk of VT. However, these studies were limited by the small number of participating women using these types of contraceptives. ${ }^{5-7}$ Since the plasma levels of progestin during use of a progestin-releasing intrauterine device are lower than during use of progestin-only pills, ${ }^{8,9}$ an even smaller effect of the hormone-releasing intrauterine device on the thrombotic risk can be expected. Yet, no studies have been published on the thrombotic risk of the levonorgestrel-releasing intrauterine system.

Several coagulation factor abnormalities are associated with an increased risk of VT. Changes in coagulation, induced by OC that may explain the increased thrombosis risk include lowering of protein $\mathrm{S}$ and antithrombin and an increase in D-dimer. ${ }^{10-14}$ Hormonal medications also increase C-reactive protein, a biomarker for an increased risk of arterial thrombosis. ${ }^{15}$ The net prothrombotic effect of hormonal contraceptives can be measured globally with 
an activated protein C (APC) resistance test that quantifies the effect of APC on thrombin generation. ${ }^{16}$ This test predicts the risk of VT and discriminates well between OC with a high and with a low thrombotic risk. ${ }^{16-19}$ Additionally, several studies have shown that sex hormone-binding globulin (SHBG) levels follow the same pattern as APC resistance during OC use ${ }^{20,21}$ and hence, can be regarded as a surrogate marker for thrombotic risk. ${ }^{20-22}$

Comparing the effect of non-oral contraceptives with that of $\mathrm{OC}$ on coagulation parameters known to contribute to thrombotic risk offers insight in and support to the preliminary epidemiologic studies of these medications. In this chapter we summarize:

1) a randomized investigator-blind cross-over study in which we compared the effect of oral and transdermal contraceptives (Ortho Cyclen ${ }^{\circledR}$ and Ortho Evra $\left.{ }^{\circledR}\right)$ containing the same hormonal agents on biomarkers that are associated with an increased risk of venous and arterial thrombosis; ${ }^{23}$

2) a randomized cross-over study in which we investigated the effects of the transdermal (Evra $\AA$ ) and the vaginal (NuvaRing ${ }^{\circledR}$ ) contraceptive, both containing a third generation progestin, with an OC, containing a second generation progestin (Microgynon $30 \AA$ ) on APC resistance and on plasma SHBG levels; ${ }^{24}$

3) a nonrandomized open-label study in which we compared the effects of the levonorgestrel-intrauterine system (Mirena ${ }^{\circledR}$ ) and a coppercontaining intrauterine device on APC resistance. ${ }^{25}$

\section{Participants \& Methods}

\section{Study Design and Participants}

Study 1. 24 nonpregnant women, 18-35 years of age, who had not used hormonal contraception for at least 2 months before the study or who were at least 3 months postpartum and nonlactating, were enrolled between October 2003 and February 2005. Exclusion criteria and sample size calculation are described elsewhere. ${ }^{23}$ Participants were assigned a random identification number that indicated the sequence in which transdermal or oral contraceptives would be given (Fig. 1A). Randomization was performed by a computergenerated list of random numbers, using a block randomization procedure, and this list was maintained by the research coordinator. The daily oral contraceptive or weekly transdermal contraceptive was given with the typical dosing of 3 weeks of active treatment followed by 1 week without hormone use. After the first 2 months of hormonal contraceptive, each participant returned to 
barrier contraceptive for a 2-month washout period, then received 2 months of the alternative hormonal contraceptive (Fig. 1A).

The oral contraceptive contained $35 \mu \mathrm{g} \mathrm{EE}$ and $250 \mu \mathrm{g}$ norgestimate (Ortho Cyclen ${ }^{\circledR}$, Ortho-McNeil Pharmaceutical, Raritan, NJ). The transdermal hormonal contraceptive contained $0.75 \mathrm{mg} \mathrm{EE}$ and $6.0 \mathrm{mg}$ norelgestromin (Ortho Evra ${ }^{\circledR}$, Ortho-McNeil Pharmaceutical). Norelgestromin is the active progestin metabolite of orally administered norgestimate.

Study 2. 13 nonpregnant women 18-45 years of age were recruited between January and December 2005 through advertisements in local newspapers and through posters in general practioners' practices and public and university buildings. Exclusion criteria and sample size calculation are described elsewhere. ${ }^{24}$

The volunteers were required not to use any hormonal contraception for at least two normal menstrual cycles (washout at baseline), and were then randomly assigned to one of two study arms (Fig. 1B). The randomisation was done in blocks of five to ensure evenly distributed groups, even in case of recruitment difficulties. The intention was to include 20 patients overall. Women in the first arm were randomly assigned the transdermal contraceptive patch or monophasic OC for two cycles, followed by a two cycle washout after which contraceptives were switched. Women in the second arm were randomly assigned either the contraceptive vaginal ring or OC for two cycles, followed by a two cycle washout after which contraceptives were switched. The weekly transdermal contraceptive contained $0.6 \mathrm{mg}$ EE and $6.0 \mathrm{mg}$ norelgestromin, and released $20 \mu \mathrm{g}$ EE and $150 \mu \mathrm{g}$ norelgestromin/day (Evra ${ }^{\circledR}$, Janssen-Cilag B.V., Tilburg, The Netherlands). The daily OC contained $30 \mu \mathrm{g}$ EE and $150 \mu \mathrm{g}$ levonorgestrel (Microgynon 30 ${ }^{\circledR}$, Bayer Schering Pharma AG, Berlin, Germany). The contraceptive vaginal ring contained $2.7 \mathrm{mg}$ EE and $11.7 \mathrm{mg}$ etonogestrel and released $15 \mu \mathrm{g}$ EE and $120 \mu \mathrm{g}$ etonogestrel per day (NuvaRing ${ }^{\circledR}$, Organon, Oss, The Netherlands).

Since it was difficult to recruit volunteers, participants who had finished the study on OC were asked to switch arm and finish with patch or vaginal ring for a final two cycles after a second two-cycle washout. Four volunteers consented. These volunteers had blood samples taken in six cycles.

Study 3. All consecutive women scheduled for insertion of coppercontaining $(n=24)$ or levonorgestrel-releasing intrauterine device $(n=67)$ at the gynaecology out-patient department of Leiden University Medical Center between October 2003 and June 2005 were asked to participate in the study. Exclusion criteria are described elsewhere. ${ }^{25}$ The levonorgestrel-releasing 


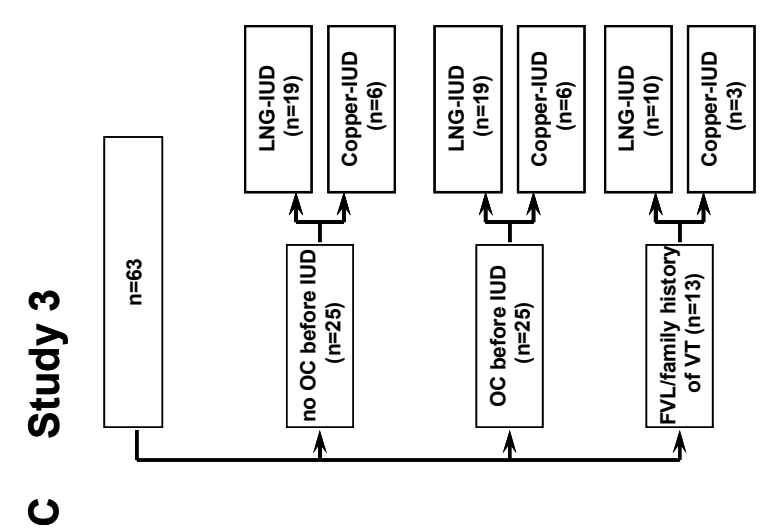

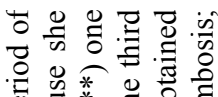
嗮 * 등 is 응

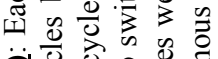
ติ N 氙造造

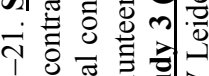

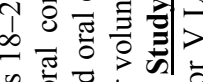

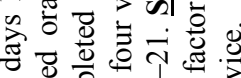
0 唍

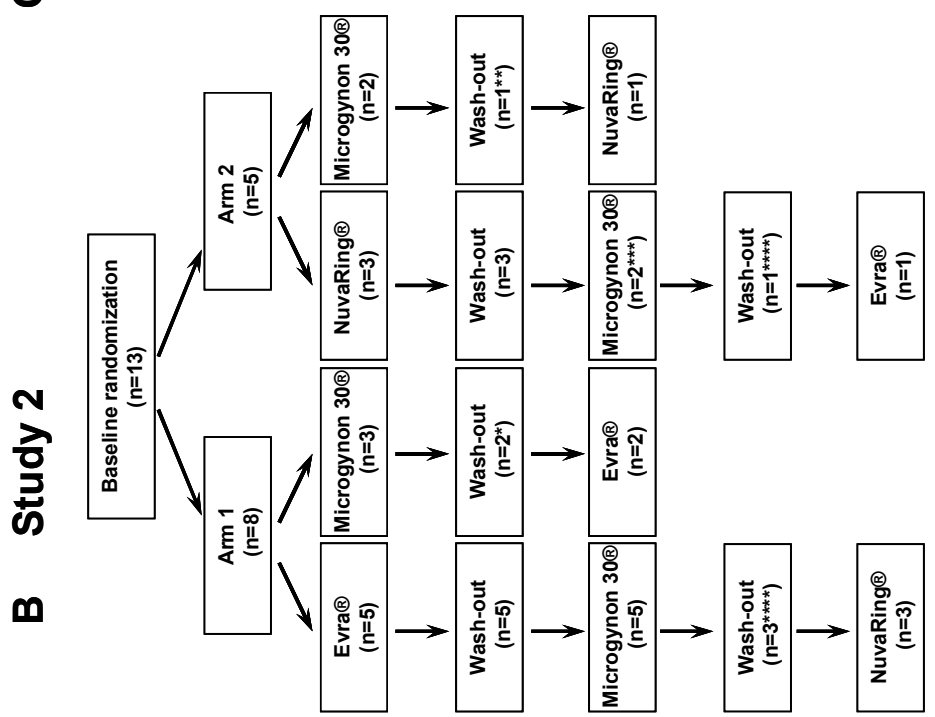

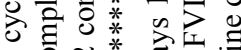
5 엉

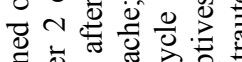

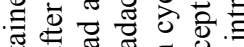

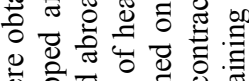
के 균당

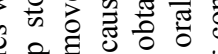

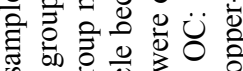
远专

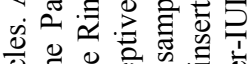
O.

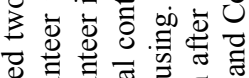

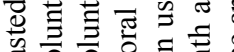

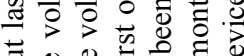
立 o 可

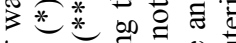

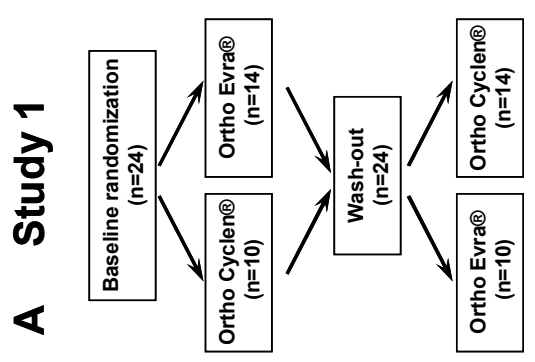
tᄒ 范远

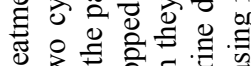

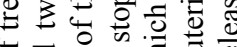
क्ष

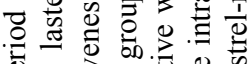

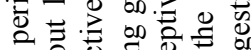

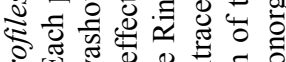

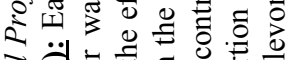

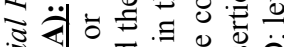

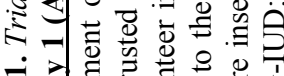

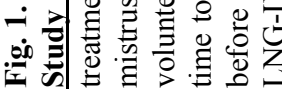


intrauterine device contained $52 \mathrm{mg}$ levonorgestrel and released $20 \mu \mathrm{g}$ levonorgestrel per day ${ }^{9}$ (Mirena ${ }^{\circledR}$, Bayer Schering Pharma Oy, Finland).

The study protocols were approved by the University of Vermont Institutional Review Board, Vermont, USA (study 1) and the Medical Ethics Committee of the Leiden University Medical Center, Leiden, The Netherlands (studies 2 and 3). All participants gave written informed consent.

\section{Collection and Handling of Plasma Samples}

Blood was drawn on menstrual cycle days 18-21 before studies 1 and 2, within 4 days of either the last pill or removal of the last patch or vaginal ring and on cycle days 18-21 in the second month of the washout period. In study 3 blood samples were drawn on menstrual cycle days 18-21 before and three months after insertion of the intrauterine device. Venous blood was collected under standardized conditions and platelet poor plasma was prepared and stored according standard operating procedures of the participating laboratories. ${ }^{23-25}$

\section{Laboratory Methods}

Laboratory assays were performed in batches, with each participant's serial samples analyzed in the same run.

D-dimer, von Willebrand factor, antithrombin, factor VIII, free and total protein S, fibrinogen, C-reactive protein and SHBG were determined as described elsewhere. ${ }^{23,24}$ The activated protein $\mathrm{C}$ sensitivity ratio (APCsr) was measured using two thrombin generation assays. In the first assay (studies 1 and 2 ), coagulation was triggered in defibrinated plasma with tissue factor in the presence and absence of APC, and the amount of thrombin captured in complex with $\alpha_{2}$-macroglobulin over 30 minutes was taken as a measure for the total amount of thrombin generated and used to calculate the APCsr $\left(\mathrm{APCsr}_{02 \mathrm{M}-\mathrm{II} a}\right){ }^{26}$ In studies 1 and 3 , the APCsr $\left(\mathrm{APCsr}_{\mathrm{CAT}}\right)$ was determined by measuring thrombin generation in the presence and absence of APC in full plasma in real time with a fluorogenic thrombin substrate using calibrated automated thrombinography (CAT). ${ }^{27}$

Participants of study 3 were screened for factor $V_{\text {Leiden }}$ by determination of the sensitivity of plasma factor Va for APC as previously described. ${ }^{28}$

\section{Statistical Analysis}

In study 1 repeated measures analysis of variance corresponding to a crossover design incorporating both baseline and washout periods were performed using SAS 8.2 (SAS Institute, Cary, NC) to determine the significance associated with differences between the hormonal contraceptive treatments for each of the 
biomarkers tested and to evaluate potential carry-over effects. Preplanned contrasts were used to test for differences between pretreatment periods for oral and transdermal contraceptives and to test for changes from pretreatment to treatment. Biomarkers that had non-normal distribution based on residual plots (CRP, D-dimer, factor VIII) were log transformed before analysis. Statistical significance was determined based on $\alpha=0.05$.

In study 2, in the unpaired comparison, statistical analysis was limited to subjects, of whom both a washout sample and at least one sample during contraceptive exposure were available. In the crossover analysis we compared OC to transdermal patch or vaginal ring within each individual; statistical analysis was limited to subjects who used at least two contraceptives with preceding washouts. Data are presented as means with $95 \% \mathrm{CI}$.

In study 3, mean APCsr with 95\%CI were calculated for each group at baseline and three months after the insertion of an intrauterine device. Additionally, we calculated mean differences with 95\%CI between APCsr determined in samples, collected before and three months after insertion of an intrauterine device.

\section{Results}

\section{Effects of Oral and Transdermal Hormonal Contraception on Risk Markers of Venous and Arterial Thrombosis}

In study 1, 33 women where screened for participation: two failed screening, three were randomized but dropped out before taking medication, three dropped out after initiation of the study medication, one became pregnant during the washout period. The remaining 24 women completed the trial. Characteristics of the participants have been described previously. ${ }^{23}$ Assays were performed only on plasma of subjects who completed the trial. Table 1 shows the effects of each contraceptive on the studied biomarkers. Fig. 2 demonstrates parameters that showed significant changes from baseline on both contraceptives. Comparison of baseline and washout values did not demonstrate any carry-over effect of the treatments ( $\mathrm{P}>0.10$ for all outcomes). Both hormonal contraceptives showed a significant decrease in total and free protein $\mathrm{S}$ and in antithrombin of $19 \%$ and $13 \%$ (total protein S), $19 \%$ and $11 \%$ (free protein S), and $13 \%$ and $10 \%$ (antithrombin) for transdermal and oral treatment, respectively (Fig. 2A). Significant increases from pretreatment levels were observed for fibrinogen $(8 \%$ and $10 \%)$ and C-reactive protein (220\% and 292\%) for transdermal and oral treatment respectively, Fig. 2B). Both contraceptives 


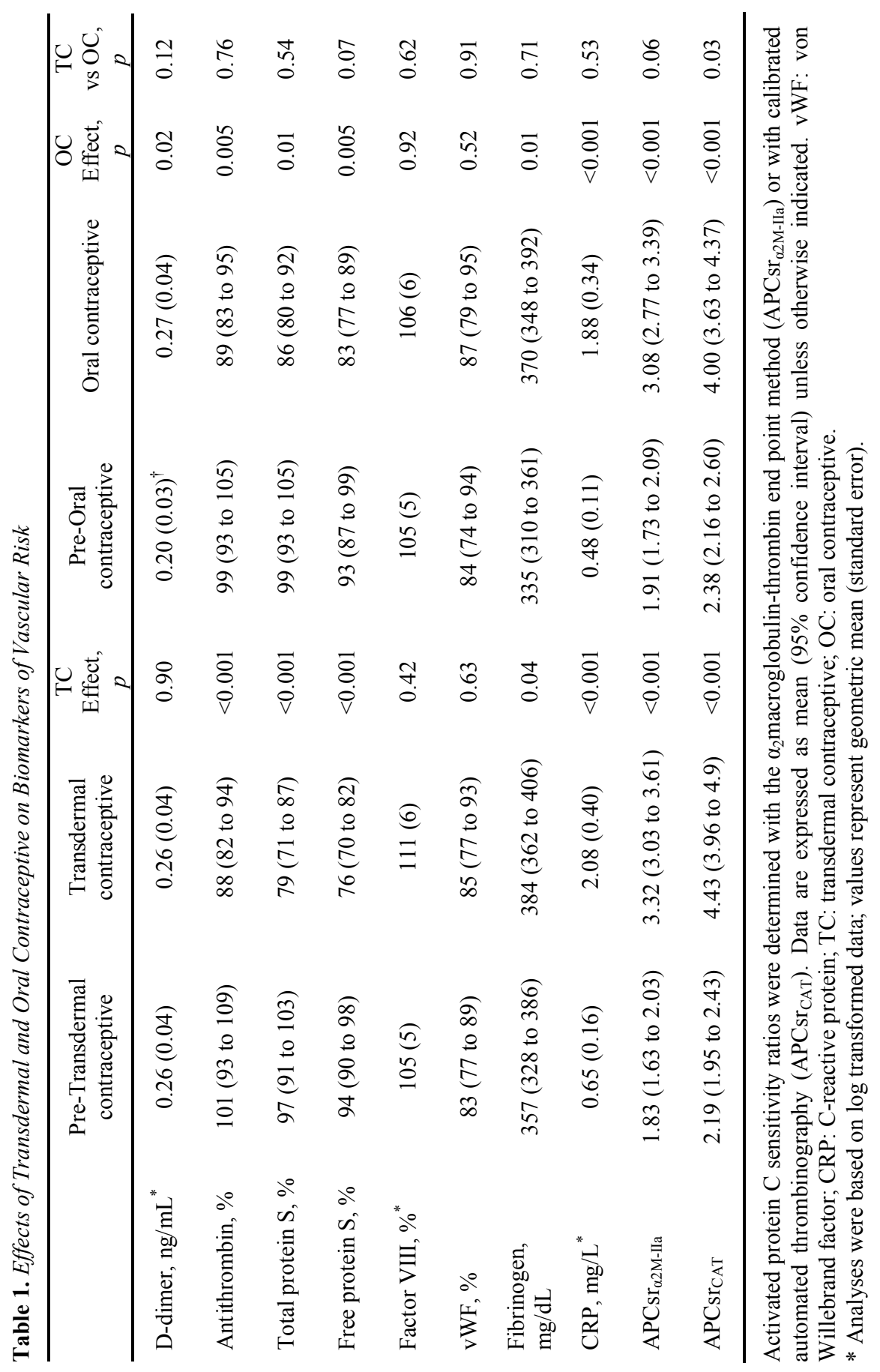


also induced a substantial increase of the APCsr with an increase of $81 \%$ and $61 \%$ of the $\mathrm{APCsr}_{\alpha 2 \mathrm{M}-\mathrm{II}}$ and $102 \%$ and $68 \%$ of the $\mathrm{APCsr}_{\mathrm{CAT}}$ for transdermal and oral treatment, respectively (Fig. 2C). D-dimer significantly increased with the oral but not with the transdermal contraceptive. However, D-dimer was the only biomarker for which pretreatment levels were significantly different $(\mathrm{P}=$ 0.04 ), being $23 \%$ lower before the oral compared with the transdermal contraceptive, whereas D-dimer levels for the active phases of the two contraceptives were similar. There was no effect of either contraceptive on the levels of factor VIII or von Willebrand factor.

When comparing the effects of oral and transdermal treatments a strong trend towards a greater effect of transdermal treatment was observed in free protein $\mathrm{S}(\mathrm{P}=0.07)$ as well as for both $\mathrm{APC}$ resistance assays $\left(\mathrm{APCsr}_{\alpha 2 \mathrm{M}-\mathrm{IIa}}, \mathrm{P}=\right.$ 0.06 and $\left.\mathrm{APCsr}_{\mathrm{CAT}}, \mathrm{P}=0.03\right)$. The other markers did not reveal a difference between the two treatments (Table 1).
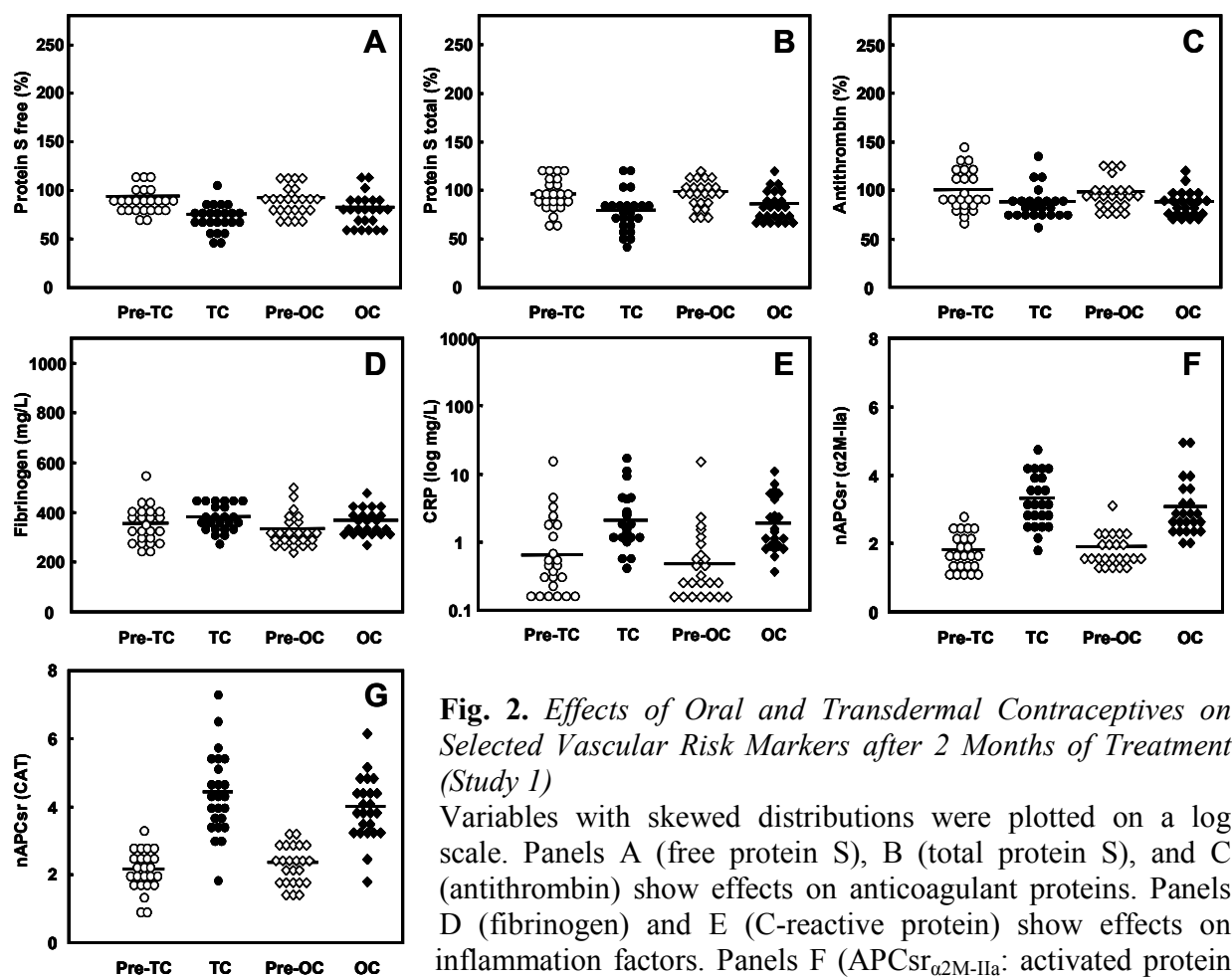

Fig. 2. Effects of Oral and Transdermal Contraceptives on Selected Vascular Risk Markers after 2 Months of Treatment (Study 1)

Variables with skewed distributions were plotted on a log scale. Panels A (free protein S), B (total protein S), and C (antithrombin) show effects on anticoagulant proteins. Panels D (fibrinogen) and E (C-reactive protein) show effects on inflammation factors. Panels F ( APCsr $_{\alpha 2 \mathrm{M}-\mathrm{II}}$ : activated protein $\mathrm{C}$ sensitivity ratio calculated from thrombin captured in complex with $\alpha_{2}$-macroglobulin) and $\mathrm{G}$ (APCsr ${ }_{\mathrm{CAT}}$ : activated protein $\mathrm{C}$ sensitivity ratio determined using calibrated automated thrombinography) show effects on the APCsr determined with two assays. TC: transdermal contraceptive; OC: oral contraceptive; pre-TC: pre-OC, baseline and washout values; $\mathrm{P}<0.05$. 


\section{Effects of Contraceptive Patch, Vaginal Ring or Oral Contraceptive on APC Resistance and SHBG Levels}

From the 13 volunteers enrolled in study 2, three withdrew during the study: one participant of the patch group stopped after two completed OC cycles, one volunteer in the ring group moved abroad after two completed OC cycles, and one woman from the vaginal contraceptive group stopped during the first OC cycle. Characteristics of participants are described elsewhere. ${ }^{24}$ Thus, plasma samples of 12 women who completed OC cycles, 7 women who completed vaginal contraceptive cycles and 8 women who completed transdermal patch cycles were available for analysis

Fig. 3 shows the $\mathrm{APCsr}_{\alpha 2 \mathrm{M}-\mathrm{II}}$ during the different contraceptive treatments and during the preceding baseline or washout period. The APCsr ${ }_{\alpha 2 \mathrm{M}-\mathrm{II} a}$ during the washout periods was similar for all treatment groups (non-paired comparison), with mean 2.03 and $95 \% \mathrm{CI} 1.56$ to 2.49 . The mean increase in the APCsr ${ }_{\alpha 2 \mathrm{M}-I \mathrm{Ia}}$ was $1.62(95 \% \mathrm{CI} 0.85$ to 2.37$)$ in the patch group, $1.05(95 \% \mathrm{CI}$ 0.44 to 1.65$)$ in the vaginal ring group and $0.28(95 \% \mathrm{CI}-0.05$ to 0.62$)$ in the $\mathrm{OC}$ group, or $87.5 \%, 46.3 \%$ and $14 \%$ correspondingly (all subjects, of whom at least one washout sample and one sample during contraceptive exposure were available were included in this analysis).

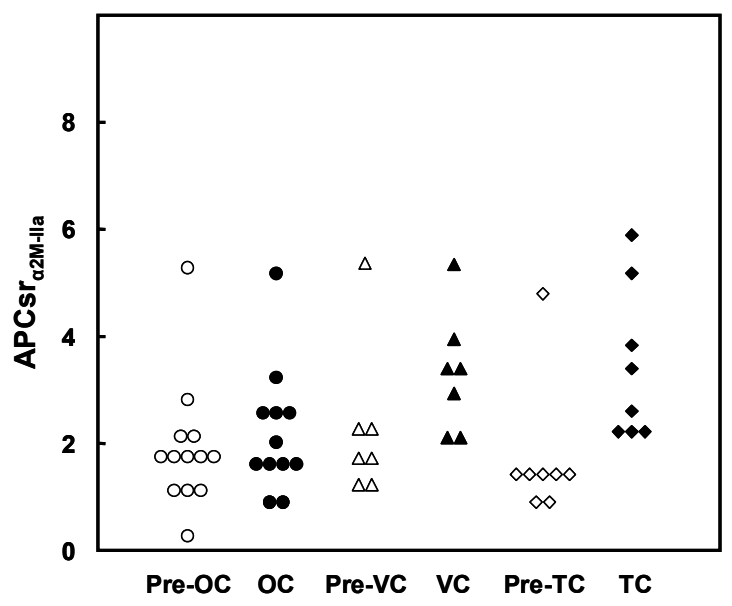

Fig. 3. Effects of Different Contraceptive Treatments on APCsr Values (Study 2) APC sensitivity ratios (APCsr) were elevated during all three contraceptive treatments, but the increase was most pronounced during the use of patch and ring. The upper outliers originate from the same volunteer. TC: transdermal contraceptive; OC: oral contraceptive; VC: vaginal contraceptive, pre-TC, pre-OC, pre- $\mathrm{VC}$ baseline and washout values.

SHBG levels showed a similar pattern with no differences during pretreatment (washout) but with a mean increase in the SHBG plasma levels of $384 \%$ in the patch group, $287 \%$ in the ring group and $57 \%$ in the OC group (data not shown). Fig. 4 shows a clear correlation between the individual changes of the $\mathrm{APCsr}_{\alpha 2 \mathrm{M}-\mathrm{II} a}$ and the changes in the SHBG levels during treatment with the three contraceptive formulations. An increase of $100 \mathrm{nmol} / \mathrm{l}$ 
of the SHBG level was associated with an increase of the $\mathrm{APCsr}_{\alpha 2 \mathrm{M}-\mathrm{IIa}}$ by 0.66 ( $95 \%$ CI 0.3 to 0.7$)$. The Pearson correlation coefficient was $0.76(\mathrm{p}<0.0001)$.

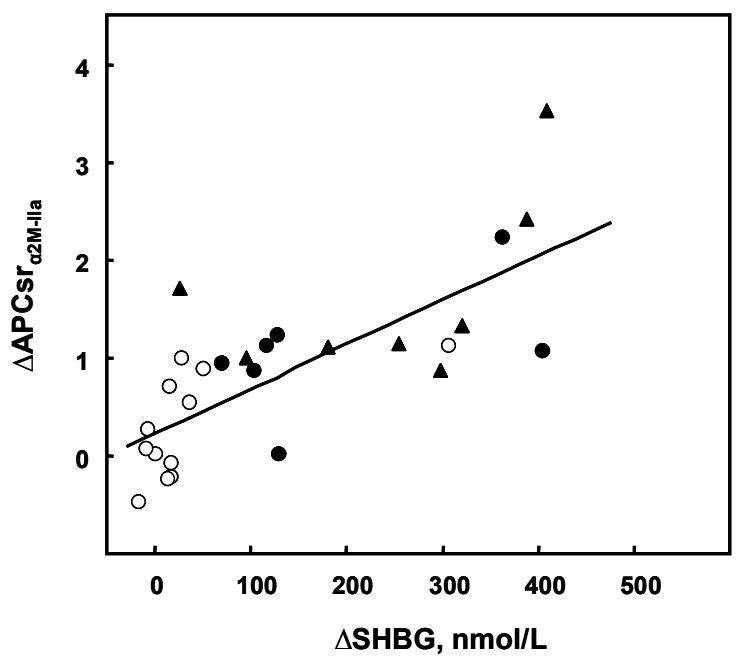

Fig. 4. Correlation between Changes of APCsr and Plasma SHBG Levels (Study 2)

Correlation between the changes in the activated protein $\mathrm{C}$ sensitivity ratio $\left(\triangle \mathrm{APCsr}_{\alpha 2 \mathrm{M}-\mathrm{II} a}\right)$ and $\mathrm{sex}$ hormone-binding globulin levels $(\triangle \mathrm{SHBG})$ upon treatment with one of the three contraceptive formulations: the levonorgestrelcontaining oral contraceptives (open circles), the transdermal patch (filled triangles) and vaginal ring (filled circles).

\section{The Effect of the Levonorgestrel-releasing and the Copper-containing Intrauterine System on APC Resistance}

From 91 women scheduled for insertion of either the levonorgestrel-releasing or a copper-containing intrauterine device in study 3 , seven did not meet inclusion criteria. The insertion of the intrauterine system failed or did not take place in three women. Two women requested removal of the intrauterine device because of abdominal pain and/or bleeding disturbances and five women discontinued the study or were lost for follow up. Women who were pregnant $(n=6)$ or used hormonal contraceptive methods other than combined OC $(n=5)$ in the three months before insertion of the intrauterine device were excluded from the current analysis. The remaining 63 women (48 levonorgestrel-releasing device, 15 copper-containing device) were stratified according to the factors influencing APC resistance and thrombotic risk and divided into three groups

The first group consisted of women who did not use hormonal contraceptives in the three months before collection of the baseline blood sample, and who were neither carrying the factor $\mathrm{V}_{\text {Leiden }}$ mutation nor had a (family) history of venous thrombosis (19 women using the levonorgestrelreleasing device and 6 the copper-containing device). The second group consisted of women who switched directly from a combined OC to an intrauterine device and who were not carrying the factor $\mathrm{V}_{\text {Leiden }}$ mutation nor had a (family) history of venous thrombosis ( 19 women using the levonorgestrel-releasing device and 6 the copper-containing device). The third 
group included women who were carrying the factor $\mathrm{V}_{\text {Leiden }}$ mutation and/or who had a (family) history of venous thrombosis (10 women using levonorgestrel-releasing device and 3- copper-containing device). A positive family history was defined as one or more first-degree relatives with venous thrombosis. Characteristics of the participants are described elsewhere. ${ }^{25}$

In the first group (no $\mathrm{OC}$ use or thrombosis risk factors) the baseline APCsr ${ }_{\text {CAT }}$ were slightly lower in the women planned for insertion of the levonorgestrel-releasing intrauterine device than in those planned for insertion of the copper-containing intrauterine device (levonorgestrel-releasing device mean 2.75 (95\%CI 2.18 to 3.33 ) versus copper-containing device mean 3.06 (95\%CI 1.54 to 4.59 ); difference -0.31 ; (95\%CI -1.52 to 0.90$)$, see Table 2. Three months after insertion of the levonorgestrel-releasing intrauterine device the $\mathrm{APCsr}_{\mathrm{CAT}}$ significantly decreased (difference with baseline -0.29; $95 \% \mathrm{CI}-0.04$ to -0.53 ; Table 2). In contrast, the mean $\mathrm{APCsr}_{\mathrm{CAT}}$ hardly changed (difference with baseline $0.11 ; 95 \% \mathrm{CI}-1.03$ to 0.82 ) upon three month insertion of the copper-containing intrauterine device. The $\mathrm{APCsr}_{\mathrm{CAT}}$ did not differ between women using for three months the levonorgestrel-releasing or a copper-containing intrauterine devices (difference -0.49 ; $95 \% \mathrm{CI}-1.57$ to 0.60 ).

In the second group, i.e. in women switching from a combined $\mathrm{OC}$ to an intrauterine device, the baseline $\mathrm{APCSr}_{\mathrm{CAT}}$ were higher (levonorgestrel-releasing device mean 4.73 ; $95 \% \mathrm{CI} 3.80$ to 5.66 and copper-containing device mean 4.96; $95 \%$ CI 2.81 to 7.12 ; Table 2) than in the women who were not using combined $\mathrm{OC}$ before insertion (first group). Moreover, the decrease in the APCsr ${ }_{\mathrm{CAT}}$ before and after insertion of the intrauterine device in this group was more pronounced than in the first group (difference with baseline for levonorgestrelreleasing device $-1.48 ; 95 \% \mathrm{CI}-0.85$ to -2.11 and for copper- containing device $-1.80 ; 95 \%$ CI -0.23 to -3.38 ). At three months the $\mathrm{APCsr}_{\mathrm{CAT}}$ did not differ between women using the levonorgestrel-releasing intrauterine device and women using a copper-containing intrauterine device (difference 0.08; $95 \%$ CI -0.89 to 1.05 ).

In the third group 10 women with a family history of venous thrombosis (including one homozygote for the factor $\mathrm{V}_{\text {Leiden }}$ mutation) received the levonorgestrel-releasing intrauterine device. In these women the $\mathrm{APCsr}_{\mathrm{CAT}}$ decreased after insertion of the device from 4.40 to 4.09 (difference -0.31 ; $95 \% \mathrm{CI}-0.98$ to 0.37 ; Table 2). Three women in the copper-containing intrauterine device group were heterozygous carriers of the factor $V_{\text {Leiden }}$ mutation, one of whom had experienced a venous thrombosis in the past and one had a family history of venous thrombosis. The mean APCsr ${ }_{\mathrm{CAT}}$ in these 


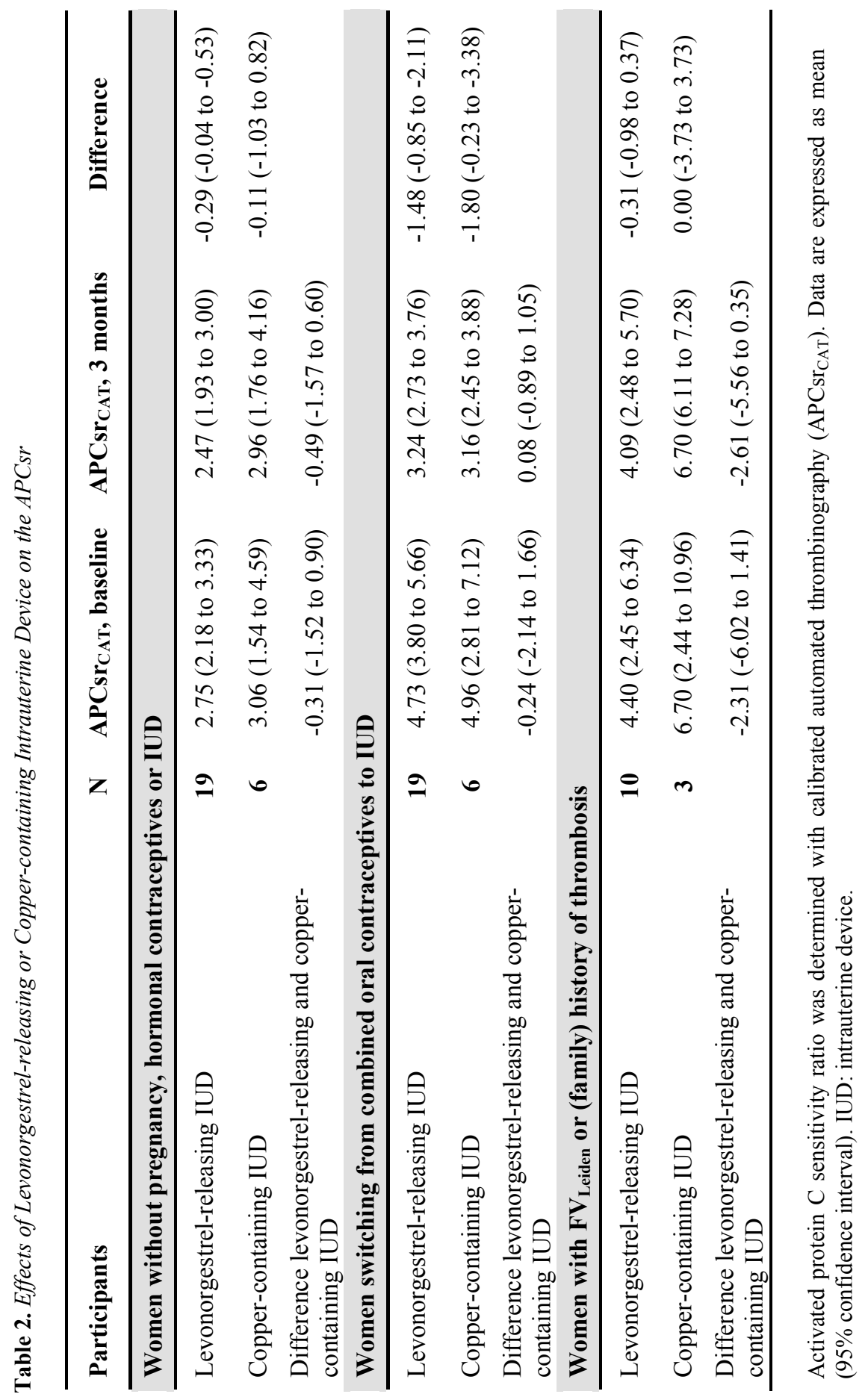


three women was not changed 3 months after insertion of the device (mean baseline 6.70; mean three months 6.70).

\section{Discussion}

In this chapter we described the effects of non-oral and oral hormonal contraceptives on a group of biomarkers that are used to estimate the risk of arterial and venous thrombosis and that are known to be affected by hormonal therapies.

In study 1 we compared transdermal and oral contraceptives containing similar estrogen and progestins, allowing conclusions regarding the effect of the route of administration on risk markers of thrombosis. The major finding of study 1 was that oral and transdermal contraceptives show similar effects on biomarkers of vascular disease risk after 2 months of treatment. Both medications were associated with decreases in total and free protein $\mathrm{S}$ and antithrombin, and increases in fibrinogen, C-reactive protein, and APC resistance. Neither treatment had an effect on factor VIII or von Willebrand factor. The increase in D-dimer observed for oral treatment resulted from a significantly lower D-dimer pre-treatment level (for which we have no explanation), whereas D-dimer levels during treatment were similar for the two contraceptives. The largest effects were observed for C-reactive protein and APC resistance. Compared to OC, transdermal administration caused a more pronounced decrease of free protein S and increase of the APCsr determined with the end point as well as with the calibrated automated thrombinography assay. However, for two of the assays, free protein S and $\mathrm{APCsr}_{\mathrm{\alpha 2M}-\mathrm{IIa}}$, the differences of the effect of the route of administration approached, but did not reach, statistical significance. This suggests insufficient power to demonstrate the true effect of these hormonal contraceptives on these biomarkers. A larger sample size might improve the confidence of some of the findings comparing the two contraceptives. Based on the most sensitive assay, APC resistance, study 1 suggests a potentially higher risk of venous thrombosis upon transdermal than upon oral treatment in spite of the fact that both contraceptives contain the same hormones.

The findings of study 1 were further confirmed in study 2 , in which we have compared a levonorgestrel-containing OC (second generation), known to have relatively little prothrombogenic effect, with third generation transdermal or vaginal contraceptives. In this study, women who used either transdermal or vaginal contraceptive had higher APCsr and plasma SHBG levels than women who used levonorgestrel-containing OC. This indicates that the transdermal 
patch and the vaginal ring are likely to have a higher prothrombotic potential than the levonorgestrel-containing OC.

The mechanism of the increased venous thrombosis risk during OC use is thought to relate partly to the first pass of estrogens and progestins through the liver with resultant changes in coagulation factor levels. ${ }^{29}$ However, our findings suggest that alternative routes of administration, without first-pass liver effect, would not attenuate the risk compared with oral agents. The trends towards larger effects for transdermal application on the biomarkers that we evaluated may be explained by higher sustained estrogen and progestin levels observed during transdermal compared to oral treatment, even though peak hormone levels are higher with oral treatment. ${ }^{30-32}$ These higher hormone levels over time may cause changes in the coagulation system independent of firstpass liver effects.

In addition, the thrombotic risk associated with combined contraceptive use is not strictly dependent on the estrogen dose but rather on the "total estrogenicity" of the formulation, which is the resultant of the estrogenic effect of EE and the anti-estrogenic effect of the progestin. It has been proposed that third-generation progestins (gestodene and desogestrel) have a lower antiestrogenic potential than the second-generation progestin levonorgestrel. ${ }^{22,33,34}$ Various studies have shown, that OC containing third-generation progestins have a greater effect on APC resistance and SHBG levels than OC containing second-generation progestins. ${ }^{13,16,20-22,34}$ Both, the transdermal and the vaginal contraceptives that we studied contain third generation progestins, i.e. for the patch norelgestromin, the primary active metabolite of norgestimate and for the vaginal ring etonogestrel, a metabolite of desogestrel. ${ }^{35}$ Therefore, the more pronounced pro-thrombotic changes induced by patch and vaginal ring may at least partially be explained by the fact that their progestin compound has a lower anti-estrogenic potency than the second-generation progestin levonorgestrel. ${ }^{22,34}$

In contrast to the observations in users of combined hormonal contraceptives, the levonorgestrel-releasing intrauterine device slightly decreased resistance to APC (study 3), whereas APC resistance did not change after insertion of the copper-containing intrauterine device. The decrease in resistance to APC after insertion of the levonorgestrel-releasing intrauterine device was more pronounced in women who switched from a combined OC to the levonorgestrel-releasing intrauterine device. This can be explained by the initially increased resistance to APC caused by OC use. ${ }^{16}$ Our findings are consistent with previous studies, in which levonorgestrel-only contraceptive pills slightly decreased APC resistance ${ }^{34}$ and the etonogestrel-implant did not 
change resistance to APC. ${ }^{36}$ Taken together these data are in agreement with case-control studies which did not find evidence for an increased risk of venous thrombosis in women using progestin-only contraceptive methods. ${ }^{6,7}$ The World Health Organization advises women with a history of deep venous thrombosis or with inherited coagulation defects, e.g. factor $V_{\text {Leiden }}$, the prothrombin mutation or deficiencies of protein $\mathrm{S}$, protein $\mathrm{C}$ or antithrombin, not to use combined OC. ${ }^{37}$ The same guidelines state that for these women "the advantages of using the levonorgestrel-releasing intrauterine system generally outweigh the theoretical or proven risks". In study 3 the number of women with the factor $\mathrm{V}_{\text {Leiden }}$ mutation or with a history of thrombosis was too small to assess the effect of the levonorgestrel-releasing intrauterine device on the resistance to APC in these women. Since Kemmeren et al. observed that levonorgestrel-only contraceptive pills cause a similar decrease in resistance to APC in non-carriers and in heterozygous carriers of the factor $\mathrm{V}_{\text {Leiden }}$ mutation, ${ }^{34}$ we do not expect that the levonorgestrel-releasing intrauterine system will have a different effect on the resistance to APC in women with and without the factor $\mathrm{V}_{\text {Leiden }}$ mutation.

In conclusion, the findings in the current studies support preliminary observations demonstrating no decrease in risk ${ }^{4}$ and a potential increase in risk ${ }^{3}$ of thrombosis with transdermal and vaginal contraceptives. Our data suggest that there is no safety advantage of the currently available transdermal and vaginal hormonal contraceptives. Women should be counselled concerning the vascular risks of all combined hormonal contraceptive medications regardless of the route of administration. On the other hand, the levonorgestrel-releasing intrauterine system does not seem to have a prothrombotic effect and therefore may present a preferred method of contraception in women who have an increased risk of venous thrombosis. However, further investigations to assess the absolute and relative risk of venous thrombosis in women using the levonorgestrel-releasing intrauterine device are required. 


\section{References}

1. Vandenbroucke JP, Rosing J, Bloemenkamp KW, et al. Oral contraceptives and the risk of venous thrombosis. N Engl J Med. 2001;344:1527-1535.

2. Baillargeon JP, McClish DK, Essah PA, Nestler JE. Association between the current use of low-dose oral contraceptives and cardiovascular arterial disease: a meta-analysis. J Clin Endocrinol Metab. 2005;90:3863-3870.

3. Cole JA, Norman H, Doherty M, Walker AM. Venous thromboembolism, myocardial infarction, and stroke among transdermal contraceptive system users. Obstet Gynecol. 2007;109:339-346.

4. Jick SS, Kaye JA, Russmann S, Jick H. Risk of nonfatal venous thromboembolism in women using a contraceptive transdermal patch and oral contraceptives containing norgestimate and 35 microg of ethinyl estradiol. Contraception. 2006;73:223-228.

5. Cardiovascular disease and use of oral and injectable progestogen-only contraceptives and combined injectable contraceptives. Results of an international, multicenter, case-control study. World Health Organization Collaborative Study of Cardiovascular Disease and Steroid Hormone Contraception. Contraception. 1998;57:315-324.

6. Heinemann LA, Assmann A, DoMinh T, Garbe E. Oral progestogen-only contraceptives and cardiovascular risk: results from the Transnational Study on Oral Contraceptives and the Health of Young Women. Eur J Contracept Reprod Health Care. 1999;4:67-73.

7. Vasilakis C, Jick H, del Mar Melero-Montes M. Risk of idiopathic venous thromboembolism in users of progestagens alone. Lancet. 1999;354:1610-1611.

8. Jensen JT. Contraceptive and therapeutic effects of the levonorgestrel intrauterine system: an overview. Obstet Gynecol Surv. 2005;60:604-612.

9. Shulman LP, Nelson AL, Darney PD. Recent developments in hormone delivery systems. Am J Obstet Gynecol. 2004;190:S39-48.

10. An open label, randomized study to evaluate the effects of seven monophasic oral contraceptive regimens on hemostatic variables. Outline of the protocol. Oral Contraceptive and Hemostasis Study Group. Contraception. 1999;59:345-355.

11. Archer DF, Mammen EF, Grubb GS. The effects of a low-dose monophasic preparation of levonorgestrel and ethinyl estradiol on coagulation and other hemostatic factors. Am J Obstet Gynecol. 1999;181:63-66.

12. Middeldorp S, Meijers JC, van den Ende AE, et al. Effects on coagulation of levonorgestreland desogestrel-containing low dose oral contraceptives: a cross-over study. Thromb Haemost. 2000;84:4-8.

13. Tans G, Curvers J, Middeldorp S, et al. A randomized cross-over study on the effects of levonorgestrel- and desogestrel-containing oral contraceptives on the anticoagulant pathways. Thromb Haemost. 2000;84:15-21.

14. Wu O, Robertson L, Langhorne $\mathrm{P}$, et al. Oral contraceptives, hormone replacement therapy, thrombophilias and risk of venous thromboembolism: a systematic review. The Thrombosis: Risk and Economic Assessment of Thrombophilia Screening (TREATS) Study. Thromb Haemost. 2005;94:17-25.

15. van Rooijen M, Hansson LO, Frostegard J, Silveira A, Hamsten A, Bremme K. Treatment with combined oral contraceptives induces a rise in serum $\mathrm{C}$-reactive protein in the absence of a general inflammatory response. J Thromb Haemost. 2006;4:77-82.

16. Rosing J, Middeldorp S, Curvers J, et al. Low-dose oral contraceptives and acquired resistance to activated protein C: a randomised cross-over study. Lancet. 1999;354:20362040.

17. Alhenc-Gelas M, Plu-Bureau G, Guillonneau S, et al. Impact of progestagens on activated protein C (APC) resistance among users of oral contraceptives. J Thromb Haemost. 2004;2:1594-1600. 
18. Tans G, van Hylckama Vlieg A, Thomassen MC, et al. Activated protein C resistance determined with a thrombin generation-based test predicts for venous thrombosis in men and women. Br J Haematol. 2003;122:465-470.

19. van Vliet HA, Winkel TA, Noort I, Rosing J, Rosendaal FR. Prothrombotic changes in users of combined oral contraceptives containing drospirenone and cyproterone acetate. J Thromb Haemost. 2004;2:2060-2062.

20. van Rooijen M, Silveira A, Hamsten A, Bremme K. Sex hormone--binding globulin--a surrogate marker for the prothrombotic effects of combined oral contraceptives. Am J Obstet Gynecol. 2004;190:332-337.

21. van Vliet HA, Frolich M, Christella M, et al. Association between sex hormone-binding globulin levels and activated protein $\mathrm{C}$ resistance in explaining the risk of thrombosis in users of oral contraceptives containing different progestogens. Hum Reprod. 2005;20:563568 .

22. Odlind V, Milsom I, Persson I, Victor A. Can changes in sex hormone binding globulin predict the risk of venous thromboembolism with combined oral contraceptive pills? Acta Obstet Gynecol Scand. 2002;81:482-490.

23. Johnson JV, Lowell J, Badger GJ, Rosing J, Tchaikovski S, Cushman M. Effects of oral and transdermal hormonal contraception on vascular risk markers: a randomized controlled trial. Obstet Gynecol. 2008;111:278-284.

24. Fleischer K, van Vliet HA, Rosendaal FR, Rosing J, Tchaikovski S, Helmerhorst FM. Effects of the contraceptive patch, the vaginal ring and an oral contraceptive on APC resistance and SHBG: a cross-over study. Thromb Res. 2009;123:429-435.

25. van Vliet HA, Tchaikovski SN, Rosendaal FR, Rosing J, Helmerhorst FM. The effect of the levonorgestrel-releasing intrauterine system on the resistance to activated protein C (APC). Thromb Haemost. 2009;101:691-695.

26. Rosing J, Tans G, Nicolaes GA, et al. Oral contraceptives and venous thrombosis: different sensitivities to activated protein $\mathrm{C}$ in women using second- and third-generation oral contraceptives. Br J Haematol. 1997;97:233-238.

27. Hemker HC, Giesen P, Al Dieri R, et al. Calibrated automated thrombin generation measurement in clotting plasma. Pathophysiol Haemost Thromb. 2003;33:4-15.

28. Nicolaes GA, Thomassen MC, van Oerle R, et al. A prothrombinase-based assay for detection of resistance to activated protein C. Thromb Haemost. 1996;76:404-410.

29. Humpel M, Wendt H, Pommerenke G, Weiss C, Speck U. Investigations of pharmacokinetics of levonorgestrel to specific consideration of a possible first-pass effect in women. Contraception. 1978;17:207-220.

30. Ortho Evra ${ }^{\circledR}$ (norelgestromin/ethinyl estradiol transdermal system). Product labeling, OrthoMcNeil Pharmaceutical, Inc, Raritan (NJ).

31. Devineni D, Skee D, Vaccaro N, et al. Pharmacokinetics and pharmacodynamics of a transdermal contraceptive patch and an oral contraceptive. J Clin Pharmacol. 2007;47:497-509.

32. van den Heuvel MW, van Bragt AJ, Alnabawy AK, Kaptein MC. Comparison of ethinylestradiol pharmacokinetics in three hormonal contraceptive formulations: the vaginal ring, the transdermal patch and an oral contraceptive. Contraception. 2005;72:168-174.

33. Hammond GL, Abrams LS, Creasy GW, Natarajan J, Allen JG, Siiteri PK. Serum distribution of the major metabolites of norgestimate in relation to its pharmacological properties. Contraception. 2003;67:93-99.

34. Kemmeren JM, Algra A, Meijers JC, et al. Effect of second- and third-generation oral contraceptives on the protein $\mathrm{C}$ system in the absence or presence of the factor VLeiden mutation: a randomized trial. Blood. 2004;103:927-933.

35. Sitruk-Ware R. New progestagens for contraceptive use. Hum Reprod Update. 2006;12:169178.

36. Lindqvist PG, Rosing J, Malmquist A, Hillarp A. Etonogestrel implant use is not related to hypercoagulable changes in anticoagulant system. J Thromb Haemost. 2003;1:601-602.

37. WHO. Medical eligibility criteria for contraceptive use. 



\section{Chapter 5}

\section{Development of a Calibrated Automated}

\section{Thrombography-based Thrombin Generation Test in Mouse Plasma}

$\underline{\text { S.N. Tchaikovski, B.J.M. van Vlijmen, J. Rosing and G. Tans }}$

Journal of Thrombosis and Haemostasis 2007; 5(10): 2079-86 


\section{Summary}

Background: Mouse models become increasingly important in thrombosis research. However, only a limited number of assays are available for assessment of the coagulation system in mouse plasma.

Objectives: To quantify tissue factor-initiated thrombin generation in murine platelet-rich and platelet-free plasma and to develop a test for measurement of resistance to activated protein C (APC) in mouse plasma.

Methods: Thrombin generation was monitored with calibrated automated thrombography (CAT) using a low affinity fluorogenic substrate for thrombin.

Results: To overcome the higher activity of coagulation inhibitors in mouse plasma as compared to human plasma, the reaction temperature was lowered to $33^{\circ} \mathrm{C}$ and the assay was carried out at a 2-fold higher final plasma dilution (1:3) than commonly used for CAT in human plasma. This increased the ETP 4- to 5fold and enabled reliable measurement of thrombin generation in both plateletfree and platelet-rich mouse plasma. For the APC resistance measurement the reaction conditions were further optimised with respect to tissue factor, phospholipid, APC and $\mathrm{CaCl}_{2}$ concentrations. The test was validated using plasma of mice with different genetic background with respect to the factor $\mathrm{V}_{\text {Leiden }}$ mutation $\left(\mathrm{FV}_{\text {Leiden }}\right)$. Mice homozygous for $\mathrm{FV}_{\text {Leiden }}$ had higher APC sensitivity ratios (mean 5.46; 95\% CI 4.88-6.03) than heterozygous $\mathrm{FV}_{\text {Leiden }}$ mice (mean $4.21 ; 95 \%$ CI $3.53-4.89$ ) and than wild-type mice (mean $2.71 ; 95 \% \mathrm{CI}$ 2.15-3.27).

Conclusions: We have established reaction conditions for measurement of thrombin generation and APC resistance in mouse plasma. This assay enables evaluation of the coagulation system and the function of the protein $\mathrm{C}$ system in mouse models. 


\section{Introduction}

Venous thromboembolism (VTE) is a complex disease which results from the interplay between inherited predisposition and environmental factors. ${ }^{1}$ The multifactorial origin of VTE i.e. the numerous acquired and congenital risk factors involved, makes the use of animal models in thrombosis and haemostasis research inevitable. Particularly, mouse models are of interest because of the ease of breeding, the availability of the entire genome and the potential for generating genetically modified animals. Various transgenic mouse strains ${ }^{2}$ are available for investigation of the (patho)physiology of in vivo thrombus formation and clot lysis and for evaluation of new therapeutical agents. Especially, factor $\mathrm{V}_{\text {Leiden }}\left(\mathrm{FV}_{\text {Leiden }}\right)$ mice may become a useful model to study the interaction between genetic and acquired risk factors in the development of VTE. ${ }^{3,4}$ These mice carry the murine equivalent of human $\mathrm{FV}_{\text {Leiden, }}{ }^{5}$ a single point mutation in the factor $\mathrm{V}$ gene, ${ }^{6}$ which is the most prevalent risk factor for VTE in the Caucasian population. ${ }^{7}$ The $\mathrm{FV}_{\text {Leiden }}$ mutation renders factor $\mathrm{Va}$ less susceptible to inactivation by the natural anticoagulant, activated protein C (APC). ${ }^{8}$

Despite the availability of numerous assays for evaluation of the coagulation system in humans, methods used in mice are restricted to evaluation of induced thrombosis, determination of coagulation factor levels or clotting times. ${ }^{2,9}$ However, measurement of thrombin generation, which is an overall functional test, sensitive for both prothrombotic and haemophilic phenotypes, ${ }^{10,11}$ is currently recognised as an important tool in haemostasis research. The recent development of calibrated automated thrombography (CAT) allows assessment of thrombin generation in clotting (human) plasma with or without platelets. In this paper we describe the development and optimization of CAT for evaluation of thrombin generation in platelet-free and platelet-rich mouse plasma and we define test conditions for assessment of APC resistance in mouse plasma.

\section{Materials \& Methods}

\section{Materials}

Ancrod was from NIBSC, Hertfordshire, UK; ecarin from Pentapharm, Basel, Switzerland; the chromogenic thrombin substrate D-phenylalanyl-L-pipecolylL-arginine-p-nitroanilide (S2238) from Chromogenix, Mölndal, Sweden and the fluorogenic thrombin substrate Z-Gly-Gly-Arg-AMC from Bachem, Bubendorf, Switzerland. A phospholipid emulsion composed of phosphatidylcholine, phosphatidylserine and sphingomyelin (Phospholipid-TGT) was provided by Rossix, Mölndal, Sweden. Human recombinant tissue factor (hrTF) was from 
Dade Innovin ${ }^{\circledR}$, Behring, Germany. Mouse thromboplastin ${ }^{12}$ was a gift of R. van Oerle. One unit of mouse thromboplastin equals the activity of $1 \mathrm{pM}$ hrTF (Innovin) in bovine factor X activation by human recombinant factor VIIa.

Human APC was from Enzyme Research Laboratories, Kordia, Leiden, the Netherlands. Mouse APC was a gift of Dr. H. Spronk. The thrombin calibrator and PPP-Reagents were from Thrombinoscope BV, Maastricht, The Netherlands.

\section{Animals}

Mice carrying the $\mathrm{FV}_{\text {Leiden }}$ mutation (R504Q) were described by Cui et al. ${ }^{5}$ Factor V R504Q mice were backcrossed to C57BL/6J mice (Jackson Labs, Bar Harbor, ME) for at lest 8 generations (N8), and N8 heterozygous mice were intercrossed to produce homozygous $(\mathrm{n}=16,11$ males and 5 females, age 7-14 weeks), heterozygous ( $\mathrm{n}=18,12$ males and 6 females, age 7-14 weeks), and wild-type ( $\mathrm{n}=18,12$ males and 6 females, age 7-14 weeks) littermates. The $\mathrm{FV}_{\text {Leiden }}$ genotype was confirmed by PCR analysis of tail DNA.

\section{Collection and Handling of Plasma Samples}

For tail blood collection, restrained mice were placed under a heating lamp $\left(37^{\circ} \mathrm{C}\right)$. The tail was cut $1 \mathrm{~cm}$ from the tip. Within $10-15 \mathrm{sec}, 200 \mu \mathrm{L}$ blood was collected in eppendorf tubes (first droplet discarded), $180 \mu \mathrm{L}$ blood was pipetted to $20 \mu \mathrm{L} 3.2 \%$ (wt/vol) trisodium citrate. Plasma was prepared by centrifugation at $21000 \times \mathrm{g}$ for $10 \mathrm{~min}$ at room temperature (RT), snap-frozen, and stored at $-80^{\circ} \mathrm{C}$ prior to analysis.

Mouse pooled normal plasma (MPNP) was prepared as follows. Mouse blood was collected as previously described ${ }^{13}$ with minor modifications. After intraperitoneal anaesthesia with Nembutal ${ }^{\circledR}$ (CEVA, Sante Animale, France) $200 \mathrm{mg} / \mathrm{kg}$, the abdominal cavity was opened and phlebotomy of Vena cava inferior was performed. Blood was drawn into a syringe, containing 3.2\% sodium citrate $(9: 1 \mathrm{vol})$. Platelet-free plasma (PFP) was prepared by centrifuging twice at $21000 \times \mathrm{g}$ for $10 \mathrm{~min}$ at RT after which the supernatant plasmas of $10 \mathrm{C} 57 \mathrm{BL} / 6$ healthy mice (5 males and 5 females, 8-14 weeks old) were pooled. Blood samples containing a visible fibrin clot were rejected. MPNP was snap-frozen and stored at $-80^{\circ} \mathrm{C}$ until use.

Platelet-rich plasma (PRP) was prepared by consecutive centrifugations ( 3 min at $280 \times \mathrm{g}$ and $1 \mathrm{~min}$ at $625 \times \mathrm{g}$ ) at RT without brake and was used within 2 hours. 
Human pooled normal plasma (HPNP) was prepared by pooling plasma of 87 healthy donors free of medication (53 male and 34 female, mean age 38.6 years) as previously described. ${ }^{14}$

\section{Thrombin Generation}

Thrombin generation was measured in duplicate via CAT in a Fluoroskan Ascent ${ }^{\circledR}$ reader (Thermo Labsystems, Helsinki, Finland; filters 390-nmexcitation and 460-nm-emission) using the fluorogenic substrate Z-Gly-GlyArg-AMC. ${ }^{15}$ Thrombin generation curves and the area-under-the-curve (endogenous thrombin potential, ETP) were calculated using the Thrombinoscope $\mathrm{T}^{\mathrm{TM}}$ software (Thrombinoscope BV, Maastricht, The Netherlands) and thrombin calibrator to correct for inner filter and substrate consumption effects. ${ }^{15}$ Since mouse thrombin converts the fluorogenic substrate $(420 \mu \mathrm{M})$ at a $20 \%$ lower rate than human thrombin (data not shown), thrombin concentrations and ETP calculated in mouse plasma were corrected for this difference in activity. Alternatively, the correct amount of thrombin generated in mouse plasma will be calculated by the Thrombinoscope ${ }^{\mathrm{TM}}$ software after increasing the calibrator activity by $20 \%$ in the program settings. Thrombin generation was initiated by addition of either hrTF or mouse thromboplastin in the presence of calcium $\left(\mathrm{Ca}^{2+}\right)$ and phospholipids as described under Results. APC resistance was assessed by quantification of the effect of added APC (human or mouse) on the ETP. Normalized APC sensitivity ratios (nAPCsr) were defined as the ratio of the ETP's determined in the presence $\left(\mathrm{ETP}_{+\mathrm{APC}}\right)$ and absence of APC (ETP-APC) normalized against the same ratio determined in MPNP in the same experiment.

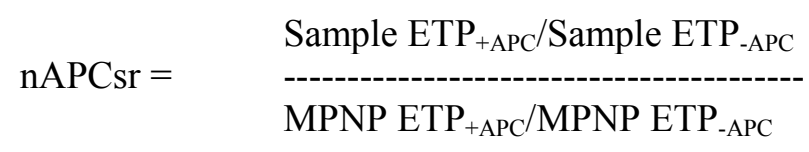

\section{Prothrombin Activation and Subsequent Thrombin Inactivation}

Human and mouse plasma were defibrinated with Ancrod for $10 \mathrm{~min}$ at $37^{\circ} \mathrm{C}$, diluted in Buffer A ( $25 \mathrm{mM}$ Hepes, $175 \mathrm{mM} \mathrm{NaCl}, 5 \mathrm{~g} / \mathrm{L} \mathrm{BSA}$, pH 7.7 at RT) and prothrombin was activated by addition of Ecarin (final concentration 6.5 $\mathrm{U} / \mathrm{mL}$ ) in the presence of $5 \mathrm{mM} \mathrm{CaCl}_{2}$ at $37^{\circ} \mathrm{C}$ at $1: 50$ final plasma dilution. The amount of Ecarin added was sufficient to completely activate prothrombin within 30 seconds. At various time intervals aliquots of the reaction mixture were diluted 25-fold in ice-cold buffer containing $25 \mathrm{mM}$ Hepes (pH 7.9 at RT), $175 \mathrm{mM} \mathrm{NaCl}, 60 \mathrm{mM}$ EDTA and $0.5 \mathrm{~g} / \mathrm{L}$ ovalbumin. Thrombin amidolytic activity was subsequently determined at $37^{\circ} \mathrm{C}$ using S2238 and expressed as percentage of the activity present at $30 \mathrm{sec}$ activation. 


\section{Results}

\section{Reduction of Assay Volume}

Thrombin generation is routinely performed in a total volume of $120 \mu \mathrm{L}$, which consists of $80 \mu \mathrm{L}$ plasma and $40 \mu \mathrm{L}$ buffer containing phospholipids, TF, fluorogenic substrate and $\mathrm{CaCl}_{2 .}{ }^{15}$ Additionally, analysis of thrombin generation requires for each plasma sample calibration of fluorogenic substrate conversion with a thrombin calibrator to correct for 'inner filter effects', substrate consumption, state of the thrombinoscope filters and lamp, and plasma colour. When thrombin generation is assessed in the presence of APC (APC resistance test) a minimum of $240 \mu \mathrm{L}$ plasma is required for an APCsr determination. With small animals such as mice this represents a great part of the total blood volume. Thus, initial experiments were aimed at reduction of the assay volume. The APC resistance test in HPNP in twice reduced assay volumes ( $60 \mu \mathrm{L}$ total volume containing $40 \mu \mathrm{L}$ plasma) was compared with the same measurement in $120 \mu \mathrm{L}$ ( $80 \mu \mathrm{L}$ plasma). The decrease in reaction volumes resulted in $\sim 10 \%$ reduction of the $\mathrm{ETP}_{-\mathrm{APC}}$ and the $\mathrm{ETP}_{+\mathrm{APC}}$, but the APCsr was not affected. The intra-assay coefficients of variation (human plasma) were $4 \%$ and $5 \%\left(\mathrm{ETP}_{-\mathrm{APC}}\right), 10 \%$ and $9 \%\left(\mathrm{ETP}_{+\mathrm{APC}}\right)$ and $7 \%$ and $11 \%(\mathrm{APCsr})$ for assay volumes of 120 and $60 \mu \mathrm{L}$, respectively $(\mathrm{n}=32)$. All further thrombin generation measurements were performed in $60 \mu \mathrm{L}$ reaction volume.

\section{Measurement of the ETP in Mouse Plasma}

Fig. 1 shows time courses of thrombin generation obtained in human and mouse PFP using commercially available reagents (PPP reagents, Fig. 1A,B,C) or a coagulation trigger used in the thrombin generation-based APC resistance test for human plasma ${ }^{16}$ (13.6 pM TF, $30 \mu \mathrm{M}$ phospholipid, Fig. 1D). Thrombin generation in mouse plasma showed substantially shorter lag times and lower amounts of thrombin (reduced peak height and ETP) than in human plasma and proved unsuitable for accurate measurement of thrombin generation and APC resistance. The virtual absence of a lag time before the onset of thrombin generation (Fig. 1B,C,D) triggered at high $\mathrm{TF}$ concentrations $(5,13.6$ and 20 $\mathrm{pM}$ ) precluded calculation of thrombin generation curves and ETP's by the Thrombinoscope ${ }^{\mathrm{TM}}$ software. At low TF concentrations (Fig. 1A), thrombin formation was too low to reliably calculate the ETP and determine effects of anticoagulants (e.g. APC).

The low amounts of free thrombin formed in mouse plasma likely result from higher activities of coagulation inhibitors (e.g. antithrombin) in mouse than in human plasma. This was confirmed by the experiment presented 

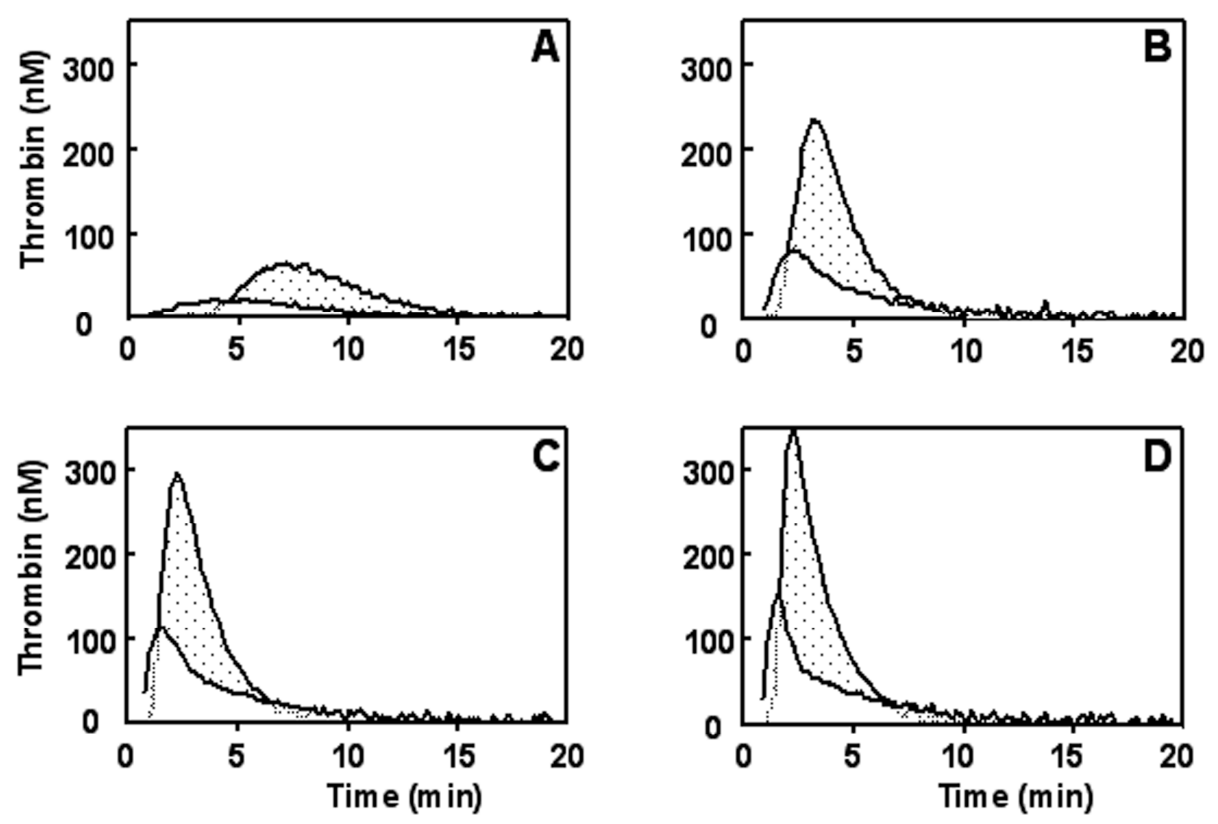

Fig. 1. CAT in Human and in Mouse Plasma

Thrombin generation in $\square$ mouse and $\because$ human plasmas was measured by CAT at $37^{\circ} \mathrm{C}$ in $60 \mu \mathrm{L}$ reaction mixtures, containing $40 \mu \mathrm{L}$ plasma and $10 \mu \mathrm{L}$ (A) PPP-Reagent LOW (1 pM TF/4 $\mu \mathrm{M}$ phospholipids), (B) PPP-Reagent (5 pM TF/4 $\mu \mathrm{M}$ phospholipids), (C) PPP-Reagent HIGH (20 $\mathrm{pM} \mathrm{TF} / 4 \mu \mathrm{M}$ phospholipids) or (D) $13.6 \mathrm{pM} \mathrm{hrTF} / 30 \mu \mathrm{M}$ phospholipids. Thrombin generation was initiated with $16.4 \mathrm{mM} \mathrm{CaCl}_{2}$ and $0.42 \mathrm{mM}$ fluorogenic substrate (final concentrations). Since the Thrombinoscope $\mathrm{T}^{\mathrm{TM}}$ software could not calculate the thrombin generation curves in mouse plasma all curves were calculated from the fluorescence data as previously described. ${ }^{17}$

in Fig. 2, which shows disappearance of thrombin activity with time in human and murine plasma after complete and rapid activation of plasma prothrombin with Ecarin. The amidolytic activity generated in mouse and human plasma was fully inhibited by hirudin indicating that thrombin was the only coagulation factor contributing to S2238 conversion. As judged from the initial slopes of the inactivation time courses, thrombin inhibition was $\sim 9$-fold faster in murine than in human plasma. To overcome the inhibitory activity and to increase the amount of thrombin generated, thrombin generation experiments were performed at higher plasma dilutions and at lower reaction temperatures. Fig. $3 \mathrm{~A}$ shows the effect of mouse plasma dilution on thrombin generation. The peak height and the ETP (Fig. 3A) increased at higher dilutions, showing an optimum at final plasma dilutions of $1: 3$ and 1:4. Fig. 3B shows that lowering temperature also increased the ETP. From these experiments the combination of 


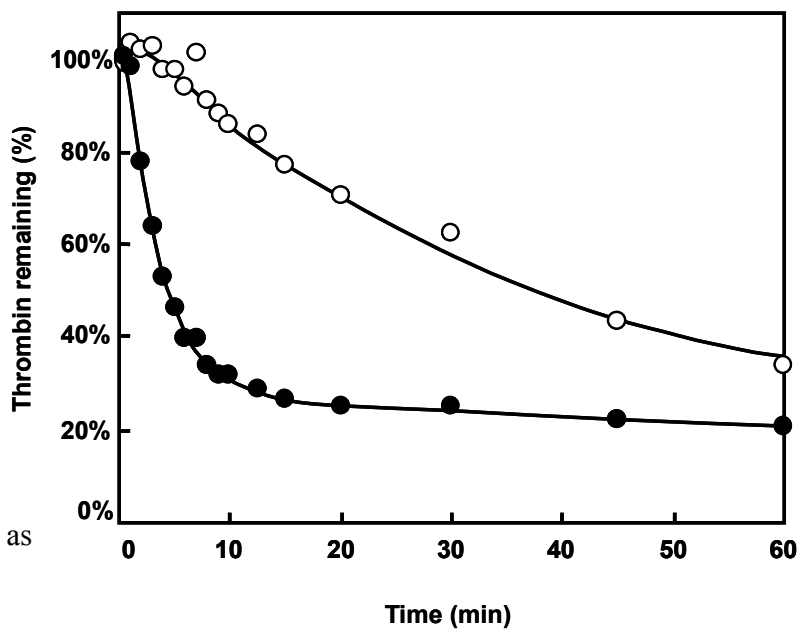

Fig. 2. Inhibition of Thrombin in

Diluted Human and Mouse

Plasmas

Plasma prothrombin was fully activated in 1:50 diluted defibrinated human ( $(\circ)$ and mouse $(\bullet)$ plasmas by addition of Ecarin to result in complete activation within $30 \mathrm{sec}$. The time course of inhibition of thrombin amidolytic activity by the plasma inhibitors was followed in time and expressed percentage of the activity determined at $30 \mathrm{sec}$.

Time (min)
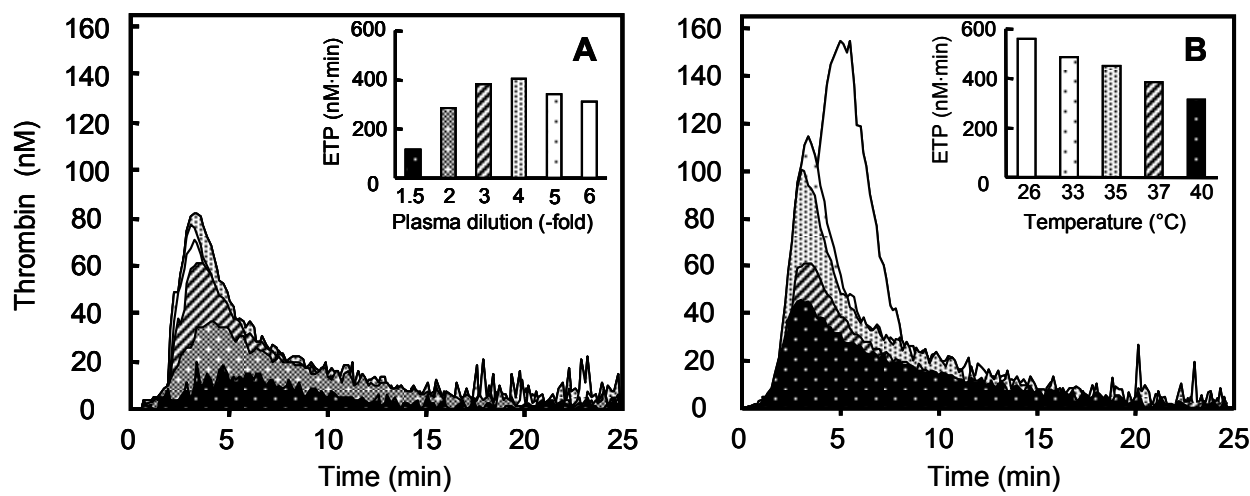

Fig. 3. Effect of Plasma Dilution and Temperature on Thrombin Generation in Mouse Plasma

(A) Thrombin generation was measured by CAT with $\because 40 \mu \mathrm{L} ; \mathbf{D S} 30 \mu \mathrm{L} ; \mathbb{W} 20 \mu \mathrm{L}$; BXX15 $\mu \mathrm{L} ; \cdots 12 \mu \mathrm{L}$ and $\square 10 \mu \mathrm{L}$ mouse plasma in a total assay volume of $60 \mu \mathrm{L}$. Thrombin generation was initiated at $37^{\circ} \mathrm{C}$ in the presence of $1 \mathrm{pM} \mathrm{hrTF}, 16.4 \mathrm{mM} \mathrm{CaCl}_{2}, 4 \mu \mathrm{M}$ phospholipids, $0.42 \mathrm{mM}$ fluorogenic substrate (final concentrations). Inset: ETP as function of plasma dilution.(B) Thrombin generation was measured by CAT in reaction mixtures $(60 \mu \mathrm{L})$ containing $20 \mu \mathrm{L}$ mouse plasma and $1 \mathrm{pM}$ hrTF, $16.4 \mathrm{mM}$ added $\mathrm{CaCl}_{2}, 4 \mu \mathrm{M}$ phospholipids,

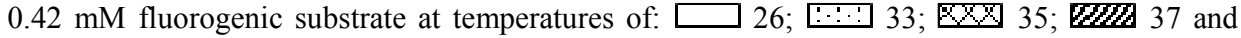
$\therefore 40^{\circ} \mathrm{C}$, respectively. Inset: ETP as function of temperature.

final 1:3 dilution ( $20 \mu \mathrm{L}$ mouse plasma in $60 \mu \mathrm{L}$ total reaction volume) and a reaction temperature of $33^{\circ} \mathrm{C}$, together resulting in a 4-5-fold higher ETP and a prolonged lag time, were chosen for further optimization of thrombin generation. 


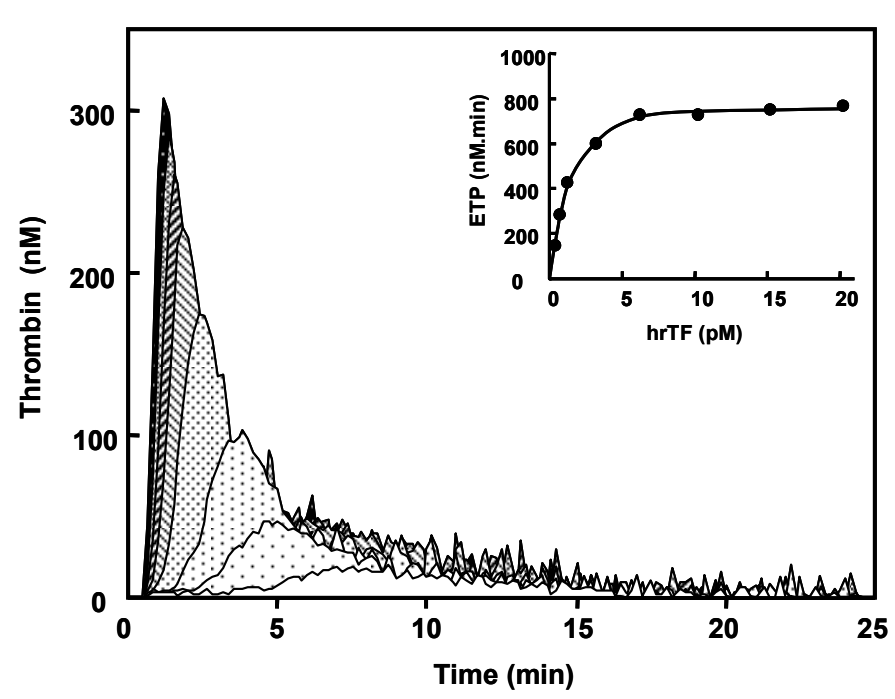

Fig. 4. Effect of Tissue Factor Concentration on Thrombin Generation in Mouse Plasma Thrombin generation was initiated by $0.2 ; \square 0.5 ; \cdots 1$; एO $3 ;$ WN $6 ; \dddot{W}$ 10; \&\& 15 and $20 \mathrm{pM} \mathrm{hrTF}$ at $33^{\circ} \mathrm{C}$ in $60 \mu \mathrm{L}$ reaction mixtures containing $20 \mu \mathrm{L}$ mouse plasma and $16.4 \mathrm{mM}$ $\mathrm{CaCl}_{2}, \quad 4 \quad \mu \mathrm{M}$ phospholipid, $0.42 \mathrm{mM}$ fluorogenic substrate. Inset: ETP values plotted as function of hrTF concentrations.

Fig. 4 shows that increasing amounts of hrTF increased thrombin generation and reduced the lag time. The effects on the lag time and the ETP were similar when thrombin generation was triggered in mouse plasma with increasing amounts of mouse thromboplastin (data not shown). Since $6 \mathrm{pM}$ hrTF yielded a sufficiently high ETP and a reliably measurable lag time $(\sim 1 \mathrm{~min})$, this TF concentration was chosen for the thrombin generation-based APC resistance test.

\section{CAT-based APC Resistance Test in Mouse Plasma}

Fig. 5 shows the effect of increasing phospholipid concentrations on the ETP in MPNP. In the absence of APC the ETP increased at increasing phospholipid concentration with an optimal plateau between $10 \mu \mathrm{M}$ and $60 \mu \mathrm{M}$ phospholipid. The data obtained in the presence of $25 \mathrm{nM}$ APC illustrate that APC hardly inhibited thrombin formation at low phospholipid and that higher phospholipid concentrations were needed to increase the sensitivity to APC. In the final optimization step the $\mathrm{CaCl}_{2}$ concentration was decreased to $8.2 \mathrm{mM}$ (added concentration) to match the decrease in citrate concentration due to the lower amounts of plasma present in the assay (data not shown).

Fig. 6 shows down-regulation of thrombin generation in mouse plasma initiated with $6 \mathrm{pM}$ hrTF by varying amounts of human APC. Approximately 4 nM APC was necessary to achieve $90 \%$ inhibition of the ETP in mouse plasma, which is comparable to the amount of APC used in the thrombin generationbased APC resistance test in human plasma. ${ }^{18,19}$ A similar experiment using 


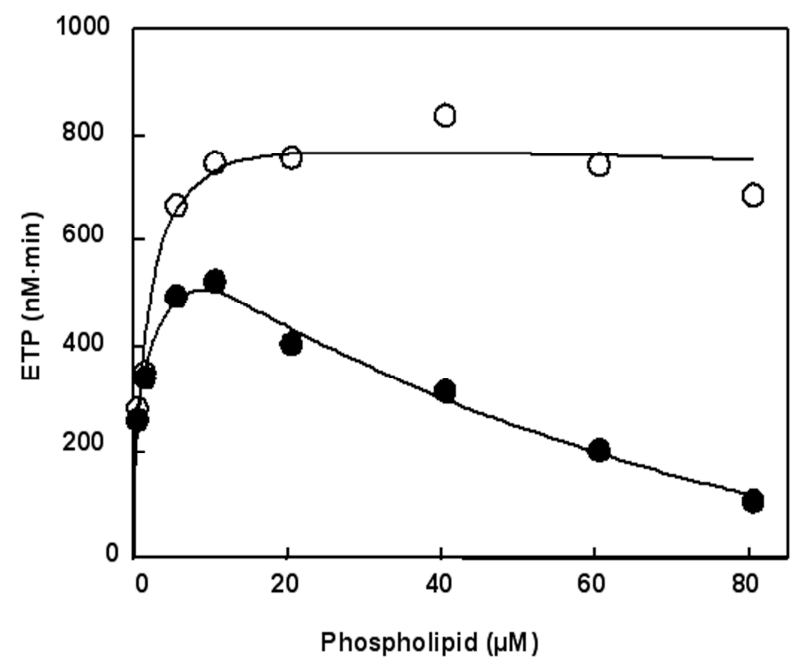

Fig. 5. Effect of Phospholipid Concentration on Thrombin Generation in the Absence and Presence of APC in Mouse Plasma

Thrombin generation was measured by $\mathrm{CAT}$ at $33^{\circ} \mathrm{C}$ in 60 $\mu \mathrm{L}$ reaction mixtures containing $20 \mu \mathrm{L}$ mouse plasma, $6 \mathrm{pM}$ hrTF, $\quad 16.4 \mathrm{mM} \quad \mathrm{CaCl}_{2}$, phospholipid concentrations as indicated in the figure and 0.42 $\mathrm{mM}$ fluorogenic substrate with (•) or without (०) $25 \mathrm{nM}$ of human APC present.

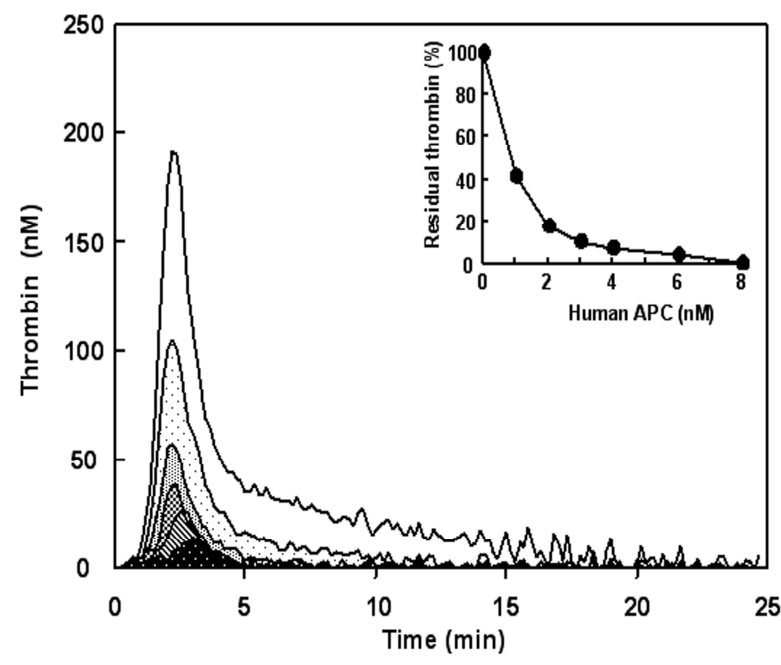

Fig. 6. Effect of the Concentration of Human APC on Thrombin Generation in Mouse Plasma

Thrombin generation was measured by $\mathrm{CAT}$ at $33^{\circ} \mathrm{C}$ in 60 $\mu \mathrm{L}$ reaction mixtures containing $20 \mu \mathrm{L}$ mouse plasma, $6 \mathrm{pM}$ hrTF, $8.2 \mathrm{mM} \mathrm{CaCl} 2,60 \mu \mathrm{M}$ phospholipids, $0.42 \mathrm{mM}$ fluorogenic substrate and amounts of human APC indicated in the inset of panel. Inset: the residual ETP determined in the presence of APC was calculated as percentage of the ETP determined in the absence of $\mathrm{APC}$ and is shown as function of APC concentration.

mouse thromboplastin $(0.25 \mathrm{U})$ and murine APC showed the same pattern of inhibition (data not shown).

\section{Resistance to APC in Plasma of F $V_{\text {Leiden }}$ Mice}

The APC resistance test was validated using plasma samples of mice with different genetic background with respect to the $\mathrm{FV}_{\text {Leiden }}$ mutation. Fig. 7 shows that nAPCsr values were low in wild-type mice (mean 2.71; 95\% CI 2.15 to 3.27), higher in $\mathrm{FV}_{\text {Leiden }}$ heterozygous mice (mean 4.21; 95\%CI 3.53 to 4.89) 
and further increased in $\mathrm{FV}_{\text {Leiden }}$ homozygous mice (mean 5.46; 95\%CI 4.88 to 6.03 ). The differences between all groups were significant according to one-way ANOVA followed by post-hoc analysis with Bonferroni correction for multiple comparisons $(\mathrm{p} \leq 0.01)$. The higher APC resistance in the test samples as compared to the reference MPNP may be explained by differences in blood sampling techniques (Materials and Methods).

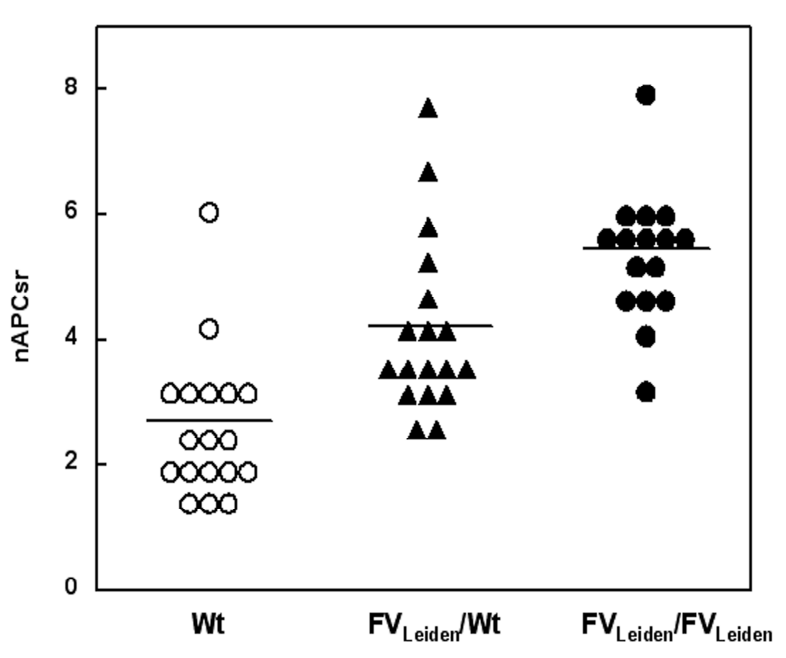

Fig. 7. APC Resistance in Wildtype, Heterozygous and Homozygous F $V_{\text {Leiden }}$ Mice

Thrombin generation was measured in plasma from wildtype (WT), heterozygous $\left(\mathrm{FV}_{\text {Leiden }} / \mathrm{WT}\right)$ and homozygous $\left(\mathrm{FV}_{\text {Leiden }} / \mathrm{FV}_{\text {Leiden }}\right) \mathrm{FV}_{\text {Leiden }}$ mice at $33^{\circ} \mathrm{C}$ in the absence and presence of $5 \mathrm{nM}$ human APC in $60 \mu \mathrm{L}$ reaction mixtures containing $20 \mu \mathrm{L}$ mouse plasma, $6 \mathrm{pM}$ hrTF, $8.2 \mathrm{mM} \mathrm{CaCl}_{2}, 60$ $\mu \mathrm{M}$ phospholipids and $0.42 \mathrm{mM}$ fluorogenic substrate. The nAPCsr was calculated as described under Materials \& Methods. Solid lines indicate the mean nAPCsr.

\section{Thrombin Generation in Platelet-rich Mouse Plasma}

Thrombin generation under the modified conditions $\left(1: 3\right.$ diluted plasma, $\left.33^{\circ} \mathrm{C}\right)$ was measured in the presence of platelets (mouse PRP) without phospholipids added. Reliable thrombin generation curves were obtained at a final platelet concentration of $100 \times 10^{9} / \mathrm{L}$ after triggering coagulation with $2.5 \mathrm{pM} \mathrm{hrTF}$ in the presence of $8.2 \mathrm{mM}$ of $\mathrm{CaCl}_{2}$ (Fig. 8). Thrombin formation was plateletdependent since under these conditions no thrombin was generated in PFP (data not shown). The peak height of the thrombin generation curve $(\sim 100 \mathrm{nM}$ thrombin) was twice as high as that reported by Leon et al. ${ }^{20}$ who measured thrombin generation in mouse PRP triggered with $\sim 0.7 \mathrm{pM}$ hrTF $(1: 12,000$ dilution of Innovin) at $300 \times 10^{9}$ platelets/L. In our hands, a higher platelet count in the assay mixture resulted in a further increase of the peak height but also induced scattering (data not shown). 
Summary of the Methodology for Measurement of Thrombin Generation via CAT in Mouse Plasma

Thrombin generation in mouse PFP: $20 \mu \mathrm{L}$ PFP is mixed with $20 \mu \mathrm{L}$ $\mathrm{hrTF} /$ phospholipid mixture in buffer $\mathrm{A}$ and thrombin generation is initiated at $33^{\circ} \mathrm{C}$ with $20 \mu \mathrm{L}$ fluorogenic substrate $/ \mathrm{CaCl}_{2}$ mixture. Final concentrations: $33.3 \%$ mouse PFP, $6 \mathrm{pM}$ hrTF, $60 \mu \mathrm{M}$ phospholipid, $8.2 \mathrm{mM} \mathrm{CaCl}_{2}$ and 0.42 $\mathrm{mM}$ fluorogenic substrate. Comparable thrombin generation curves were obtained when coagulation was triggered with 5 times concentrated PPPReagent LOW yielding final concentrations of $5 \mathrm{pM} \mathrm{TF}$ and $20 \mu \mathrm{M}$ phospholipid.

Thrombin generation in mouse PRP: $20 \mu \mathrm{L}$ PRP is mixed with $20 \mu \mathrm{L}$ hrTF in buffer $\mathrm{A}$ and thrombin generation is initiated at $33^{\circ} \mathrm{C}$ with $20 \mu \mathrm{L}$ fluorogenic substrate $/ \mathrm{CaCl}_{2}$ mixture. Final concentrations: $33.3 \%$ mouse PRP, $100 \times 10^{9} / \mathrm{L}$ platelets, $2.5 \mathrm{pM}$ hrTF, $8.2 \mathrm{mM} \mathrm{CaCl}_{2}$ and $0.42 \mathrm{mM}$ fluorogenic substrate.

Thrombin generation-based APC resistance test in mouse PFP: $20 \mu \mathrm{L}$ PFP is mixed with $10 \mu \mathrm{L} \mathrm{hrTF/phospholipid} \mathrm{mixture} \mathrm{in} \mathrm{buffer} \mathrm{A} \mathrm{and} 10 \mu \mathrm{L}$ human APC or buffer A and thrombin generation is initiated at $33^{\circ} \mathrm{C}$ with $20 \mu \mathrm{L}$ fluorogenic substrate $/ \mathrm{CaCl}_{2}$ mixture. Final concentrations: $33.3 \%$ mouse PFP, 6 pM hrTF, $60 \mu \mathrm{M}$ phospholipid, $8.2 \mathrm{mM} \mathrm{CaCl}_{2}$ and $0.42 \mathrm{mM}$ fluorogenic substrate \pm 4 nM human APC.

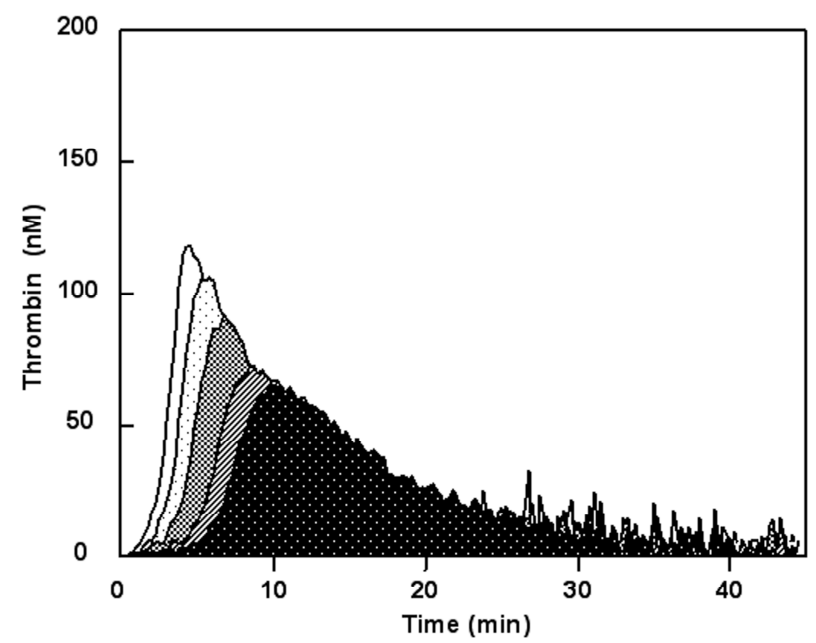

Fig. 8. Effect of Varying Tissue Factor Concentration on Thrombin Generation in Platelet-rich Mouse Plasma Thrombin generation was initiated by: $\because 0.5 ; \dddot{W} 1$; $\mathbb{R Q 8} 2.5 ; \cdots 5$ and $\square 10$ $\mathrm{pM}$ hrTF at $33^{\circ} \mathrm{C}$ in reaction mixtures containing $8.2 \mathrm{mM}$ $\mathrm{CaCl}_{2}, 0.42 \mathrm{mM}$ fluorogenic substrate and 33\% PRP (final platelet count $100 \times 10^{9} / \mathrm{L}$ ). 


\section{Discussion}

Use of mouse models is widespread in thrombosis research. ${ }^{21,22}$ However, a limited number of assays are available for overall evaluation of the coagulation system in mouse plasma. Here we describe the development of a thrombin generation assay in platelet-free and platelet-rich mouse plasma using CAT. Additionally, we have developed a thrombin generation-based test, which enables evaluation of APC resistance and the function of the protein $\mathrm{C}$ system in mice.

For reliable measurement of thrombin generation in the presence of an inhibitor (e.g. an anticoagulant drug or APC) it is essential that substantial amounts of thrombin are formed in the absence of inhibitor. The conditions for thrombography developed for human plasma yielded in mouse plasma low thrombin generation curves at the trigger usually employed in human plasma (1 pM TF, Fig. 1A) and extremely short lag times at higher trigger concentrations (5, 13.6 and $20 \mathrm{pM} \mathrm{TF}$, Fig. 1B,C,D) which made it impossible to reliably calculate the ETP. The low thrombin generation can be explained by a high activity of naturally occurring coagulation inhibitors (e.g. antithrombin) present in mouse plasma which results in much faster inhibition of thrombin in mouse than in human plasma (Fig. 2). Since the amount of free (measurable) thrombin present at any time point in plasma is the resultant of the amounts of thrombin formed and inhibited, an increase of the ETP may be achieved either by increasing the rate of thrombin formation or slowing down its inhibition. Increasing thrombin formation by increasing the coagulation trigger proved unsuitable since lag times in murine plasma became too short to reliably calculate the ETP (Fig. 1B,C,D). A decrease of thrombin inhibition was achieved by lowering the reaction temperature to $33^{\circ} \mathrm{C}$ and measuring thrombin generation at a higher plasma dilution. This resulted in sufficiently long lag times and large amounts of thrombin formed (cf. Fig. 3). It is interesting to note that plasma dilution, which decreases the amount of prothrombin available for activation, is accompanied with an increase of the ETP (Fig. 3A). This is explained by the observation that at low TF concentrations the percentage of prothrombin that is activated during thrombin generation increases upon plasma dilution presumably due to reduced inhibition of TF-FVIIa and FXa-FVa by TFPI and antithrombin, respectively (unpublished observations). Since dilution of plasma also results in a proportionally slower inhibition of thrombin by plasma protease inhibitors (e.g. antithrombin), the ETP, which is defined as the time integral of thrombin (thrombin formed $\mathrm{x}$ time it is active) is increased when plasma is diluted. 
Generally, conditions of a thrombin generation-based APC resistance test for human plasma are adjusted in such a way that added APC inhibits thrombin generation in HPNP $\sim 90 \%$. This provides a wide range for evaluation of an individual's resistance to APC: from plasmas more sensitive than HPNP (thrombin generation is inhibited $>90 \%$ by APC) to a 10 times higher resistance to APC than HPNP (no inhibition of thrombin generation by APC).

However, in agreement with previous reports, ${ }^{23,24}$ a relatively low susceptibility of thrombin generation in mouse plasma to human APC was observed. To avoid using high amounts of APC we have optimized the assay conditions to improve the efficacy of APC. As expected, increasing phospholipid concentration enhanced the activity of APC, while thrombin generation in the absence of APC was not affected up to $60 \mu \mathrm{M}$ phospholipids (Fig. 5). The low affinity of APC for negatively charged phospholipids ${ }^{25}$ can account for the increasing efficacy of APC at higher phospholipid concentrations. ${ }^{19,26}$ Furthermore, the concentration of $\mathrm{Ca}^{2+}$ in the assay was changed. Since APC-catalyzed inactivation of factor $\mathrm{Va}$ has a sharp $\mathrm{Ca}^{2+}$ optimum and is inhibited at high $\mathrm{Ca}^{2+}$ concentrations, ${ }^{27}$ the 2-fold reduction of the amount of plasma used in the assay which caused a proportional decrease of sodium citrate concentration likely resulted in an excess of $\mathrm{Ca}^{2+}$ and subsequent inhibition of APC. Lowering $\mathrm{CaCl}_{2}$ concentration two-fold greatly increased sensitivity to APC and enabled inhibition of thrombin generation by $90 \%$ with APC amounts, comparable to those used in the thrombin generation-based APC resistance test in human plasma. ${ }^{18,19}$

We have demonstrated that APC resistance in mouse plasma can be assessed by evaluation of the effect of human APC on thrombin generation triggered with human recombinant TF (Fig. 6). Human and mouse APC showed a similar efficacy to down-regulate thrombin generation in mouse plasma triggered with either hrTF or mouse thromboplastin (data not shown), which confirms that human TF is fully functional in murine factor $\mathrm{X}$ activation. ${ }^{28}$

The thrombin generation-based APC resistance test showed a differentially impaired response to APC in plasma of $\mathrm{FV}_{\text {Leiden }}$ heterozygous and homozygous mice as compared to wild-type mice (Fig. 7). Thus, the newly developed assay allows evaluating (dys)function of the protein $\mathrm{C}$ system in mouse. It should be emphasised, however, that possible species specificity in the regulation of the protein $\mathrm{C}$ system should be taken in account. In human plasma APC resistance is not only caused by $\mathrm{FV}_{\text {Leiden, }}$, but is also associated with elevated plasma levels of the procoagulant proteins prothrombin ${ }^{29}$ and factor VIII ${ }^{30}$ or decreased levels of anticoagulant proteins protein $\mathrm{S}$ and TFPI, ${ }^{31}$ conditions that have been shown to be associated with an increased risk for 
VTE in humans. ${ }^{32,33}$ Although, there are limited data available on the modulation of the protein $\mathrm{C}$ system in mouse, ${ }^{3,4}$ the variation of the nAPCsr in mice with the same genetic background ( $\mathrm{FV}$ or $\mathrm{FV}_{\text {Leiden }}$ ) shows that, like in humans, other factors (e.g. sex and age) contribute to the level of APC resistance.

We believe that the assays described here may become a useful tool in the evaluation of the overall state of the coagulation system and of the function of the protein $\mathrm{C}$ pathway in mouse plasma. 


\section{References}

1. Rosendaal FR. Venous thrombosis: a multicausal disease. Lancet. 1999;353:1167-1173.

2. Emeis JJ, Jirouskova M, Muchitsch EM, Shet AS, Smyth SS, Johnson GJ. A guide to murine coagulation factor structure, function, assays, and genetic alterations. J Thromb Haemost. 2007;5:670-679.

3. Yin ZF, Huang ZF, Cui J, et al. Prothrombotic phenotype of protein Z deficiency. Proc Natl Acad Sci U S A. 2000;97:6734-6738.

4. Eitzman DT, Westrick RJ, Bi X, et al. Lethal perinatal thrombosis in mice resulting from the interaction of tissue factor pathway inhibitor deficiency and factor V Leiden. Circulation. 2002;105:2139-2142.

5. Cui J, Eitzman DT, Westrick RJ, et al. Spontaneous thrombosis in mice carrying the factor V Leiden mutation. Blood. 2000;96:4222-4226.

6. Bertina RM, Koeleman BP, Koster T, et al. Mutation in blood coagulation factor V associated with resistance to activated protein C. Nature. 1994;369:64-67.

7. Franco RF, Reitsma PH. Genetic risk factors of venous thrombosis. Hum Genet. 2001;109:369-384.

8. Dahlback B, Carlsson M, Svensson PJ. Familial thrombophilia due to a previously unrecognized mechanism characterized by poor anticoagulant response to activated protein C: prediction of a cofactor to activated protein C. Proc Natl Acad Sci U S A. 1993;90:10041008 .

9. Furie B, Furie BC. Thrombus formation in vivo. J Clin Invest. 2005;115:3355-3362.

10. Chantarangkul V, Clerici M, Bressi C, Giesen PL, Tripodi A. Thrombin generation assessed as endogenous thrombin potential in patients with hyper- or hypo-coagulability. Haematologica. 2003;88:547-554.

11. Al Dieri R, Peyvandi F, Santagostino E, et al. The thrombogram in rare inherited coagulation disorders: its relation to clinical bleeding. Thromb Haemost. 2002;88:576-582.

12. de Waard V, Hansen HR, Spronk HH, et al. Differential expression of tissue factor mRNA and protein expression in murine sepsis. The role of the granulocyte revisited. Thromb Haemost. 2006;95:348-353.

13. Schnell MA, Hardy C, Hawley M, Propert KJ, Wilson JM. Effect of blood collection technique in mice on clinical pathology parameters. Hum Gene Ther. 2002;13:155-161.

14. Rosing J, Tans G, Nicolaes GA, et al. Oral contraceptives and venous thrombosis: different sensitivities to activated protein $\mathrm{C}$ in women using second- and third-generation oral contraceptives. Br J Haematol. 1997;97:233-238.

15. Hemker HC, Giesen P, Al Dieri R, et al. Calibrated automated thrombin generation measurement in clotting plasma. Pathophysiol Haemost Thromb. 2003;33:4-15.

16. Brugge JM, Tans G, Rosing J, Castoldi E. Protein S levels modulate the activated protein C resistance phenotype induced by elevated prothrombin levels. Thromb Haemost. 2006;95:236-242.

17. Hemker HC, Wielders S, Kessels $\mathrm{H}$, Beguin S. Continuous registration of thrombin generation in plasma, its use for the determination of the thrombin potential. Thromb Haemost. 1993;70:617-624.

18. Brugge JM, Simioni P, Bernardi F, et al. Expression of the normal factor V allele modulates the APC resistance phenotype in heterozygous carriers of the factor V Leiden mutation. J Thromb Haemost. 2005;3:2695-2702.

19. Curvers J, Christella M, Thomassen LG, et al. Effects of (pre-)analytical variables on activated protein $\mathrm{C}$ resistance determined via a thrombin generation-based assay. Thromb Haemost. 2002;87:483-492.

20. Leon C, Ravanat C, Freund M, Cazenave JP, Gachet C. Differential involvement of the P2Y1 and $\mathrm{P} 2 \mathrm{Y} 12$ receptors in platelet procoagulant activity. Arterioscler Thromb Vasc Biol. 2003;23:1941-1947. 
21. Leadley RJ, Jr., Chi L, Rebello SS, Gagnon A. Contribution of in vivo models of thrombosis to the discovery and development of novel antithrombotic agents. J Pharmacol Toxicol Methods. 2000;43:101-116.

22. Dorffler-Melly J, Schwarte LA, Ince C, Levi M. Mouse models of focal arterial and venous thrombosis. Basic Res Cardiol. 2000;95:503-509.

23. Katsuura Y, Mochizuki T, Tamura M, et al. Species specificity of anticoagulant activity of activated human protein $\mathrm{C}$ : involvement of factor $\mathrm{V}$ as well as protein $\mathrm{S}$. Thromb Res. 1996;82:147-157.

24. Yang TL, Cui J, Rehumtulla A, et al. The structure and function of murine factor V and its inactivation by protein C. Blood. 1998;91:4593-4599.

25. Nelsestuen GL, Kisiel W, Di Scipio RG. Interaction of vitamin K dependent proteins with membranes. Biochemistry. 1978;17:2134-2138.

26. Smirnov MD, Esmon CT. Phosphatidylethanolamine incorporation into vesicles selectively enhances factor Va inactivation by activated protein C. J Biol Chem. 1994;269:816-819.

27. Bakker HM, Tans G, Janssen-Claessen T, et al. The effect of phospholipids, calcium ions and protein $\mathrm{S}$ on rate constants of human factor $\mathrm{Va}$ inactivation by activated human protein $\mathrm{C}$. Eur J Biochem. 1992;208:171-178.

28. Petersen LC, Norby PL, Branner S, et al. Characterization of recombinant murine factor VIIa and recombinant murine tissue factor: a human-murine species compatibility study. Thromb Res. 2005;116:75-85.

29. Tripodi A, Chantarangkul V, Mannucci PM. Hyperprothrombinemia may result in scquired activated protein C reistance. Blood. 2000;96:3295-3296.

30. Laffan MA, Manning R. The influence of factor VIII on measurement of activated protein C resistance. Blood Coagul Fibrinolysis. 1996;7:761-765.

31. de Visser MC, van Hylckama Vlieg A, Tans G, et al. Determinants of the APTT- and ETPbased APC sensitivity tests. J Thromb Haemost. 2005;3:1488-1494.

32. de Visser MC, Rosendaal FR, Bertina RM. A reduced sensitivity for activated protein C in the absence of factor $\mathrm{V}$ Leiden increases the risk of venous thrombosis. Blood. 1999;93:1271-1276.

33. Tans G, van Hylckama Vlieg A, Thomassen MC, et al. Activated protein C resistance determined with a thrombin generation-based test predicts for venous thrombosis in men and women. Br J Haematol. 2003;122:465-470. 



\section{Chapter 6}

\section{Pregnancy-associated Changes in the Haemostatic System in Wild-type and}

Factor $V_{\text {Leiden }}$ Mice

S.N. Tchaikovski, B.J.M. van Vlijmen, A.C.A. Cleuren, M.C.L.G.D. Thomassen, V. Tchaikovski, G. Tans, J. Rosing 


\section{Summary}

Background: Pregnancy, oral contraceptive use and hormone replacement therapy are established risk factors for venous thrombosis. Acquired resistance to activated protein C (APC) has been proposed to contribute to the increased thrombosis risk. Mouse models are often used for preclinical testing of newly developed hormone preparations. However, it is not known whether hormoneinduced APC resistance is also observed in laboratory animals.

Objectives: To investigate whether hormonal changes modulate APC resistance in mice, we used pregnant mice as a model of hormone-induced APC resistance. The effect of pregnancy on APC resistance was studied in wild type and factor $\mathrm{V}_{\text {Leiden }}$ mice.

Methods: APC resistance was determined in mouse plasma using a thrombin generation-based APC resistance test. APC resistance determinants, i.e. prothrombin, factor $\mathrm{V}$, factor $\mathrm{X}$, antithrombin and protein $\mathrm{S}$ levels, and of TFPI activity were evaluated in plasma from non-pregnant and pregnant mice.

Results: In contrast to humans, pregnancy induced a decrease in APC resistance in wild type and in factor $\mathrm{V}_{\text {Leiden }}$ mice. Pregnant mice had higher levels of prothrombin, factor $\mathrm{V}$, factor $\mathrm{X}$, protein $\mathrm{S}$ and TFPI activity as compared to nonpregnant mice.

Conclusions: Pregnancy causes a decrease in APC resistance in mice, which can be explained by the elevation of protein S levels and increased TFPI activity in plasma. Our findings show species specificity in the effects of pregnancy on the major determinants of the protein $\mathrm{C}$ system and suggest that protein $\mathrm{S}$ and TFPI play an important role in the development of pregnancy-induced APC resistance in humans. 


\section{Introduction}

Pregnancy, oral contraceptive (OC) use and hormone replacement therapy (HRT) are associated with an increased risk of venous thromboembolism (VTE). Pregnant women are exposed to an $\sim 4$ times higher risk of VTE than nonpregnant women, ${ }^{1}$ whereas OC use or HRT increase the thrombosis risk 2- to 6fold or 2- to 4-fold, respectively. ${ }^{2}$

Elevation of endogenous hormones (pregnancy) or administration of exogenous hormones (OC, HRT) are accompanied by changes of the plasma concentrations of almost all coagulation factors and anticoagulant proteins. ${ }^{3-5}$ Some of these changes are believed to affect the efficacy of the activated protein C (APC) system and thereby cause APC resistance. APC resistance was originally described to be associated with a point mutation in the factor $\mathrm{V}$ gene $\left(\mathrm{FV}_{\text {Leiden }}\right)$, which renders activated factor $\mathrm{V}$ less susceptible to inactivation by APC. ${ }^{6}$ Later, APC resistance was also shown to occur in the absence of $\mathrm{FV}_{\text {Leiden }}$ and to be associated with increased plasma levels of procoagulant proteins (prothrombin ${ }^{7}$ and factor VIII ${ }^{8}$ ) or decreased levels of anticoagulant proteins (protein S and TFPI ${ }^{5,9}$ ). Hormone-induced APC resistance is even more pronounced in the presence of the $\mathrm{FV}_{\text {Leiden }}$ mutation. ${ }^{10} \mathrm{APC}$ resistance can be assessed either with a thrombin generation-based or with an activated partial thromboplastin time (aPTT)-based APC resistance test. Both tests predict the risk of VTE ${ }^{8,11}$ but the aPTT-based test has been shown to be less sensitive to hormone-induced APC resistance than the thrombin generation-based test. ${ }^{10}$

Whereas mouse models are widely used for preclinical investigation of rather complex in vivo effects of newly developed compounds of OC and HRT, there are little data available on hormone-induced changes in the mouse coagulation system. Thus, it is not known whether in mice hormones modulate the plasma levels of coagulation factors in a similar way to what is observed in humans and whether these changes induce APC resistance.

Since pregnancy is an established natural cause of hormone-induced APC resistance in humans, ${ }^{12,13}$ and the changes in the coagulation proteins during pregnancy are rather pronounced, we investigated the effect of pregnancy on APC resistance and on the plasma levels of the major determinants of the APC sensitivity ratio (APCsr) that are known from human studies, ${ }^{5,9}$ such as prothrombin, factor $\mathrm{V}$, factor $\mathrm{X}$, antithrombin, protein $\mathrm{S}$ and TFPI. In addition, we studied the effect of pregnancy on APC resistance in $\mathrm{FV}_{\text {Leiden }}$ mice. 


\section{Materials \& Methods}

\section{Materials}

Ecarin was purchased from Pentapharm Ltd, Basel, Switzerland. RVV-X was purified from the crude venom of Russell's viper by the method of Schiffman et al. ${ }^{14}$ Mouse proteins were a gift of Dr. H. Spronk (Maastricht University, the Netherlands). Mouse tissue factor (TF) activity is given in units, where $1 \mathrm{U}$ equals the activity of $1 \mathrm{pM}$ human recombinant TF (Dade Innovin, Marburg, Germany) in bovine factor $\mathrm{X}$ activation with human recombinant factor VIIa. ${ }^{15}$ Human prothrombin, ${ }^{16}$ human factor $\mathrm{Va}{ }^{17}$ and bovine factor $\mathrm{Xa}{ }^{18,19}$ were prepared as previously described. Corn trypsin inhibitor (CTI) was purchased from Haematologic Technologies Inc., Essex Junction, VT, USA. rProtein A Sepharose ${ }^{\mathrm{TM}}$ Fast Flow was purchased from GE Healthcare, Uppsala, Sweden. The chromogenic thrombin substrate D-phenylalanyl-L-pipecolyl-L-arginine-pnitroanilide (S2238) was from Chromogenix, Milano, Italy and the fluorogenic thrombin substrate Z-Gly-Gly-Arg-AMC from Bachem, Bubendorf, Switzerland. A phospholipid emulsion composed of a mixture of phosphatidylcholine, phosphatidylserine and sphingomyelin was provided by Rossix, Mölndal, Sweden. 1,2-dioleoyl-sn-glycero-3-phosphoserine (DOPS), 1,2-dioleoyl-snglycero-3-phosphoethanolamine (DOPE), 1,2-dioleoyl-sn-glycero-3phosphatidylcholine (DOPC), bovine brain phosphatidylserine (PS) and egg-yolk phosphatidylcholine (PC) were from Avanti Polar Lipids, Alabaster, AL, USA. DOPS/DOPE/DOPC, 20/20/60, M/M/M and PS/PC, 10/90, M/M vesicles were prepared as described before. ${ }^{10}$

\section{Animals}

Wild type (WT) non-pregnant ( $\mathrm{n}=17$, age 10 weeks) and 14-15 days pregnant ( $\mathrm{n}=14$, age 10 weeks) C57BL/6 mice were purchased from Charles River Laboratories Inc., Wilmington, MA, USA. Mice carrying the $\mathrm{FV}_{\text {Leiden }}$ mutation (Arg 504 to Gln) were described previously by Cui et al. ${ }^{20}$ Factor V R504Q mice were backcrossed to C57BL/6J mice (Jackson Labs, Bar Harbor, ME, USA) for at least 8 generations (N8), and $\mathrm{N} 8$ heterozygous mice were intercrossed to produce homozygous mice. The $\mathrm{FV}_{\text {Leiden }}$ genotype was confirmed by PCR analysis of tail DNA. 15 non-pregnant (8-10 weeks of age) and 14 pregnant 1415 days (8-10 weeks of age) $\mathrm{FV}_{\text {Leiden }}$ homozygous mice were used in the present study. Pregnancy was confirmed visually after opening the abdominal cavity for the phlebotomy. The study was approved by the Animal Ethics committees of the Maastricht and Leiden University. 


\section{Collection and Handling of Plasma Samples}

Mouse blood was collected and platelet free plasma and pooled normal mouse plasma (PNMP) were prepared as described before. ${ }^{21}$

\section{APC Resistance}

Thrombin generation-based assay- APC resistance was assessed with a thrombin generation-based test developed for mouse plasma. ${ }^{21}$ Briefly, thrombin generation was initiated in 1:3 diluted mouse plasma by $0.6 \mathrm{U}$ mouse TF in the absence and presence of $5 \mathrm{nM}$ mouse APC and measured with calibrated automated thrombography (CAT). The APCsr was calculated as previously described. ${ }^{21}$

The aPTT-based APC resistance test was performed with Coatest ${ }^{\circledR} \mathrm{APC}^{\mathrm{TM}}$ Resistance kit (Chromogenix, Lexington, MA, USA) according to the manufacturer's instructions with minor modifications.

\section{Measurement of Plasma Factor Levels}

Prothrombin concentrations- Prothrombin levels were determined after complete activation of prothrombin present in a 750-fold dilution of mouse plasma in buffer A ( $25 \mathrm{mM}$ Hepes $\mathrm{pH} 7.7$ at room temperature, $175 \mathrm{mM} \mathrm{NaCl}$ ) containing $5 \mathrm{~g} / \mathrm{L}$ BSA with Ecarin (final concentration $0.75 \mathrm{U} / \mathrm{mL}$ ). The reaction was performed at $37^{\circ} \mathrm{C}$ and stopped after $8 \mathrm{~min}$ by addition of ice-cold buffer B ( 25 $\mathrm{mM}$ Hepes pH 7.9 at room temperature, $175 \mathrm{mM} \mathrm{NaCl}, 60 \mathrm{mM}$ EDTA and 0.5 $\mathrm{g} / \mathrm{L}$ ovalbumin). The amidolytic activity of thrombin was subsequently determined at $37^{\circ} \mathrm{C}$ using the chromogenic substrate S2238.

Factor $V$ quantification- Factor $\mathrm{V}$ was activated with $2.5 \mathrm{nM}$ human thrombin in mouse plasma diluted 2000-fold in buffer A containing $5 \mathrm{~g} / \mathrm{L}$ BSA and $5 \mathrm{mM} \mathrm{CaCl}$ during $10 \mathrm{~min}$ at $37{ }^{\circ} \mathrm{C}$. Factor $\mathrm{Va}$ cofactor activity was assessed in factor Xa-catalyzed prothrombin activation at conditions at which rates of prothrombin activation were linearly dependent on factor $\mathrm{Va}$ and the concentrations of bovine factor $\mathrm{Xa}$, human prothrombin and phospholipid vesicles $(\mathrm{PS} / \mathrm{PC}, 10 / 90, \mathrm{M} / \mathrm{M})$ were saturating.

Factor X quantification- Factor X was activated with $0.8 \mu \mathrm{g} / \mathrm{mL}$ RVV-X in mouse plasma diluted 800 -fold in buffer A containing $5 \mathrm{~g} / \mathrm{L}$ BSA and $5 \mathrm{mM}$ $\mathrm{CaCl}_{2}$ during $5 \mathrm{~min}$ at $37^{\circ} \mathrm{C}$. Activation was stopped by addition of $8 \mathrm{mM}$ EDTA. Levels of factor $\mathrm{Xa}$ were determined in factor Xa-mediated prothrombin activation at saturating concentrations of human factor $\mathrm{Va}$, human prothrombin and phospholipid vesicles (PS/PC, 10/90, M/M) and limiting amounts of factor Xa. 
Antithrombin concentrations in mouse plasma were measured with the Coamatic ${ }^{\circledR}$ antithrombin kit (Chromogenix, Milano, Italy) according to the manufacturer's recommendations. Prothrombin, antithrombin, factor V and factor $\mathrm{X}$ concentrations were expressed as $\mathrm{U} / \mathrm{mL}$, where $1 \mathrm{U}$ is the amount present in 1 $\mathrm{mL}$ of PNMP.

\section{TFPI Activity}

Tissue factor pathway inhibitor (TFPI) activity was estimated by quantifying the effect of polyclonal rabbit affinity purified anti-mouse TFPI antibody (American Diagnostica, Stamford, CT, USA) on thrombin generation. Thrombin generation was initiated in $60 \mu \mathrm{L}$ reaction mixtures containing $20 \mu \mathrm{L}$ mouse plasma, $0.05 \mathrm{U}$ mouse thromboplastin, $0.04 \mathrm{~g} / \mathrm{L}$ CTI, $30 \mu \mathrm{M}$ DOPS/DOPE/DOPC vesicles $(20 / 20 / 60, \mathrm{M} / \mathrm{M} / \mathrm{M})$ and $8 \mathrm{mM} \mathrm{CaCl}_{2}$. Thrombin generation was measured with CAT in the presence of varying amounts of anti-mouse TFPI antibody $(0,1,2,4$, 8,16 and $18.3 \mu \mathrm{L}$ ). The increase of the maximum thrombin formed (the peak height of thrombin generation) induced by addition of anti-TFPI antibody as compared to the measurement in the absence of the antibody was used as a measure for the TFPI activity in plasma (see also results and the legend to Fig. 3). The antibody was dialysed against buffer $\mathrm{A}$ at $4{ }^{\circ} \mathrm{C}$ prior to use in the experiments and the dialysis buffer was used as a control.

\section{Immunoprecipitation and Western Blotting}

Plasma samples $(52 \mu \mathrm{L})$ were diluted 1:7 in buffer A and pre-treated with $12 \%$ rProtein A Sepharose ${ }^{\mathrm{TM}}$ for 1 hour at $4{ }^{\circ} \mathrm{C}$ to remove non-specific binding material. For immunoprecipitation samples were incubated with $0.2 \mathrm{mg} / \mathrm{mL}$ polyclonal antibody directed against human protein S (DAKO, Glostrup, Denmark) for 16 hours at $4{ }^{\circ} \mathrm{C}$. The resulting immune complexes were isolated with $16 \%$ rProtein A Sepharose ${ }^{\mathrm{TM}}$ (1 hour at $\left.4{ }^{\circ} \mathrm{C}\right)$. Beads with attached immunoprecipitate were collected by centrifugation at $21000 \mathrm{xg}$ for 2 minutes at $4{ }^{\circ} \mathrm{C}$ and washed 4 times with buffer A. Immune complexes were eluted from rProtein A Sepharose ${ }^{\mathrm{TM}}$ beads with SDS-PAGE loading buffer ( $8 \mathrm{mM}$ Tris-HCl, $0.6 \%$ SDS, $10 \%$ Glycerol, $1.25 \% \beta$-mercaptoethanol, $0.1 \%$ bromophenol blue) and boiled for $4 \mathrm{~min}$. Eluates were subjected to SDS-PAGE and subsequently transferred to a PVDF membrane. The membrane was blocked for 2 hours in buffer A containing 5\% non-fat dry milk (Merck, Darmstadt, Germany) and incubated with primary polyclonal antibody directed against the C-terminus of human protein S (C-17, Santa Cruz Biotechnology Inc., 1:150 diluted in blocking buffer) for 16 hours at $4{ }^{\circ} \mathrm{C}$. The membrane was washed 3 times in washing buffer (buffer A containing $0.1 \%$ Tween). The secondary antibody (HRP-labelled 
bovine anti-goat, Santa Cruz Biotechnology Inc.) was then added at 1:2000 dilution in blocking buffer and incubated for $60 \mathrm{~min}$ at room temperature. After 4 washing steps the antigen was visualised using the enhanced chemiluminescent procedure (Pierce, Rochford, IL; USA) according to the manufacturer's instructions. Images were captured utilizing a luminescent scanning image analyzer LAS-3000, FujiFilm. Thereafter, quantitative analysis of the negative images and 2D-densitometry was performed using Advanced Image Data Analyzer (Raytest, Sprockhövel, Germany).

All measurements were performed in duplicate.

\section{Statistical Analysis}

Statistical analysis was performed using SPSS 11.0 for Windows (SPSS, Chicago, IL, USA). Due to the small sample size, data were analyzed with the Kruskal-Wallis H-test and the Mann-Whitney U-test was used as a post-hoc test. Significance level was $\mathrm{p} \leq 0.05$, with the exception of post-hoc Bonferroni correction $(\alpha / \mathrm{n})$ for multiple comparisons. Data are given as mean and 95\% confidence interval.

\section{Results}

\section{APC Resistance Tests}

In order to explore APC resistance changes during pregnancy in $\mathrm{WT}$ and $\mathrm{FV}_{\text {Leiden }}$ mice, thrombin generation was measured in mouse plasma in the absence and in the presence of APC and the APCsrs were calculated as described elsewhere. ${ }^{21}$ In accordance with an earlier report, ${ }^{21}$ non-pregnant $\mathrm{FV}_{\text {Leiden }}$ mice were considerably more resistant to APC observed in humans, ${ }^{12}$ WT pregnant mice were more sensitive to APC than non-pregnant mice (Fig. 1, Table 1, p<0.01). In $\mathrm{FV}_{\text {Leiden }}$ mice, the APCsr was also lower in pregnant mice than in non-pregnant mice (Fig. 1, Table 1, p<0.001).

We also determined the effect of APC on the aPTT in pooled plasma samples of non-pregnant and pregnant $\mathrm{WT}$ and $\mathrm{FV}_{\text {Leiden }}$ mice. Consistent with a previous report, ${ }^{20} \mathrm{FV}_{\text {Leiden }}$ mice were more resistant to APC than WT mice. However, pregnancy had no effect on the aPTT-based APCsr either in WT or in $\mathrm{FV}_{\text {Leiden }}$ mice (data not shown). 
Fig. 1. Effect of Pregnancy on the APCsr

Thrombin generation was measured by $\mathrm{CAT}$ at $33^{\circ} \mathrm{C}$ in $60 \mu \mathrm{L}$ reaction mixtures containing $20 \mu \mathrm{L}$ mouse plasma, 0.6 U mouse thromboplastin, $30 \mu \mathrm{M}$ phospholipids, $0.42 \mathrm{mM}$ fluorogenic substrate and $8 \mathrm{mM}$ $\mathrm{CaCl}_{2}$ in the absence and in the presence of $5 \mathrm{nM}$ mouse APC (all final concentrations). The APCsr, calculated as previously described, ${ }^{21}$ was determined in non-pregnant wild-type (WT) mice $(\mathrm{O} ; \mathrm{n}=17)$, pregnant WT mice $(\mathbf{O} ; \mathrm{n}=14)$, nonpregnant $\mathrm{FV}_{\text {Leiden }}(\mathrm{FVL})$ mice $(\diamond$; $\mathrm{n}=15)$ and pregnant $\mathrm{FV}_{\text {Leiden }}$ mice $(\diamond ; n=14)$. Solid lines represent average of the group.

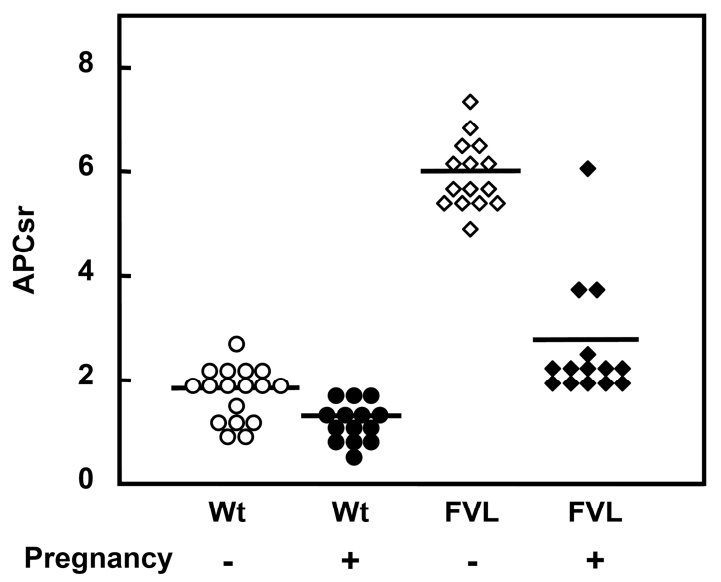

Table 1 Effect of Pregnancy on Haemostatic Parameters in Mouse Plasma

\begin{tabular}{|l|c|c|c|c|}
\hline \multirow{2}{*}{ APCsr } & \multicolumn{2}{|c|}{ WT } & \multicolumn{2}{c|}{ FV $_{\text {Leiden }}$} \\
\cline { 2 - 5 } & non-pregnant & pregnant & non-pregnant & pregnant \\
\hline \multirow{2}{*}{ Prothrombin } & $\begin{array}{c}1.84 \\
(1.56 \text { to } 2.11)\end{array}$ & $\begin{array}{c}1.30 \\
(1.07 \text { to } 1.54)\end{array}$ & $\begin{array}{c}6.02 \\
(5.65 \text { to } 6.38)\end{array}$ & $\begin{array}{c}2.76 \\
\text { (2.11 to } 3.41)\end{array}$ \\
\hline \multirow{2}{*}{ Factor V } & 0.86 & 1.31 & 0.82 & 1.25 \\
$(0.83$ to 0.89$)$ & $(1.24$ to 1.37$)$ & $(0.79$ to 0.85$)$ & (1.17 to 1.33$)$ \\
\hline \multirow{2}{*}{ Factor X } & 0.93 & 1.95 & 0.74 & 1.30 \\
& $(0.86$ to 0.99$)$ & $(1.80$ to 2.11$)$ & $(0.61$ to 0.86$)$ & $(1.15$ to 1.45$)$ \\
\hline \multirow{2}{*}{ Antithrombin } & 0.78 & 1.27 & 0.74 & 1.32 \\
$(0.74$ to 0.82$)$ & $(1.20$ to 1.34$)$ & $(0.69$ to 0.80$)$ & (1.23 to 1.41$)$ \\
\hline
\end{tabular}

Prothrombin, factor $\mathrm{V}$, factor $\mathrm{X}$ and antithrombin are expressed in units considering that normal mouse pooled plasma contains $1 \mathrm{unit} / \mathrm{ml}$. The APCsr is calculated as previously described. ${ }^{21}$ The data are presented as average with $95 \%$ confidence interval.

\section{Measurement of Plasma Factor Levels}

To test whether changes in the major determinants of the APCsr, established for the thrombin generation-based assay in human plasma, ${ }^{5,9}$ can explain the decrease of the APCsr in pregnant mice, we measured levels of prothrombin, factor $\mathrm{V}$, factor $\mathrm{X}$ and antithrombin in plasma of non-pregnant and pregnant WT and $\mathrm{FV}_{\text {Leiden }}$ mice. Pregnant $\mathrm{WT}$ as well as $\mathrm{FV}_{\text {Leiden }}$ mice had considerably higher plasma levels of prothrombin, factors $\mathrm{V}$ and $\mathrm{X}$ (Fig.2 A, B, C, Table 1) than their 
non-pregnant counterparts, whereas the antithrombin levels were similar in nonpregnant and pregnant mice (Fig.2 D, Table 1). The plasma levels of prothrombin, factor $\mathrm{X}$ and antithrombin did not differ between WT and $\mathrm{FV}_{\text {Leiden }}$ mice of corresponding gravidity status (Fig. 2 A, B, D, Table 1). In agreement with an earlier report, ${ }^{22}$ both non-pregnant and pregnant $\mathrm{FV}_{\text {Leiden }}$ mice had factor $\mathrm{V}$ levels that were $\sim 20 \%$ lower than in WT mice (Fig. 2 C, Table 1).
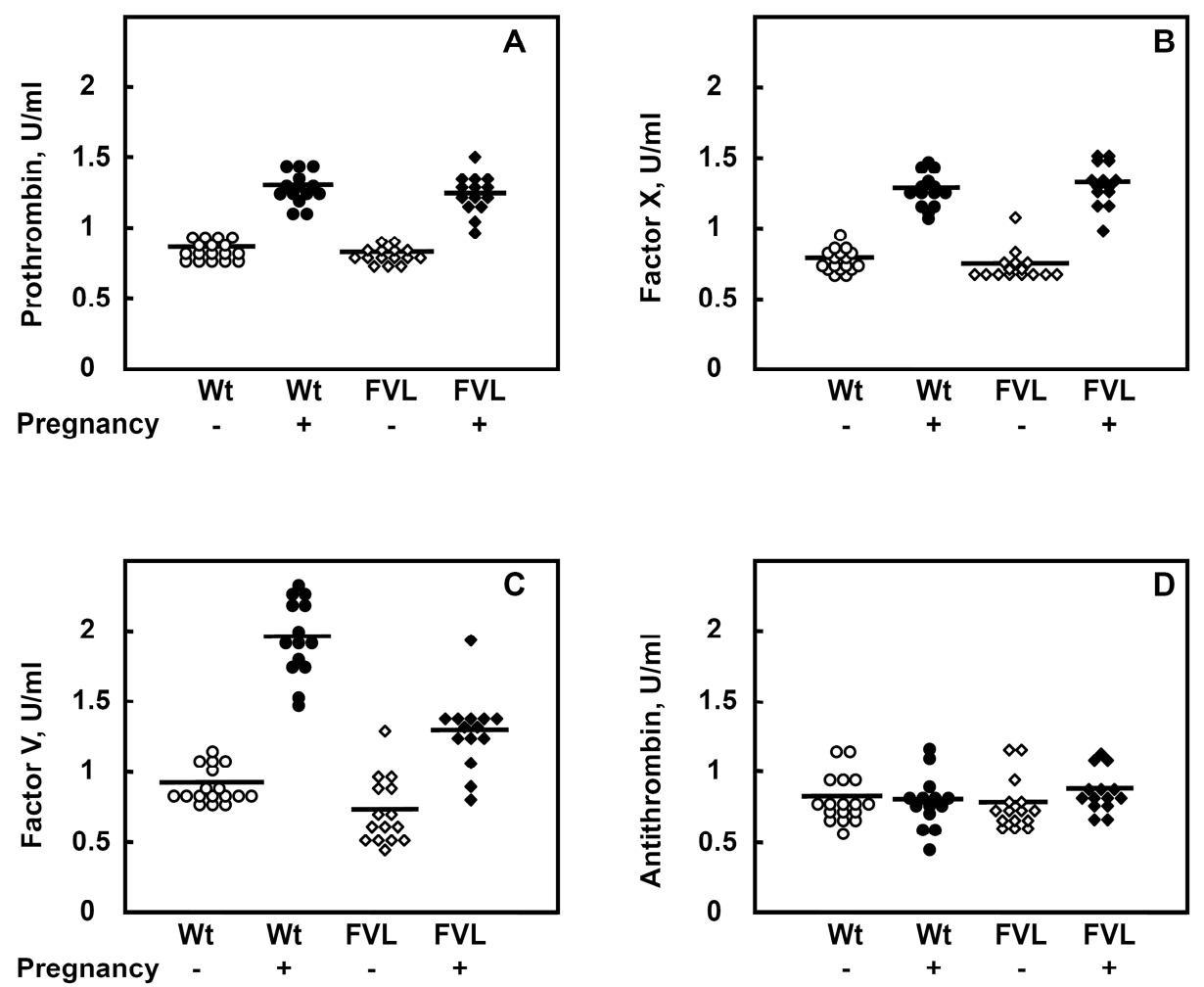

Fig. 2. Effect of Pregnancy on Selected Haemostatic Parameters

Prothrombin (panel A), factor X (panel B), factor V (panel C) and antithrombin (panel D) plasma levels were measured as described under Methods in non-pregnant wild-type (WT) mice (O; $\mathrm{n}=17)$, pregnant WT mice $(\mathbf{O} ; \mathrm{n}=14)$, non-pregnant $\mathrm{FV}_{\text {Leiden }}(\mathrm{FVL})$ mice $(\diamond ; \mathrm{n}=15)$ and pregnant $\mathrm{FV}_{\text {Leiden }}$ mice $(\diamond ; \mathrm{n}=14)$. Solid lines represent average of the group.

\section{Quantification of TFPI Activity}

Since TFPI is an important determinant of the APCsr, its activity was assessed with a thrombin generation-based assay. Thrombin generation, triggered with a low amount of mouse TF, was measured in the absence and presence of an inhibitory anti-mouse TFPI antibody. Since under these conditions thrombin 
generation is very sensitive to TFPI activity, the increase of the maximum amount of thrombin formed (the peak height of the thrombin generation curve) induced by addition of the anti-TFPI antibody is a measure for the TFPI activity in plasma (Maurissen et al., manuscript in preparation). The effect of varying amounts of anti-mouse TFPI antibody on thrombin generation was evaluated in pooled plasma samples of non-pregnant and pregnant $\mathrm{WT}$ and $\mathrm{FV}_{\text {Leiden }}$ mice. The stimulatory effect of the anti-mouse TFPI antibody was more pronounced in plasma from pregnant mice of either WT or $\mathrm{FV}_{\text {Leiden }}$ genetic background than in plasma from non-pregnant mice (Fig. 3), indicating that TFPI activity in mouse plasma is increased during pregnancy. There were no differences detected in the TFPI activity between WT and FV $\mathrm{V}_{\text {Leiden }}$ mice of a corresponding gravidity status.

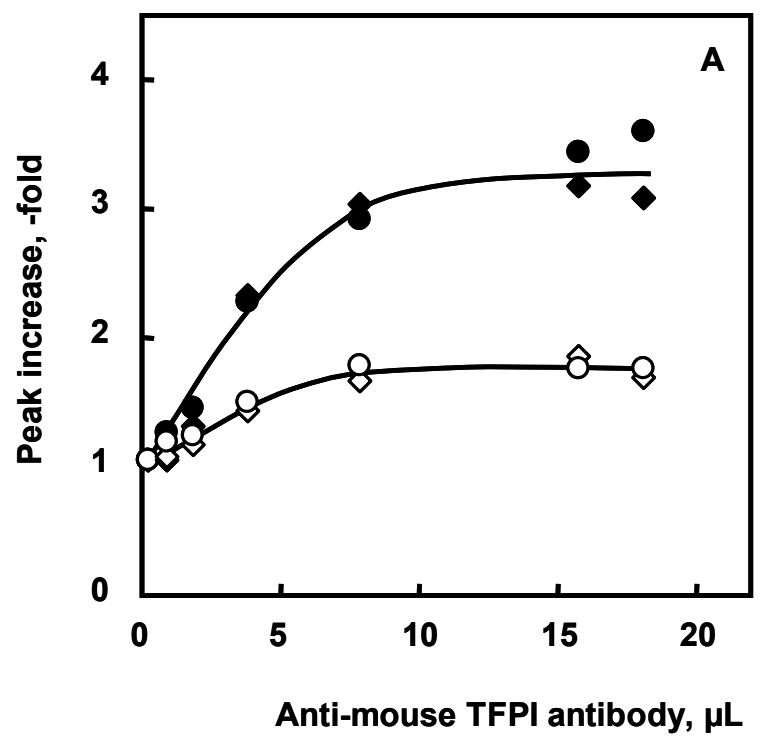

Fig. 3. Effect of Varying Amounts of Anti-mouse TFPI Antibody on Thrombin Generation in Mouse Plasma

Thrombin generation was measured at $33^{\circ} \mathrm{C}$ in $60 \mu \mathrm{L}$ reaction mixtures containing $20 \mu \mathrm{L}$ mouse plasma, $0.05 \mathrm{U}$ mouse thromboplastin, $0.04 \mathrm{~g} / \mathrm{L}$ corn trypsin inhibitor, $30 \mu \mathrm{M}$ DOPS/DOPE/DOPC, 20/20/60, M/M/M phospholipids, $0.42 \mathrm{mM}$ fluorogenic substrate and $8 \mathrm{mM} \mathrm{CaCl}_{2}$ (all final concentrations). The peak height increase (fold) of thrombin generation measured in the presence of varying amounts of anti-mouse TFPI antibody $(0,1,2,4,8,16$ and $18.3 \mu \mathrm{L})$ is presented as a function of the antibody amount present in the reaction mixture. Measurements were performed in pooled plasmas of non-pregnant WT mice $(O ; n=17)$, pregnant WT mice $(\mathbf{O} ; n=14)$, non-pregnant $\mathrm{FV}_{\text {Leiden }}$ mice $(\diamond ; \mathrm{n}=15)$ and pregnant $\mathrm{FV}_{\text {Leiden }}$ mice $(\diamond ; \mathrm{n}=14)$. Thrombin generation in the absence of anti-mouse TFPI antibody was measured in duplicate; and in the presence of varying amounts of anti-mouse TFPI antibody single measurements were performed. 


\section{Quantification of Protein S Total Antigen}

Protein $\mathrm{S}$ total antigen level was semi-quantatively assessed in pooled plasma samples of non-pregnant and pregnant WT and $\mathrm{FV}_{\text {Leiden }}$ mice using immunoprecipitation followed by Western blotting. Protein S appeared on the Western blot as a double band with a $\mathrm{Mr}$ of $\sim 75 \mathrm{kDa}$, presumably representing full length protein $\mathrm{S}$ (upper band) and thrombin-cleaved protein $\mathrm{S}$ (lower band) (Fig. 4A).

The band of $\sim 50 \mathrm{kDa}$ corresponded to the heavy chain of the precipitating immunoglobulins and was used as a loading control. The intensities of the protein $\mathrm{S}$ double band and the immunoglobulin band were expressed relative to the average intensities of the corresponding bands in the plasma samples of nonpregnant mice of the same genetic background on the same blot. The intensity of the protein $\mathrm{S}$ bands in the pooled plasma of pregnant $\mathrm{WT}$ and of pregnant $\mathrm{FV}_{\text {Leiden }}$ mice was $\sim 50 \%$ higher than in the pooled plasma of non-pregnant mice (Fig. 4B).
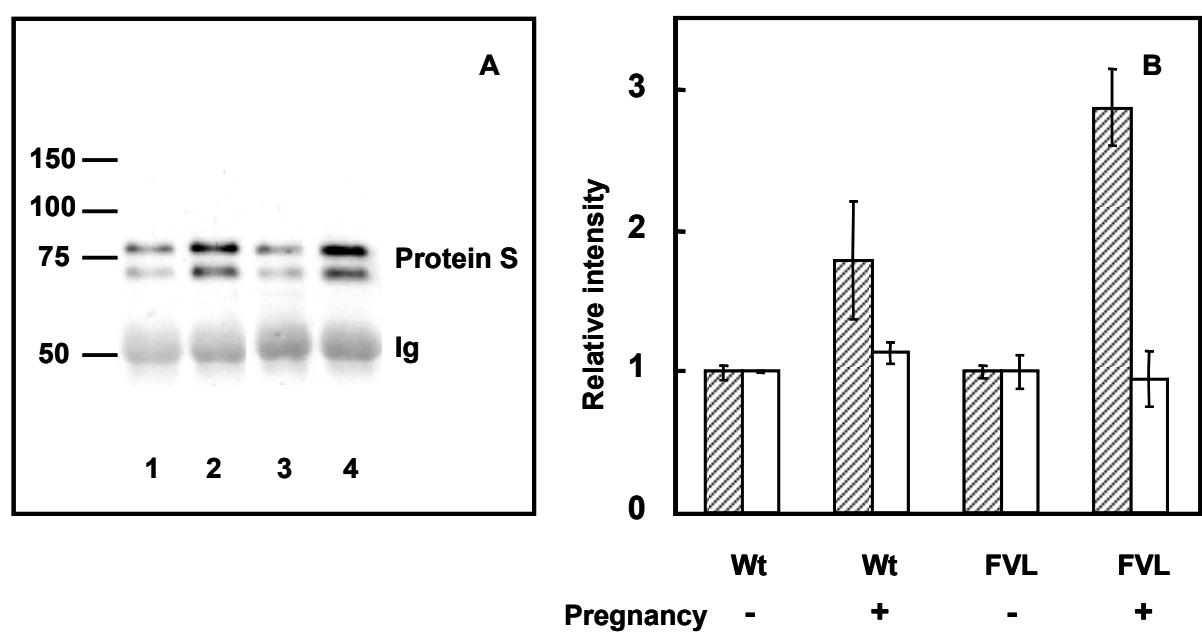

Fig. 4. Effect of Pregnancy on Plasma Protein S Total Antigen

Panel A: protein $\mathrm{S}$ was immunoprecipitated from pooled plasma samples of non-pregnant wild-type (WT) mice, $\mathrm{n}=17$ (lane 1), pregnant WT mice, $\mathrm{n}=14$ (lane 2), non-pregnant $\mathrm{FV}_{\text {Leiden }}$ (FVL) mice, $\mathrm{n}=15$ (lane 3) and pregnant $\mathrm{FV}_{\text {Leiden }}$ mice, $\mathrm{n}=14$ (lane 4). Immunoprecipitates were subjected to SDS-PAGE and Western blotting (see Materials and Methods).

Panel B: Semi-quantitive comparison of the protein S double band and immunoglobulin intensities in the plasma samples of non-pregnant and pregnant mice. The intensities of the protein $\mathrm{S}$ double band (dashed bar) and immunoglobulin (open bar) were expressed relative to the average intensities of the corresponding bands in the plasma samples of non-pregnant mice of the same genetic background on the same blot. The bars represent the average of two immunoprecipitations with the whiskers showing the two individual measurements. 


\section{Discussion}

In this study we have investigated the effect of pregnancy on APC resistance in $\mathrm{WT}$ and $\mathrm{FV}_{\text {Leiden }}$ mice. In humans, pregnancy causes a 2- to 3-fold increase in APC resistance in the thrombin generation-based assay both in the absence and presence of $\mathrm{FV}_{\text {Leiden }},{ }^{12}$ whereas much smaller effects have been reported for APC resistance determined with aPTT-based assays. ${ }^{13}$ In the current paper we show that plasmas from pregnant mice of both $\mathrm{WT}$ and $\mathrm{FV}_{\text {Leiden }}$ genetic background were not more, but less APC resistant than non-pregnant counterparts in the thrombin generation-based assay. This finding supports previous reports that demonstrated that estrogen, which induces a hypercoagulable state in women, ${ }^{2}$ has antithrombotic effects in mouse thrombosis models. ${ }^{23,24}$

Neither in WT nor in $\mathrm{FV}_{\text {Leiden }}$ mice did pregnancy have a significant effect on APCsr determined with the aPTT-based APC resistance test. The different results obtained with the aPTT- and thrombin generation-based assays are likely explained by the fact that both assays do not share the same determinants ${ }^{9}$ and that the major determinants of the thrombin generation-based assay (protein $\mathrm{S}$ and TFPI) are specifically sensitive to hormonal changes. ${ }^{5,25}$ To find an explanation for the decreased APC resistance in pregnant mice, we have determined the plasma levels of several determinants of the thrombin generationbased APCsr in plasma of non-pregnant and pregnant mice. Similar to humans, ${ }^{3}$ pregnancy in mice induced an elevation of the plasma levels of prothrombin and factor X, whereas the antithrombin concentration remained unchanged. Since the plasma levels of prothrombin and factor X correlate positively with the APCsr in humans, ${ }^{9}$ the increase in their levels cannot explain the decreased APC resistance in mice during pregnancy.

Factor $\mathrm{V}$ levels were almost twice as high in pregnant mice as in nonpregnant mice, independent of the genetic background. Since factor $\mathrm{V}$ is a negative determinant of the APCsr, ${ }^{9}$ presumably due to its anticoagulant activity, ${ }^{26}$ the elevated plasma levels of factor V can contribute to the decreased APC resistance in pregnant WT mice. However, assuming that mouse $\mathrm{FV}_{\text {Leiden, }}$, like human $\mathrm{FV}_{\text {Leiden, }}$, does not express anticoagulant activity, ${ }^{27}$ the elevated factor $\mathrm{V}$ levels cannot explain the decreased APCsr in $\mathrm{FV}_{\text {Leiden }}$ pregnant mice.

Free TFPI is a strong negative determinant of the APCsr. ${ }^{5,9}$ We evaluated TFPI activity in plasma of non-pregnant and pregnant mice with a functional assay which correlates very well with free TFPI levels (Maurissen et al., manuscript in preparation). Pregnant mice exhibited higher TFPI activity than non-pregnant mice. Although it has been reported that the TFPI activity in serum ${ }^{28}$ and plasma levels of total TFPI ${ }^{29}$ are elevated during pregnancy in humans, 
there are no data available on the changes of functional TFPI levels (free TFPI or full-length TFPI) in plasma from pregnant women. Thus, it is possible that the increased TFPI activity in plasma of pregnant mice not only results in a decreased APC resistance, but may also be partially responsible for the different effects of pregnancy on the APCsr in humans and in mice.

Another important negative determinant of the APCsr in humans is protein S. ${ }^{5,9}$ It appears that the protein $\mathrm{S}$ total antigen levels in pregnant mice are considerably higher than in non-pregnant mice (Fig. 4). This finding is in complete contrast with that observed in humans, where protein $\mathrm{S}$ total plasma levels are decreased during pregnancy. ${ }^{3}$ The pregnancy-induced decrease in the protein $\mathrm{S}$ free levels in women is even more pronounced due to an elevation of $\mathrm{C} 4 \mathrm{~b}$ binding protein (C4BP) during pregnancy. ${ }^{30}$ An elevation of the C4BP levels increases the fraction of protein $\mathrm{S}$ that forms a complex with C4BP and thereby significantly reduces protein $\mathrm{S}$ activity. ${ }^{31}$ Interestingly, mouse C4BP does not contain a $\beta$-chain and hence is not able to bind protein $\mathrm{S} .{ }^{32,33}$ As a result, all protein $S$ in mouse circulates in free active form. Thus, the increase in the total protein $\mathrm{S}$ antigen observed in plasma of pregnant mice likely leads to increased activity of protein $\mathrm{S}$ in plasma and we propose that in addition to the higher TFPI activity, the elevated protein S levels decrease APC resistance in mice during pregnancy.

It has recently been shown that the promoter of the human protein $\mathrm{S}$ gene contains a progesterone responsive element and hence can be regulated by hormones. ${ }^{34}$ The authors suggested that their finding can explain a decrease in the protein S plasma levels during pregnancy, OC use or HRT. The opposite changes in the protein $\mathrm{S}$ levels in mice during pregnancy suggest differences in the regulation of the protein $\mathrm{S}$ gene between mice and humans.

In this study we focused on known determinants of the thrombin generation-based APC resistance test in human plasma. However, it is possible that not all determinants are identified yet. For instance, although not recognised as a determinant of the APCsr, protein $Z$ levels appear to modulate the risk of VTE in humans ${ }^{35}$ and in mice ${ }^{36}$ that carry the $\mathrm{FV}_{\text {Leiden }}$ mutation. This suggests that protein $\mathrm{Z}$ and/or protein Z-dependent protease inhibitor (ZPI) might modulate APC resistance. Preliminary experiments performed in our laboratory indicate that mRNA levels of protein $\mathrm{Z}$ and ZPI are elevated in the liver of WT and $\mathrm{FV}_{\text {Leiden }}$ mice during pregnancy (data not shown); and therefore, protein $\mathrm{Z}$ and ZPI might also contribute to the decreased APC resistance in pregnant mice.

In conclusion, opposite to humans, mice become less resistant to APC during pregnancy. The pregnancy-induced decrease in the APC resistance in mice can be explained by elevated plasma levels of protein S and TFPI. Our 
findings underscore the importance of protein S and TFPI as major determinants of APCsr determined with assays in which coagulation is triggered via the TF pathway and suggest an important role of these proteins in the development of pregnancy-induced APC resistance in humans. In addition, we demonstrate that there is species specificity in the regulation of the protein $\mathrm{C}$ system and therefore the choice of an animal model in thrombosis research should be carefully considered.

\section{Acknowledgements}

We thank René van Oerle for valuable discussions and Henry Spronk for assistance in animal experiments and providing us with mouse proteins. We acknowledge Irma $\mathrm{K}$. van der Linden for technical assistance. 


\section{References}

1. Rosendaal FR. Risk factors for venous thrombotic disease. Thromb Haemost. 1999;82:610619.

2. Rosendaal FR, Helmerhorst FM, Vandenbroucke JP. Female hormones and thrombosis. Arterioscler Thromb Vasc Biol. 2002;22:201-210.

3. Franchini M. Haemostasis and pregnancy. Thromb Haemost. 2006;95:401-413.

4. Tchaikovski S, Tans G, Rosing J. Venous thrombosis and oral contraceptives: current status. Womens Health (Lond Engl). 2006;2:761-772.

5. Tchaikovski SN, van Vliet HA, Thomassen MC, et al. Effect of oral contraceptives on thrombin generation measured via calibrated automated thrombography. Thromb Haemost. 2007;98:1350-1356.

6. Bertina RM, Koeleman BP, Koster T, et al. Mutation in blood coagulation factor V associated with resistance to activated protein C. Nature. 1994;369:64-67.

7. Castaman G, Tosetto A, Simioni M, Ruggeri M, Madeo D, Rodeghiero F. Phenotypic APC resistance in carriers of the A20210 prothrombin mutation is associated with an increased risk of venous thrombosis. Thromb Haemost. 2001;86:804-808.

8. de Visser MC, Rosendaal FR, Bertina RM. A reduced sensitivity for activated protein C in the absence of factor V Leiden increases the risk of venous thrombosis. Blood. 1999;93:12711276.

9. de Visser MC, van Hylckama Vlieg A, Tans G, et al. Determinants of the APTT- and ETPbased APC sensitivity tests. J Thromb Haemost. 2005;3:1488-1494.

10. Curvers J, Thomassen MC, Nicolaes GA, et al. Acquired APC resistance and oral contraceptives: differences between two functional tests. Br J Haematol. 1999;105:88-94.

11. Tans G, van Hylckama Vlieg A, Thomassen MC, et al. Activated protein C resistance determined with a thrombin generation-based test predicts for venous thrombosis in men and women. Br J Haematol. 2003;122:465-470.

12. Curvers J, Thomassen MC, Rimmer J, et al. Effects of hereditary and acquired risk factors of venous thrombosis on a thrombin generation-based APC resistance test. Thromb Haemost. 2002;88:5-11.

13. Mahieu B, Jacobs N, Mahieu S, et al. Haemostatic changes and acquired activated protein $\mathrm{C}$ resistance in normal pregnancy. Blood Coagul Fibrinolysis. 2007;18:685-688.

14. Schiffman S, Theodor I, Rapaport SI. Separation from Russell's viper venom of one fraction reacting with factor $X$ and another reacting with factor V. Biochemistry. 1969;8:1397-1405.

15. de Waard V, Hansen HR, Spronk HH, et al. Differential expression of tissue factor mRNA and protein expression in murine sepsis. The role of the granulocyte revisited. Thromb Haemost. 2006;95:348-353.

16. Koedam JA, Meijers JC, Sixma JJ, Bouma BN. Inactivation of human factor VIII by activated protein C. Cofactor activity of protein S and protective effect of von Willebrand factor. J Clin Invest. 1988;82:1236-1243.

17. Rosing J, Bakker HM, Thomassen MC, Hemker HC, Tans G. Characterization of two forms of human factor Va with different cofactor activities. J Biol Chem. 1993;268:21130-21136.

18. Fujikawa K, Legaz ME, Davie EW. Bovine factor X 1 (Stuart factor). Mechanism of activation by protein from Russell's viper venom. Biochemistry. 1972;11:4892-4899.

19. Fujikawa K, Legaz ME, Davie EW. Bovine factors X 1 and X 2 (Stuart factor). Isolation and characterization. Biochemistry. 1972;11:4882-4891.

20. Cui J, Eitzman DT, Westrick RJ, et al. Spontaneous thrombosis in mice carrying the factor V Leiden mutation. Blood. 2000;96:4222-4226.

21. Tchaikovski SN, BJ VANV, Rosing J, Tans G. Development of a calibrated automated thrombography based thrombin generation test in mouse plasma. J Thromb Haemost. 2007;5:2079-2086. 
22. Nagai N, Lijnen HR, Cleuren AC, et al. Factor V Leiden mutation is associated with enhanced arterial thrombotic tendency in lean but not in obese mice. Thromb Haemost. 2007;98:858863.

23. Uzunova AD, Ramey ER, Ramwell PW. Arachidonate-induced thrombosis in mice: effects of gender or testosterone and estradiol administration. Prostaglandins. 1977;13:995-1002.

24. Abu-Fanne R, Brzezinski A, Golomb M, et al. Effects of estradiol and raloxifene on arterial thrombosis in ovariectomized mice. Menopause. 2008;15:98-104.

25. van Vliet HA, Bertina RM, Dahm AE, et al. Different effects of oral contraceptives containing different progestogens on protein $\mathrm{S}$ and tissue factor pathway inhibitor. J Thromb Haemost. 2008;6:346-351.

26. Shen L, Dahlback B. Factor V and protein S as synergistic cofactors to activated protein C in degradation of factor VIIIa. J Biol Chem. 1994;269:18735-18738.

27. Thorelli E, Kaufman RJ, Dahlback B. Cleavage of factor V at Arg 506 by activated protein C and the expression of anticoagulant activity of factor V. Blood. 1999;93:2552-2558.

28. Sandset PM, Hellgren M, Uvebrandt M, Bergstrom H. Extrinsic coagulation pathway inhibitor and heparin cofactor II during normal and hypertensive pregnancy. Thromb Res. 1989;55:665670.

29. Rosenkranz A, Hiden M, Leschnik B, et al. Calibrated automated thrombin generation in normal uncomplicated pregnancy. Thromb Haemost. 2008;99:331-337.

30. Malm J, Laurell M, Dahlback B. Changes in the plasma levels of vitamin K-dependent proteins $\mathrm{C}$ and $\mathrm{S}$ and of $\mathrm{C} 4 \mathrm{~b}$-binding protein during pregnancy and oral contraception. $\mathrm{Br} \mathrm{J}$ Haematol. 1988;68:437-443.

31. Maurissen LF, Thomassen MC, Nicolaes GA, et al. Re-evaluation of the role of the protein S$\mathrm{C} 4 \mathrm{~b}$ binding protein complex in activated protein $\mathrm{C}$-catalyzed factor Va-inactivation. Blood. 2008;111:3034-3041.

32. Takahashi S, Takahashi M, Kaidoh T, Natsuume-Sakai S, Takahashi T. Genetic mapping of mouse C4-bp locus to the H-2D-Qa interval. J Immunol. 1984;132:6-8.

33. Rodriguez de Cordoba S, Perez-Blas M, Ramos-Ruiz R, Sanchez-Corral P, Pardo-Manuel de Villena F, Rey-Campos J. The gene coding for the beta-chain of C4b-binding protein (C4BPB) has become a pseudogene in the mouse. Genomics. 1994;21:501-509.

34. Hughes Q, Watson M, Cole V, Sayer M, Baker R, Staton J. Upregulation of protein S by progestins. J Thromb Haemost. 2007;5:2243-2249.

35. Martinelli I, Razzari C, Biguzzi E, Bucciarelli P, Mannucci PM. Low levels of protein Z and the risk of venous thromboembolism. J Thromb Haemost. 2005;3:2817-2819.

36. Yin ZF, Huang ZF, Cui J, et al. Prothrombotic phenotype of protein Z deficiency. Proc Natl Acad Sci U S A. 2000;97:6734-6738. 


\section{Chapter 7}

Summary and General Discussion 


\section{Introduction}

More than 100 million women worldwide use steroid hormone contraceptive methods, 93 million of whom use combined oral contraceptives (OC). Epidemiological studies suggest that $\mathrm{OC}$ use increases the absolute risk of venous thrombosis from 0.8 per 10,000 per year among premenopausal women not using OC to 3.0 per 10,000 per year among OC users. ${ }^{2}$ These numbers indicate a low absolute risk even for OC users. Nevertheless, because OC are so widely used, they are responsible for a large part, if not the majority, of all venous thromboses in young women. A simple calculation results in $\sim 20,500$ venous thrombosis events that could have been avoided worldwide every year, when safer contraception methods would have been available. However, insufficient understanding of the pathogenesis of the hormone-induced venous thrombosis hampers the development of better formulations of hormonal contraceptives. In addition, the absence of reliable tests with a predictive value for venous thromboembolism in clinical practice complicates defining women who are prone to venous thrombosis during OC use. Due the complexity of the coagulation system, it is very difficult to estimate an individual's risk on the basis of the concentrations of coagulation factors and anticoagulant proteins. Therefore, functional tests that probe the over-all state of coagulation might potentially be better predictors of venous thromboembolism.

A remarkable correlation was found between the risk of venous thrombosis and resistance to activated protein C (APC) determined with a thrombin generation-based assay. ${ }^{3}$ The relevance of this test for prediction of venous thrombosis was confirmed in the presence and in the absence of the factor $\mathrm{V}_{\text {Leiden }}$ mutation, ${ }^{4,5}$ a heritable abnormality of the factor $\mathrm{V}$ molecule that makes it resistant to the anticoagulant effect of APC. ${ }^{6}$ Compared to the classical APC resistance test that measures the effect of APC on the activated partial thromboplastin time (aPTT), ${ }^{7}$ the thrombin generation-based assay ${ }^{8}$ is much more sensitive to acquired APC resistance, caused by hormonal changes during pregnancy, OC use ${ }^{9,10}$ or hormone replacement therapy (HRT). ${ }^{11-13}$ In contrast to the aPTT-based APC resistance test, the thrombin generation-based assay discriminates well between hormonal preparations that cause different risks of VT. ${ }^{10}$ Moreover, the multiplicative effect of OC, ${ }^{2}$ HRT ${ }^{14}$ or pregnancy ${ }^{15,16}$ with the factor $\mathrm{V}_{\text {Leiden }}$ mutation on the risk of venous thrombosis correlates rather well with the additional increase of APC resistance determined with the thrombin generation-based assay in plasma from carriers of the factor $\mathrm{V}_{\text {Leiden }}$ mutation during pregnancy, OC use or HRT. ${ }^{3}$ 
The differences in the sensitivity of the two APC resistance tests can be explained by the different determinants of the assays. ${ }^{17}$ The clotting of plasma, which is used as end-point in the aPTT-based assay, occurs when only a small amount of thrombin is generated. ${ }^{18}$ Therefore, the outcome of this test mainly probes the initiation phase of thrombin generation. By contrast, the thrombin generation-based assay mainly depends on the propagation and the termination phases of thrombin generation, which results in a higher sensitivity to defects of anticoagulant components, such as antithrombin, tissue pathway inhibitor and proteins of the protein $\mathrm{C}$ pathway. Therefore, the changes in these parameters during OC use, HRT or pregnancy (for an overview see chapter 2 and other reviews ${ }^{19,20}$ ) might be responsible for increased APC resistance determined with the thrombin generation-based assay and at least partially account for the hormone-induced increase in the risk of venous thromboembolism.

In the classical thrombin generation-based APC resistance test, described by Nicolaes et al., ${ }^{8}$ the effect of APC on the final plateau of thrombin amidolytic activity trapped in complex with $\alpha_{2}$-macroglobulin $\left(\alpha_{2} \mathrm{M}\right.$-IIa) was used as a measure for APC resistance. The limitations of this assay are 1) that the measurements of the final plateau of $\alpha_{2} \mathrm{M}$-IIa do not yield information about the complete time course of thrombin formation and 2) that they do not allow evaluation of the separate measurements, i.e. the endogenous thrombin potential (ETP) determined in the absence and in the presence of APC, as the final plateau of $\alpha_{2} \mathrm{M}$-IIa strongly depends on the amount of $\alpha_{2} \mathrm{M}$ present in plasma. Since the APC sensitivity ratio (APCsr) is defined as the ratio of $\alpha_{2} \mathrm{M}-\mathrm{II} a$ determined in the presence and in the absence of APC, the APCsr becomes independent of the individual $\alpha_{2} \mathrm{M}$ level. These limitations do not apply to the semi-automated thrombin generation measurement, in which the presence of a low-affinity fluorogenic substrate for thrombin in non-defibrinated clotting plasma allows continuous monitoring of thrombin generation and calculation of the parameters that describe the thrombin generation curve, i.e. the ETP, lag time, time to peak and peak height of the thrombin generation curve. ${ }^{21}$ Thus, the APC resistance test based on calibrated automated thrombography (CAT) evaluates the effect of APC on the ETP yielding the APCsr while at the same time providing information on the individual ETP values.

In chapter 3 of this thesis we compared the previously described method of Nicolaes et al. ${ }^{8}$ that is based on determination of the APCsr via the endlevels of $\alpha_{2} \mathrm{M}$-IIa and via the CAT-based APC resistance test. These two tests were further used to assess APC resistance induced by different hormonal contraceptives (chapters 3 and 4). In chapter 5 we described the development of the CAT-based APC resistance test for mouse plasma that allowed us to 
investigate APC resistance in mouse models. In chapter 6 we used a mouse model to study the hormone-induced changes in APC resistance and in its main determinants. In this discussion a summary of the results presented in this thesis is given.

\section{Two Thrombin Generation-based APC Resistance Tests}

In chapter 3 we compared two thrombin generation-based APC resistance tests in two study populations that included men, women not using OC or women using different types of OC. This study demonstrated that in both populations the APCsr determined with the CAT-based APC resistance assay correlated well with those measured with the $\alpha_{2} \mathrm{M}$-IIa-based test (Fig. $1 \mathrm{~A}, \mathrm{~B}$ ).
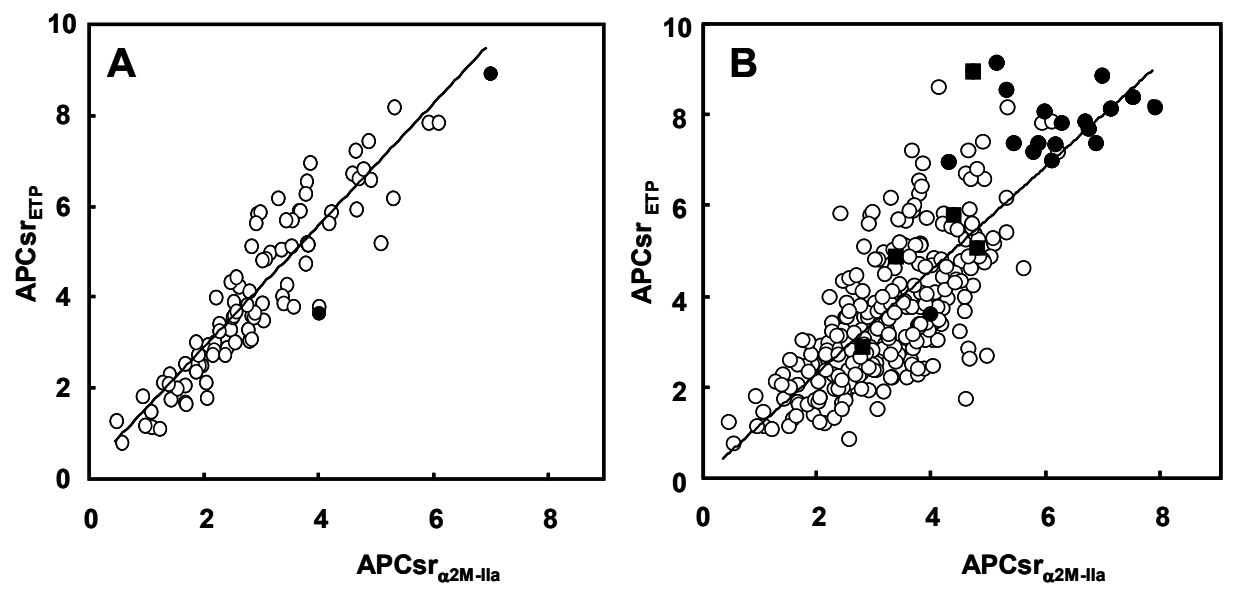

Fig. 1. Correlation between Two Thrombin Generation-based APC Resistance Tests APC sensitivity ratios were determined via measurement of tissue factor-initiated thrombin generation in plasma in the absence and presence of APC in the populations that have been described by Koenen et al. (A) ${ }^{22}$ and van Vliet et al. (B) ${ }^{23,24}$ Filled circles represent heterozygous factor $V_{\text {Leiden }}$ individuals and filled squares represent individuals heterozygous for the G20210A prothrombin mutation. $\mathrm{APCsr}_{\alpha 2 \mathrm{M}-\mathrm{II} a}$ was calculated from the ratio of final plateau's of amidolytic activity trapped in $\alpha_{2} \mathrm{M}$-IIa complexes during tissue factor-initiated thrombin generation in the presence and absence of APC in defibrinated plasma. $\mathrm{APCsr}_{\mathrm{ETP}}$ was calculated from the ratio of the endogenous thrombin potentials (ETP's), determined by continuous monitoring tissue factorinitiated of thrombin generation in the presence and absence of APC.

Similarly to the $\alpha_{2} \mathrm{M}$-IIa-based test, the CAT-based assay was also sensitive to the hormone-induced changes in the coagulation system both in the absence and in the presence of the factor $\mathrm{V}_{\text {Leiden }}$ mutation and discriminated well between OC with a lower risk of VT (levonorgestrel-containing pills) and OC with a higher risk of VT (desogestrel-, gestodene- and cyproterone acetate- 
containing pills). Given the good correlation between the APCsr determined with the two thrombin generation-based tests, it was not surprising that the CAT-based and the $\alpha_{2}$ M-IIa-based APC resistance tests shared major determinants: prothrombin, protein $\mathrm{S}$ free and TFPI free. These data are in agreement with the reports in which the determinants of the APCsr obtained with the thrombin generation-based tests were established in healthy populations. ${ }^{17,25}$ The observed increase in the APCsr in pill-users could most likely be attributed to the changes in these main determinants during OC use. A decrease in plasma levels of protein S free and TFPI free during OC use is proposed to be particularly important in the development of hormone-induced APC resistance. ${ }^{26}$ Several studies reported that OC with a higher risk of VT induce a more pronounced decrease in plasma levels of protein $\mathrm{S}$ free and TFPI free as compared to the changes induced by OC with a lower VT risk. ${ }^{27-29}$ Taken together, this indicates that the differential changes in plasma levels of protein $\mathrm{S}$ free and TFPI free during use of OC with different risk of VT are responsible for the observed differential changes in the APCsr.

Our results suggest that the CAT-based APC resistance test equally well predicts the risk of venous thrombosis as the previously validated $\alpha_{2}$ M-IIabased assay. Furthermore, the CAT-based assay offers a number of advantages when compared to the $\alpha_{2} \mathrm{M}$-IIa-based APC resistance test. In the CAT-based assay, additional information on the parameters that describe thrombin generation curves (ETP, lag time, time to peak and peak height) can readily be obtained with the appropriate software. Even though the clinical relevance of the thrombin generation parameters remains to be elucidated in clinical studies, they are already widely used as a research tool. ${ }^{30}$ In our study, the CAT-based method enabled us to demonstrate that the differences in the APC sensitivity ratios between users of OC formulations with differential risk for VT can be completely attributed to differential effects of the OC on the ETP determined in the presence of APC that are due to a differential impairment of the function of the protein $\mathrm{C}$ system and not to changes in thrombin generation in the absence of APC, as was earlier suggested by Gris et al. ${ }^{31,32}$ We did observe an increase in the ETP upon OC use, confirming earlier reports ${ }^{33}$ but there were no differences in the ETP determined in the absence of APC between users of different OC.

An excellent correlation exists between the $\mathrm{ETP}_{+\mathrm{APC}}$ and the APCsr whereas the ETP-APC and the APCsr do not correlate at all. This indicates that a single measurement in the presence of APC would suffice to evaluate an individual's APC resistance. However, the ETP determined in the absence of APC as well as other parameters of thrombin generation curves may provide 
additional information on the state of the coagulation system and possibly indicate the cause of APC resistance. For instance, unchanged ETP-APC and elevated $\mathrm{ETP}_{+\mathrm{APC}}$ in combination with a shortening of the lag time and the time to peak in the presence of APC might indicate the presence of the factor $\mathrm{V}_{\text {Leiden }}$ mutation, while increased $\mathrm{ETP}_{-\mathrm{APC}}$ and $\mathrm{ETP}_{+\mathrm{APC}}$ in combination with a prolongation of the lag time and the time to peak suggests the presence of the prothrombin mutation. ${ }^{34}$ Furthermore, the ETP value itself is proposed to have clinical relevance in predicting a first ${ }^{35}$ or recurrent venous thrombosis. ${ }^{36,37}$ However, the data on the association of the ETP with the risk of venous thromboembolism remain controversial, ${ }^{35,36}$ possibly due to differences in preanalytical (plasma preparation) and analytical variables (assay conditions) in these studies. Furthermore, the CAT-based assays that probe the function of the protein $\mathrm{C}$ system in plasma by adding either exogenous APC or by activating endogenous protein $\mathrm{C}$ with thrombomodulin seem to be more of importance for prediction of venous thrombosis. ${ }^{37,38}$

In addition we also tested the effect of $\mathrm{OC}$, containing the so-called fourth generation progestin, drospirenone, on thrombin generation and on APC resistance (chapter 3). We observed that users of this recently introduced OC (Yasmin) had an increase in APC resistance that was comparable to the increase observed in users of OC, containing third generation progestins (gestodene and desogestrel), or the anti-androgen cyproterone acetate. These findings suggest that the risk of VT in the users of the drospirenone-containing OC is similar to that in users of $\mathrm{OC}$ that contain third generation progestins or cyproterone acetate. However, epidemiological studies are required to accurately estimate the risk.

\section{Alternative Ways of Hormonal Contraceptive Administration}

Ever since combined OC were introduced on the market, concerns about their adverse effects were raised, promoting efforts to improve safety of hormonal birth control. A progressive decrease of the hormone dose to the lowest dose necessary for effective contraception and reliable cycle control resulted in a reduction of side effects. Further attempts to improve OC formulation concerned the chemical structure of the progestin compound of OC. Early OC contained so-called first-generation progestins which in the 1970s were replaced by OC containing second-generation progestins (levonorgestrel). The thirdgeneration medications (containing desogestrel or gestodene) were introduced in the early 1980s and 1990s and so-called fourth generation OC, containing drospirenone in $2000 .{ }^{39} \mathrm{OC}$ that contain third or fourth generation progestins 
possess higher biological availability and cause less adverse metabolic effects. On the other hand, these $\mathrm{OC}$ were found to be 2-3 times more thrombogenic as compared to the formulations containing a progestin of the previous (second) generation. ${ }^{40,41}$ This observation led to the development of a hypothesis that the prothrombotic effects of OC are not strictly dependent on the dose of estrogen but rather on the "total estrogenicity" of the formulation that rises with increasing dose of estrogen, but decreases with increasing anti-estrogenic capacity of progestin compound. OC containing third generation progestins or cyproterone acetate were considered to be more estrogenic ${ }^{28,42}$ than levonorgestrel-containing OC due to weaker anti-estrogenic capacity of their progestin compounds.

The prothrombotic effect of $\mathrm{OC}$ was also thought to relate to the first-pass effect and, therefore, preparations lacking this effect were expected to be a safer option of hormonal contraception. Consequently, combined hormonal contraceptives with non-oral ways of administration, i.e. the hormone-releasing transdermal patch and the vaginal ring were recently introduced on the market.

Surprisingly, epidemiological studies showed that the transdermal hormonal contraceptives are at least as thrombogenic ${ }^{43}$ or even induce a 2 to 3 times higher risk of venous thrombosis as compared to third generation OC. ${ }^{44}$ In chapter 4 we lend support to these observations, by demonstrating similar changes in the levels of protein S total, antithrombin, fibrinogen, C-reactive protein in users of oral and transdermal contraceptives, containing the same hormones. Moreover, the transdermal contraceptives caused an even more pronounced lowering in the protein S free level and increase in the APCsr, which can explain a higher risk of VT in users of the transdermal contraceptives as compared to oral contraceptive users.

There is no data available on the venous thrombosis risk introduced by vaginal hormonal contraceptive use. In chapter 4 we demonstrate that the vaginal hormonal contraceptive induces less pronounced changes in the APCsr as compared to the thransdermal contraceptive, but more pronounced as compared to levonorgestrel-containing OC. Therefore, our results (chapters 3-4) suggest that the risk of venous thrombosis during use of combined hormonal contraceptives increases in the order second generation $\mathrm{OC}<$ vaginal contraceptive $<$ third and fourth generation OC and OC containing cyproterone acetate $\leq$ transdermal contraceptives. Accordingly, it appears that compared with OC, alternative ways of administration do not attenuate the risk of VT. This may be due to higher sustained endogenous estrogen and progestin levels observed with the transdermal compared to oral agents, even though peak hormone levels are higher with oral than transdermal treatment. ${ }^{45}$ These higher 
hormone levels over time may cause unfavorable changes in coagulation factors and anticoagulant proteins independent of first-pass liver effects.

The vaginal ring sustains lower estrogen and progestin levels in blood as compared to the transdermal patch, ${ }^{45}$ which might explain why it has a less pronounced effect on the APCsr (chapter 4). However, despite relatively low estrogen levels, the vaginal ring is likely more thrombogenic than levonorgestrel-containing OC, which is suggested by its more pronounced effect on the APCsr (chapter 3), A higher thrombogenicity of the vaginal ring may be at least partially explained by the fact that the progestin compound of the vaginal ring- etonogestrel (third generation) is less effective than levonorgestrel in counterbalancing the prothrombotic effects of ethinylestradiol, ${ }^{28}$ which results in a higher "total estrogenicity" of the formulation.

In contrast to combined hormonal contraceptives, the levonorgestrelreleasing intrauterine device caused a small decrease in the APCsr (chapter 4), which suggests that it hardly increases the risk of venous thrombosis and might even have a weak antithrombotic effect. Our data confirm previous findings that compared to combined OC, oral and subcutaneous progestin-only contraceptives have very limited and maybe even opposite effects on the coagulation system. ${ }^{46-49}$ Therefore, the levonorgestrel-containing intrauterine device might be a safer option of hormonal contraception for women with a known increased risk of venous thrombosis, like the presence of a prothrombotic mutation or a family or personal history of venous thrombosis. However, due to the small effects of progestin-only contraception on the coagulation system, large epidemiological studies are necessary to confirm possible advantages of the levonorgestrel-containing intrauterine device and other progestin-only contraceptives (e.g. oral, injectable, implantable contraceptives) for these women.

\section{Thrombin Generation in Mouse Plasma}

Despite a large number of studies performed on the effect of contraceptives, hormone replacement therapy on coagulation system, the pathogenesis of the hormone-induced changes in the coagulation system remains ambiguous. Use of animal models may help to gain insight into the mechanism of action of steroid hormones in vivo. Biological effects of the steroid hormones are mediated at the cellular level via intracellular steroid receptors, e.g. estrogen receptors $(\alpha$ and $\beta)$, progesterone receptors (A and $B$ ) and androgen receptors (A and $B)$. The ability to bind to different steroid receptors varies between different steroid hormones and compounds of hormone replacement therapy and hormonal 
contraceptives and thereby determines their biological effects. Mouse models are particularly attractive in studying the mechanisms of hormone-induced changes in coagulation due to the availability of genetically-modified mice that lack one ore more steroid receptors, which enables dissecting the effects of the hormones mediated via different steroid receptors. In addition, there are mouse strains available with a known genetic defect in the metabolism of steroid hormones. The knowledge that might be obtained using genetically-modified mice can help in the development of new drugs that have no or less adverse effects on the coagulation system.

Even though mouse models are often used in thrombosis research, ${ }^{50}$ there are not many assays available to study the coagulation system in mice. The existing methods are restricted to evaluation of induced thrombosis, determination of coagulation factor levels or clotting times. In chapter 5 we described the development of a CAT-based thrombin generation assay in platelet-rich and platelet-poor mouse plasma. Due to our particular interest in studying hormone-induced APC resistance, we optimized the conditions of the assay in such a way that it enabled us to evaluate APC-resistance in mice. Using the thrombin generation-based APC resistance test we confirmed the APC resistant phenotype of R504Q mice that carry a point mutation analogous to human factor $\mathrm{V}_{\text {Leiden }}$ mutation. Furthermore, we confirmed that human tissue factor and human activated protein $\mathrm{C}$ are functional in mouse plasma and therefore can be used to study thrombin generation in mouse plasma in case the corresponding mouse proteins are not available.

We believe that the CAT-based thrombin generation assay and the thrombin generation-based APC resistance test for mouse plasma can become useful tools in thrombosis research. They have already been employed to study the effects of pregnancy on the coagulation system in wild type and factor $\mathrm{V}_{\text {Leiden }}$ mice (chapter 6), to evaluate the effects of fish oil on coagulation in APOE-2 knock-in mice, ${ }^{51}$ to characterize the phenotype of PROS+/- mice (Saller et al., Blood, in press) and to investigate the anticoagulant properties of FPR-prothrombin (Baird et al., manuscript in preparation).

\section{Pregnancy-induced Changes in Coagulation in Mouse}

Mouse models are often employed to investigate the biological effects of steroid hormones. The doses of the administrated hormones that are used in these studies vary significantly and in the majority of the cases they are much higher than those used in humans, ${ }^{52}$ which makes the reported results questionable for the extrapolation to the human situation. On the other hand, pregnancy is a well 
established natural cause of hormone-induced APC resistance and the changes in the coagulation system during pregnancy are rather pronounced in humans. Therefore, we used pregnant mice as a model for hormone-induced APC resistance. Moreover, we investigated the effects of pregnancy in combination with a prothrombotic mutation (the factor $\mathrm{V}_{\text {Leiden }}$ mutation) in mice (chapter 7).

Using the CAT-based APC resistance test we demonstrated that the pregnancy-induced changes in APC resistance in mice differed from those in humans. In contrast to humans, both wild type and factor $\mathrm{V}_{\text {Leiden }}$ mice became less resistant to the anticoagulant effect of APC during pregnancy. To explain why APC resistance decreases in pregnant mice and increases in pregnant women, we investigated in mice the pregnancy-induced changes in the main determinants of the APCsr known from human studies. ${ }^{17}$ Interestingly, factor V and protein $\mathrm{S}$ levels and TFPI activity were higher in pregnant mice than in nonpregnant mice, whereas in humans opposite changes in these parameters are observed during pregnancy. ${ }^{52}$ All three parameters were previously shown to be negative determinants of the APCsr in human plasma and therefore could account for the decrease in the APC resistance in pregnant wild type mice. However, assuming that mouse factor $\mathrm{V}_{\text {Leiden }}$, like human factor $\mathrm{V}_{\text {Leiden }}$ does not express anticoagulant activity, ${ }^{53}$ the elevated factor $\mathrm{V}$ levels could not explain the decreased APCsr in factor $\mathrm{V}_{\text {Leiden }}$ pregnant mice. Therefore, we proposed that the changes in protein S levels and TFPI activity are responsible for the decrease in the APC resistance in mice during pregnancy.

Even though these differences in the pregnancy-induced changes in coagulation between mice and humans precluded us from further use of mouse model in studying the effects of individual hormones, they allowed us to hypothesize that opposite changes in APC resistance in mice and humans are due to opposite changes in the levels of the major determinants of the APC resistance test: protein $\mathrm{S}$ and TFPI. This suggests that a decrease in the levels/activity of these two proteins play an important role in the development of the pregnancy-induced APC resistance in humans. To confirm this hypothesis we are currently performing a study on the effects of pregnancy on the TFPI system in humans. The preliminary data demonstrate a gradual decrease in plasma levels of protein S total and free and TFPI free in pregnant women. These changes lead to a pronounced impairment in the function of both the TFPI and the protein $\mathrm{C}$ systems in human plasma during pregnancy. The activity of the TFPI system is evaluated in this study via a thrombin generationbased assay. The representative thrombin generation time courses measured with CAT in plasma of non-pregnant controls (A) and in plasma of pregnant women at 8 (B), 12 (C), and 16 (D) weeks pregnancy are depicted in Fig. 2. 


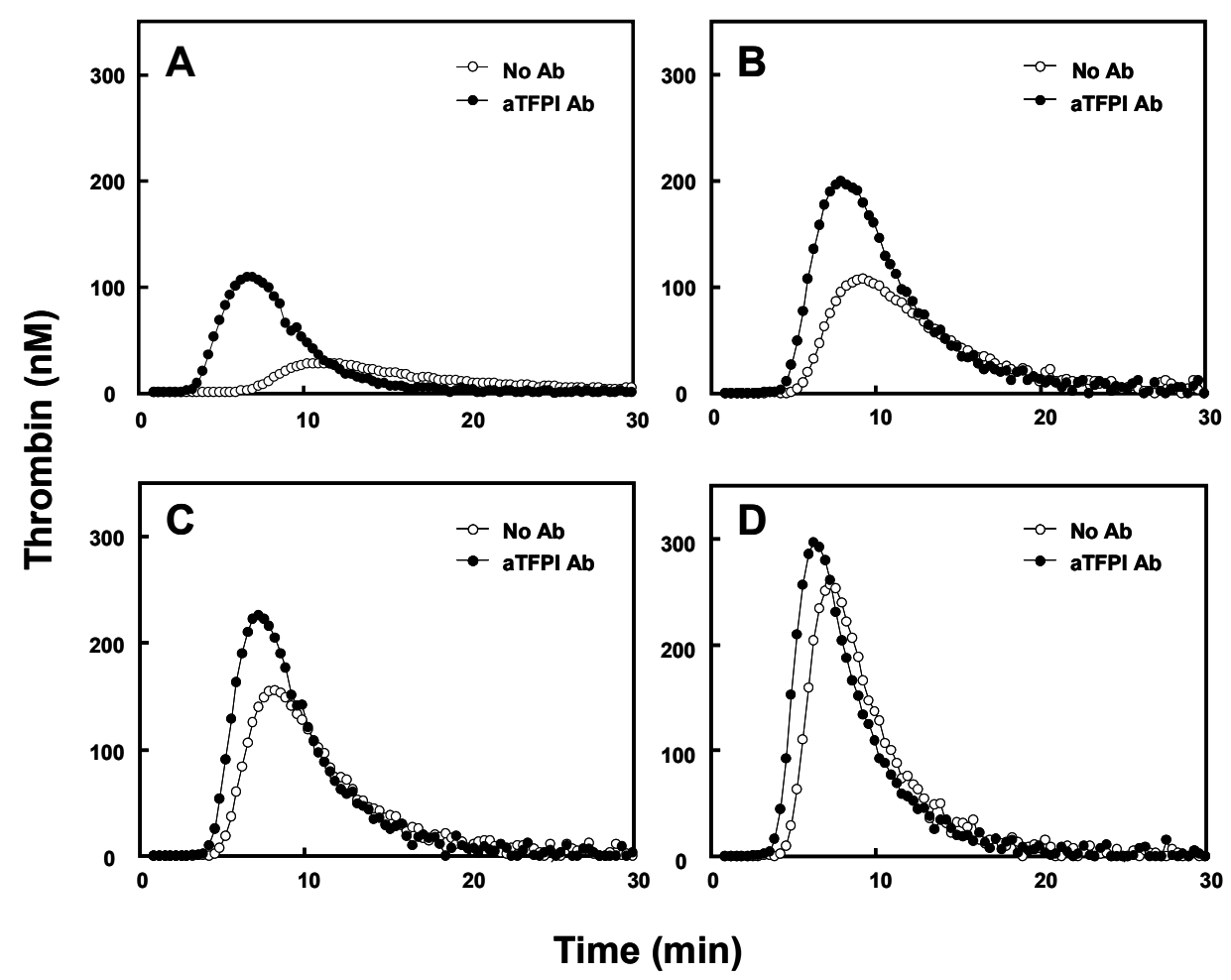

Fig. 2 Changes in the TFPI System during the First 16 Weeks of Pregnancy

Thrombin generation was initiated in citrated plasma by addition of PPP reagent Low (Thrombinoscope $\mathrm{BV}$, Maastricht, the Netherlands) and $16 \mathrm{mM} \mathrm{CaCl}_{2}$ in the absence (open circles) and in the presence (filled circles) of $4 \mu \mathrm{L}$ of monoclonal antibody against $\mathrm{C}$-terminus of tissue factor pathway inhibitor. Thrombin generation was continuously followed with fluorogenic substrate I-1140 (Z-Gly-Gly-Arg-AMC.HCl) using calibrated automated thrombography. Representative curves for plasma of non-pregnant controls (A) as well as 8, 12 and 16 weeks pregnant women ( $\mathrm{B}, \mathrm{C}$ and $\mathrm{D}$, respectively) are shown.

Thrombin generation was initiated with a low tissue factor concentration in the absence (open circles) and in the presence (filled circles) of an inhibitory anti-TFPI antibody. As under these conditions thrombin generation is very sensitive to TFPI activity, the increase of the maximum amount of thrombin formed (peak height of the thrombin generation curve) induced by addition of the anti-TFPI antibody can be used as a measure of the TFPI activity in plasma. Fig. 2 demonstrates a gradual decrease in the effect of the anti-TFPI antibody, which indicates a gradual decline in the activity of the TFPI system during first 16 weeks of pregnancy. The relevance of this decline for the risk of venous thrombosis remains to be elucidated. 
In conclusion, we showed that the CAT-based APC resistance test can be used as a predictor of venous thrombosis, since it correlates well with the clinically validated end-point method and is very sensitive to the factor $V_{\text {Leiden }}$ and the G20210A prothrombin mutations as well as to the hormone-induced changes in the coagulation system. Using this assay we assessed the effects of drospirenone-containing OC, the transdermal, vaginal and intrauterine hormonal contraceptives on coagulation. Our results indicated that the risk of venous thrombosis during use of combined hormonal contraceptives increases in the order: second generation $\mathrm{OC}<$ vaginal contraceptive $<$ third and fourth generation $\mathrm{OC}$ and $\mathrm{OC}$ containing cyproterone acetate $\leq$ transdermal contraceptives and that the levonorgestrel-releasing intrauterine device has no prothrombotic effect. Furthermore, we established a thrombin generation assay and a thrombin generation-based APC resistance test for mouse plasma. Using a mouse model we showed that the changes in the TFPI and protein S levels are likely the major determinants of the hormone-induced risk of venous thrombosis.

\section{References}

1. WHO scientific group meeting on cardiovascular disease and steroid hormone contraceptives. Wkly Epidemiol Rec. 1997;72:361-363.

2. Vandenbroucke JP, Koster T, Briet E, Reitsma PH, Bertina RM, Rosendaal FR. Increased risk of venous thrombosis in oral-contraceptive users who are carriers of factor V Leiden mutation. Lancet. 1994;344:1453-1457.

3. Curvers J, Thomassen MC, Rimmer J, et al. Effects of hereditary and acquired risk factors of venous thrombosis on a thrombin generation-based APC resistance test. Thromb Haemost. 2002;88:5-11.

4. de Visser MC, Rosendaal FR, Bertina RM. A reduced sensitivity for activated protein C in the absence of factor $\mathrm{V}$ Leiden increases the risk of venous thrombosis. Blood. 1999;93:1271-1276.

5. Tans G, van Hylckama Vlieg A, Thomassen MC, et al. Activated protein C resistance determined with a thrombin generation-based test predicts for venous thrombosis in men and women. Br J Haematol. 2003;122:465-470.

6. Bertina RM, Koeleman BP, Koster $\mathrm{T}$, et al. Mutation in blood coagulation factor $\mathrm{V}$ associated with resistance to activated protein C. Nature. 1994;369:64-67.

7. Dahlback B, Carlsson M, Svensson PJ. Familial thrombophilia due to a previously unrecognized mechanism characterized by poor anticoagulant response to activated protein C: prediction of a cofactor to activated protein C. Proc Natl Acad Sci U S A. 1993;90:10041008 .

8. Nicolaes GA, Thomassen MC, Tans G, Rosing J, Hemker HC. Effect of activated protein C on thrombin generation and on the thrombin potential in plasma of normal and APC-resistant individuals. Blood Coagul Fibrinolysis. 1997;8:28-38.

9. Olivieri O, Friso S, Manzato F, et al. Resistance to activated protein $\mathrm{C}$ in healthy women taking oral contraceptives. Br J Haematol. 1995;91:465-470.

10. Rosing J, Tans G, Nicolaes GA, et al. Oral contraceptives and venous thrombosis: different sensitivities to activated protein $\mathrm{C}$ in women using second- and third-generation oral contraceptives. Br J Haematol. 1997;97:233-238. 
11. Douketis JD, Gordon M, Johnston M, Julian JA, Adachi JR, Ginsberg JS. The effects of hormone replacement therapy on thrombin generation, fibrinolysis inhibition, and resistance to activated protein $\mathrm{C}$ : prospective cohort study and review of literature. Thromb Res. 2000;99:25-34.

12. Hoibraaten E, Mowinckel MC, de Ronde H, Bertina RM, Sandset PM. Hormone replacement therapy and acquired resistance to activated protein $\mathrm{C}$ : results of a randomized, double-blind, placebo-controlled trial. Br J Haematol. 2001;115:415-420.

13. Lowe GD, Rumley A, Woodward M, Reid E, Rumley J. Activated protein C resistance and the FV:R506Q mutation in a random population sample--associations with cardiovascular risk factors and coagulation variables. Thromb Haemost. 1999;81:918-924.

14. Rosendaal FR, Vessey M, Rumley A, et al. Hormonal replacement therapy, prothrombotic mutations and the risk of venous thrombosis. Br J Haematol. 2002;116:851-854.

15. Gerhardt A, Scharf RE, Beckmann MW, et al. Prothrombin and factor V mutations in women with a history of thrombosis during pregnancy and the puerperium. $\mathrm{N}$ Engl $\mathrm{J}$ Med. 2000;342:374-380.

16. Robertson $\mathrm{L}, \mathrm{Wu} \mathrm{O}$, Langhorne $\mathrm{P}$, et al. Thrombophilia in pregnancy: a systematic review. Br J Haematol. 2006;132:171-196.

17. de Visser MC, van Hylckama Vlieg A, Tans G, et al. Determinants of the APTT- and ETPbased APC sensitivity tests. J Thromb Haemost. 2005;3:1488-1494.

18. Hemker HC, Beguin S. Thrombin generation in plasma: its assessment via the endogenous thrombin potential. Thromb Haemost. 1995;74:134-138.

19. Bremme KA. Haemostatic changes in pregnancy. Best Pract Res Clin Haematol. 2003;16:153-168.

20. Tikkanen MJ. The menopause and hormone replacement therapy: lipids, lipoproteins, coagulation and fibrinolytic factors. Maturitas. 1996;23:209-216.

21. Hemker HC, Giesen P, AlDieri R, et al. The calibrated automated thrombogram (CAT): a universal routine test for hyper- and hypocoagulability. Pathophysiol Haemost Thromb. 2002;32:249-253.

22. Koenen RR, Christella M, Thomassen LG, Tans G, Rosing J, Hackeng TM. Effect of oral contraceptives on the anticoagulant activity of protein $\mathrm{S}$ in plasma. Thromb Haemost. 2005;93:853-859.

23. van Vliet HA, Frolich M, Christella M, et al. Association between sex hormone-binding globulin levels and activated protein $\mathrm{C}$ resistance in explaining the risk of thrombosis in users of oral contraceptives containing different progestogens. Hum Reprod. 2005;20:563568.

24. van Vliet HA, Winkel TA, Noort I, Rosing J, Rosendaal FR. Prothrombotic changes in users of combined oral contraceptives containing drospirenone and cyproterone acetate. J Thromb Haemost. 2004;2:2060-2062.

25. Dielis AW, Castoldi E, Spronk HM, et al. Coagulation factors and the protein C system as determinants of thrombin generation in a normal population. $\mathrm{J}$ Thromb Haemost. 2008;6:125-131.

26. van Vliet HA, Bertina RM, Dahm AE, et al. Different effects of oral contraceptives containing different progestogens on protein $\mathrm{S}$ and tissue factor pathway inhibitor. J Thromb Haemost. 2008;6:346-351.

27. Tans G, Curvers J, Middeldorp S, et al. A randomized cross-over study on the effects of levonorgestrel- and desogestrel-containing oral contraceptives on the anticoagulant pathways. Thromb Haemost. 2000;84:15-21.

28. Kemmeren JM, Algra A, Meijers JC, et al. Effect of second- and third-generation oral contraceptives on the protein $\mathrm{C}$ system in the absence or presence of the factor VLeiden mutation: a randomized trial. Blood. 2004;103:927-933.

29. Alhenc-Gelas M, Plu-Bureau G, Guillonneau S, et al. Impact of progestagens on activated protein C (APC) resistance among users of oral contraceptives. J Thromb Haemost. 2004;2:1594-1600. 
30. Robert S, Ghiotto J, Pirotte B, et al. Is thrombin generation the new rapid, reliable and relevant pharmacological tool for the development of anticoagulant drugs? Pharmacol Res. 2009;59:160-166.

31. Gris JC, Jamin C, Benifla JL, Quere I, Madelenat P, Mares P. APC resistance and thirdgeneration oral contraceptives: Acquired resistance to activated protein $\mathrm{C}$, oral contraceptives and the risk of thromboembolic disease. Hum Reprod. 2001;16:3-8.

32. Gris JC, Nouvellon-Cochery E, Mares P. Increased resistance to activated protein C in women taking third-generation oral contraceptives? Blood. 2004;104:1907; author reply 1908-1909.

33. Chantarangkul V, Clerici M, Bressi C, Giesen PL, Tripodi A. Thrombin generation assessed as endogenous thrombin potential in patients with hyper- or hypo-coagulability. Haematologica. 2003;88:547-554.

34. Hezard N, Bouaziz-Borgi L, Remy MG, Nguyen P. Utility of thrombin-generation assay in the screening of factor V G1691A (Leiden) and prothrombin G20210A mutations and protein S deficiency. Clin Chem. 2006;52:665-670.

35. van Hylckama Vlieg A, Christiansen SC, Luddington R, Cannegieter SC, Rosendaal FR, Baglin TP. Elevated endogenous thrombin potential is associated with an increased risk of a first deep venous thrombosis but not with the risk of recurrence. $\mathrm{Br} \mathrm{J}$ Haematol. 2007;138:769-774.

36. Hron G, Kollars M, Binder BR, Eichinger S, Kyrle PA. Identification of patients at low risk for recurrent venous thromboembolism by measuring thrombin generation. Jama. 2006;296:397-402.

37. Tripodi A, Legnani C, Chantarangkul V, Cosmi B, Palareti G, Mannucci PM. High thrombin generation measured in the presence of thrombomodulin is associated with an increased risk of recurrent venous thromboembolism. J Thromb Haemost. 2008;6:1327-1333.

38. Lecompte $\mathrm{T}$, Wahl D, Perret-Guillaume C, Hemker HC, Lacolley P, Regnault V. Hypercoagulability resulting from opposite effects of lupus anticoagulants is associated strongly with thrombotic risk. Haematologica. 2007;92:714-715.

39. Parsey KS, Pong A. An open-label, multicenter study to evaluate Yasmin, a low-dose combination oral contraceptive containing drospirenone, a new progestogen. Contraception. 2000;61:105-111.

40. Effect of different progestagens in low oestrogen oral contraceptives on venous thromboembolic disease. World Health Organization Collaborative Study of Cardiovascular Disease and Steroid Hormone Contraception. Lancet. 1995;346:1582-1588.

41. Jick H, Jick SS, Gurewich V, Myers MW, Vasilakis C. Risk of idiopathic cardiovascular death and nonfatal venous thromboembolism in women using oral contraceptives with differing progestagen components. Lancet. 1995;346:1589-1593.

42. Odlind V, Milsom I, Persson I, Victor A. Can changes in sex hormone binding globulin predict the risk of venous thromboembolism with combined oral contraceptive pills? Acta Obstet Gynecol Scand. 2002;81:482-490.

43. Jick SS, Kaye JA, Russmann S, Jick H. Risk of nonfatal venous thromboembolism in women using a contraceptive transdermal patch and oral contraceptives containing norgestimate and 35 microg of ethinyl estradiol. Contraception. 2006;73:223-228.

44. Cole JA, Norman H, Doherty M, Walker AM. Venous thromboembolism, myocardial infarction, and stroke among transdermal contraceptive system users. Obstet Gynecol. 2007;109:339-346.

45. van den Heuvel MW, van Bragt AJ, Alnabawy AK, Kaptein MC. Comparison of ethinylestradiol pharmacokinetics in three hormonal contraceptive formulations: the vaginal ring, the transdermal patch and an oral contraceptive. Contraception. 2005;72:168-174.

46. Cardiovascular disease and use of oral and injectable progestogen-only contraceptives and combined injectable contraceptives. Results of an international, multicenter, case-control study. World Health Organization Collaborative Study of Cardiovascular Disease and Steroid Hormone Contraception. Contraception. 1998;57:315-324. 
47. Heinemann LA, Assmann A, DoMinh T, Garbe E. Oral progestogen-only contraceptives and cardiovascular risk: results from the Transnational Study on Oral Contraceptives and the Health of Young Women. Eur J Contracept Reprod Health Care. 1999;4:67-73.

48. Vasilakis C, Jick H, del Mar Melero-Montes M. Risk of idiopathic venous thromboembolism in users of progestagens alone. Lancet. 1999;354:1610-1611.

49. Vieira CS, Ferriani RA, Garcia AA, et al. Use of the etonogestrel-releasing implant is associated with hypoactivation of the coagulation cascade. Hum Reprod. 2007;22:21962201.

50. Moverare S, Skrtic S, Lindberg MK, Dahlman-Wright K, Ohlsson C. Estrogen increases coagulation factor $\mathrm{V}$ mRNA levels via both estrogen receptor-alpha and -beta in murine bone marrow/bone. Eur J Endocrinol. 2004;151:259-263.

51. Vanschoonbeek K, Wouters K, van der Meijden PE, et al. Anticoagulant effect of dietary fish oil in hyperlipidemia: a study of hepatic gene expression in APOE2 knock-in mice. Arterioscler Thromb Vasc Biol. 2008;28:2023-2029.

52. Kwekel JC, Forgacs AL, Burgoon LD, Williams KJ, Zacharewski TR. Tamoxifen-elicited uterotrophy: cross-species and cross-ligand analysis of the gene expression program. BMC Med Genomics. 2009;2:19.

53. Thorelli E, Kaufman RJ, Dahlback B. Cleavage of factor V at Arg 506 by activated protein C and the expression of anticoagulant activity of factor V. Blood. 1999;93:2552-2558. 

Samenvatting 
In hoofdstuk 1 van dit proefschrift wordt een korte introductie van de functie en regulering van het stollingssysteem gepresenteerd. Het is reeds geruime tijd bekend dat genetische en verworven defecten van dit systeem aanleiding kunnen geven tot een verhoogde stollingsneiging, wat onder bepaalde omstandigheden kan leiden tot de ontwikkeling van veneuze trombose (VT). Hormonale veranderingen, zoals die optreden tijdens zwangerschap, puerperium (kraambed) en tijdens het gebruik van de anticonceptiepil of hormonale vervangingstherapie (HRT) zijn bekende verworven risicofactoren voor VT. Om meer inzicht te krijgen in het mechanisme waarmee deze hormonale veranderingen zorgen voor een verhoogd tromboserisico, zijn in dit proefschrift de effecten van zowel pilgebruik als zwangerschap op het stollingssysteem bestudeerd.

Hoofdstuk 2 geeft een literatuuroverzicht van de veranderingen die in het stollingsysteem optreden tijdens het gebruik van de anticonceptiepil. Het gebruik van combinatiepreparaten, d.w.z. pillen die zowel estrogeen als progestageen bevatten, is geassocieerd met een verhoogd trombose risico. Gebruik van anticonceptiepillen met een derde generatie progestageen (desogestrel of gestodeen) stelt vrouwen bloot aan een twee maal zo hoog trombose risico dan gebruik van pillen met een tweede generatie progestageen (levonorgestrel). Pilgebruik veroorzaakt een verhoging van de plasma concentratie van de stollingsfactor protrombine, verlaagt de concentratie van het antistollende eiwit proteïne $\mathrm{S}$ en leidt tot een verworven vorm van APC resistentie. De effecten van de pil op de bovengenoemde hemostase parameters zijn meer uitgesproken in gebruiksters van de zogenaamde derde generatie pil dan in tweede generatie pilgebruiksters.

De inschatting van een individueel risco op veneuze trombose is vrijwel onmogelijk wanneer men zich enkel baseert op de concentratie van stollings- of antistollingseiwitten. Daarentegen zijn functionele testen, die gevoelig zijn voor de "overall" effecten van de veranderingen in het stollingssysteem, potentieel betere testen om het individuele tromboserisico te voorspellen. Zo is de APC resistentie test, gebaseerd op kwantitering van de antistollende werking van het eiwit geactiveerd protein C (APC) op de vorming van het stollingseiwit trombine, een informatieve test die in staat is het individuele trombose risico te voorspellen. In hoofdstuk 3 hebben we twee testen die in staat zijn trombine vorming in de tijd te volgen (trombinegeneratietesten) met elkaar vergeleken. We hebben laten zien dat de op het Calibrated Automated Thrombogram (CAT)-gebaseerde APC resistentie test een uitstekende correlatie vertoond met de eerder gevalideerde APC resistentie test, die gebaseerd is op meting van het effect van APC op de hoeveelheid trombine die in het stollende plasma een 
complex vormt met een ander eiwit, $\alpha_{2}$-macroglobuline. Daarnaast verschafte de CAT methode extra informatie betreffende andere parameters van trombine vorming (vertragings-tijd oftewel de tijd totdat de trombinevorming op gang komt, piekhoogte en endogene trombinepotentiaal), die behulpzaam kunnen zijn bij de inschatting van het trombose risico.

APC resistentie gemeten met de CAT methode was zowel in de aan- als afwezigheid van de factor $\mathrm{V}_{\text {Leiden }}$ mutatie gevoelig voor veranderingen in het stollingssysteem ten gevolge van hormonale fluctuaties. Ook was er een significant verschil in APC resistentie van gebruiksters van anticonceptiepillen met een laag risico voor VT (levonorgestrel bevattende pillen) en gebruiksters van pillen met een hoger trombose risico (desogestrel-, gestodeen- en cyproteron acetaat bevattende pillen). De verschillen in APC resistentie in gebruiksters van de verschillende typen pil werd veroorzaakt door verschillen in het proteïne $\mathrm{C}$ systeem en niet door verschillende effecten van de tweede en derde generatie pil op de trombine vorming gemeten in afwezigheid van APC. Metingen in plasma van gebruiksters van een zogenaamde vierde generatie anticonceptiepil, die het progestageen drospirenon bevat, lieten een APC resistentie zien vergelijkbaar met die van derde generatie pilgebruiksters. Dit is een aanwijzing dat zowel gebruiksters van drospirenon- als van desogestrel-, gestodeen- of cyproteronacetaat bevattende anticonceptiepillen blootgesteld worden aan een vergelijkbaar verhoogd risico voor trombose.

Pogingen tot verbetering van de veiligheid van hormonale preparaten hebben geleid tot de ontwikkeling van contraceptiva die op "alternatieve" wijze worden toegediend. In hoofdstuk 4 zijn drie klinische studies samengevat, waarin we gekeken hebben naar de effecten van oraal en niet oraal (spiraal, pleister, vaginale ring) toegediende contraceptiva op verschillende risico factoren van zowel veneuze als arteriële trombose. Deze studies toonden aan dat voor de combinatiepreparaten de APC resistentie in toenam volgens: tweede generatie pil $<$ spiraal $<$ derde generatie pil $\leq$ anticonceptiepleister. Aangezien er een goede correlatie bestaat tussen de APC resistentie en trombose risico, zijn we van mening dat het risico voor VT van deze verschillende preparaten weerspiegelt wordt in diezelfde volgorde. De door ons gemeten verlaging van de APC resistentie tijdens het gebruik van het levonorgestrel-bevattende spiraaltje, zou kunnen duiden op een onveranderd of zelfs een verminderd trombose risico.

Muismodellen zijn van onschatbare waarde bij het onderzoek naar trombose. Niettemin zijn maar een beperkt aantal methodes beschikbaar waarmee de functie van het gehele stollingssysteem in de muis gemeten kan worden. In hoofdstuk 5 hebben we de ontwikkeling van een op CAT 
gebaseerde test beschreven en toegepast op muizen plasma. Deze test hebben we ondermeer gevalideerd door gebruik te maken van plasma van muizen met de factor $\mathrm{V}_{\text {Leiden }}$ mutatie $\left(\mathrm{FV}_{\text {Leiden }}\right)$.

Bij mensen leidt zwangerschap tot een forse toename van APC resistentie. In hoofdstuk 6 hebben we zowel de effecten van hormonale veranderingen ten gevolge van zwangerschap op APC resistentie bepaald in muizen met en zonder de $\mathrm{FV}_{\text {Leiden }}$ mutatie alsmede op de belangrijkste determinanten die APC resistentie beïnvloeden (proteïne S, TFPI (Tissue Factor Pathway Inhibitor), protrombine, factor $\mathrm{V}$ en factor $\mathrm{X}$ ) . In tegenstelling tot de mens, veroorzaakte zwangerschap in muizen, een verlaging van APC resistentie in beide muizen populaties. Deze verlaging kon verklaard worden door een verhoging van de plasma concentratie proteïne $S$ en een verhoogde activiteit van het eiwit TFPI in muizen plasma. Onze bevindingen tonen aan dat er een duidelijke soortspecificiteit bestaat voor wat betreft de effecten van zwangerschap op het stollingssysteem en op de determinanten van de APC resistentietest. Deze resultaten geven aan dat proteïne $S$ en TFPI een belangrijke rol spelen in de ontwikkeling van zwangerschap-gerelateerde APC resistentie bij de mens.

Samengevat: onze resultaten tonen aan dat de op CAT-gebaseerde APC resistentie test potentiëel een methode is die gebruikt kan worden voor de bepaling van het risico op VT. Onze bevindingen suggereren verder dat het trombose risico toeneemt na inname van anticonceptiepreparaten en wel in de volgende volgorde: tweede generatie pil $<$ vaginale ring $<$ derde generatie pil $=$ vierde generatie pil $=$ cyproteronacetaat bevattende anticonceptie pillen $\leq$ anticonceptiepleister. Het levonorgestrel-bevattende spiraaltje daarentegen, laat een verlaging van de APC resistentie zien, wat duidt op een onveranderd/verminderd trombose risico. Onze dierstudies laten zien dat de hormoon-gerelateerde veranderingen van de plasma concentratie en/of activiteit van proteïne $\mathrm{S}$ en TFPI een belangrijke rol spelen in de ontwikkeling van APC resistentie, en daarmee waarschijnlijk ook belangrijk zijn voor het verhoogde risico voor trombose. 


\section{Publications}

- Punyadeera C, Thijssen VL, Tchaikovski S, Kamps R, Delvoux B, Dunselman GA, de Goeij AF, Griffioen AW, Groothuis PG. Expression and regulation of vascular endothelial growth factor ligands and receptors during menstruation and post-menstrual repair of human endometrium. Mol Hum Reprod. 2006; 12(6): 367-75.

- Tchaikovski S, Tans G, Rosing J. Venous thrombosis and oral contraceptives: current status. Women's Health, 2006; 2(5): 761-772.

- Tchaikovski S, Tans G, Rosing J. Mechanism of hormonal therapy related thrombosis. Thrombosis Res. 2007; 119(S1): S64-S66.

- Tchaikovski SN, van Vlijmen BJ, Rosing J, Tans G. Development of a calibrated automated thrombography based thrombin generation test in mouse plasma. J Thromb Haemost. 2007; 5(10): 2079-86.

- Tchaikovski SN, van Vliet HA, Thomassen MC, Bertina RM, Rosendaal FR, Sandset PM, Helmerhorst FM, Tans G, Rosing J. Effect of oral contraceptives on thrombin generation measured via calibrated automated thrombography. Thromb Haemost. 2007; 98(6): 1350-6.

- Johnson JV, Lowell J, Badger GJ, Rosing J, Tchaikovski S, Cushman M. Effects of oral and transdermal hormonal contraception on vascular risk markers: a randomized controlled trial. Obstet Gynecol. 2008; 111(2 Pt 1): $278-84$.

- Rosing J, Maurissen LFA, Tchaikovski SN, Tans G, Hackeng TM. Protein $\mathrm{S}$ is a cofactor for tissue factor pathway inhibitor. Thrombosis Res. 2008, 122 (S1), S60-S63.

- Fleischer K, van Vliet HA, Rosendaal FR, Rosing J, Tchaikovski S, Helmerhorst FM. Effects of the contraceptive patch, the vaginal ring and an oral contraceptive on APC resistance and SHBG: A cross-over study. Thrombosis Res. 2009, 123(3): 429-435.

- Tchaikovski SN, van Vlijmen BJM, Cleuren ACA, Thomassen MCLGD, Tchaikovski V, Tans G, Rosing J. Pregnancy-associated changes in the haemostatic system in wild type and factor $\mathrm{V}_{\text {Leiden }}$ mice. $\mathrm{J}$ Thromb Haemost. 2009; 7(2): 312-318.

- van Vliet HAAM, Tchaikovski SN, Rosendaal FR, Rosing J, Helmerhorst FM. The effect of the levonorgestrel-releasing intrauterine system on the resistance to activated protein C. Thromb Haemost. 2009; 101(4): 691-695. 
- Saller F, Brisset AC, Tchaikovski SN, Azevedo M, Chrast R, Fernández JA, Schapira M, Hackeng TM, Griffin JH\& Angelillo-Scherrer A. Generation and phenotypic analysis of protein S-deficient mice. Blood in press.

- Tchaikovski V, Tchaikovski SN, Olieslagers S, Waltenberger J. Monocyte dysfunction as a previously unrecognized pathophysiological mechanism in ApoE-/- mice contributing to impaired arteriogenesis. Submitted

- Tchaikovski S \& Rosing J. Mechanism of estrogen-induced venous thromboembolism. Submitted

- Baird TR, Panizzi P, Tchaikovski SN, Chang N, Tans G, Rosing J, Furie $\mathrm{Br}$, Furie B, and Bock PE. Localization and inhibition of prothrombin activation by active site-labled prothrombin during thrombosis in vivo and in in vitro reaction systems. In preparation. 


\section{Abstracts}

- Tchaikovski SN Rusina NF Blood level of long-life radionuclides in women with benign ovarian cysts. Oral presentation at Republic Conference for Young Scientists, Grodno, Belarus, 1998, Book of abstracts, p. 117.

- Tchaikovski SN, Egorova T. Serotonin blood level in women with preeclampsia. Oral presentation at International Conference on $40^{\text {th }}$ Anniversary of Grodno State Medical University, Grodno, 2000, Book of abstracts, p. 139

- Tchaikovski SN, van Vliet HAAM., Thomassen MLGD, Bertina RM, Rosendaal FR, Sandset PM, Helmerhorst FM, Tans G, Rosing J. Effect of oral contraceptives on thrombin generation measured via Calibrated Automated Thromborgaphy. Poster at XXIst ISTH Congress, J Thromb Haemost 2007; 5(S2): P-W-596.

- Tchaikovski SN, van Vlijmen BJM, Rosing J, Tans G. Measurement of thrombin generation and APC resistance in mouse plasma. Oral presentations at NVTH symposium 2007 and XXIst ISTH Congress, J Thromb Haemost 2007; 5(S2): O-T-092

- Tchaikovski SN, van Vlijmen BJM, Thomassen MCLGD, Castoldi E, Peeters LL, Tans G, Rosing J.Changes in the coagulation system in humans and mice during pregnancy. Poster at XXIInd ISTH Congress; PP-TH-377

\section{Awards}

Young investigator award of the International Society on Thrombosis and Haemostasis, XXIst ISTH Congress, Geneva, Switzerland (July 2007). 



\section{Curriculum Vitae}

Svetlana Nikolayevna Tchaikovski was born on November $17^{\text {th }}$, 1976 in Mikashevichi, Republic of Belarus, where she attended a primary and high school. After obtaining her high school diploma with distinction in 1993 she started her medical training at the Grodno State Medical University (Belarus). Due to her particular interest in Obstetrics and Gynaecology she became a member of the Student Scientific Society of Obstetrics and Gynaecology and participated in several scientific projects under supervision of Dr. Rusina N.F. and Dr. Egorova T.Y.

In 1999 she obtained her Medical Degree cum laude and started her internship in Obstetrics and Gynecology at the Grodno Regional Maternity Hospital (Belarus). At the same time she started her postgraduate training in Obstetrics and Gynecology at the Belarusian Medical Academy for Postgraduate Training, Minsk (Belarus), which was successfully finished in 2002. In 2000 she started her specialization in Obstetrics and Gynaecology at the Minsk Maternity City Hospital 2 (Belarus). In 2002 she spent two months at the Laboratory of Infertility and Reproductive Medicine (Head: Prof. Dr. C. Brucker), the University of Ulm (Germany) as a visiting research fellow. In 2003 she moved to Maastricht (the Netherlands), where she started working as research fellow at the Departments of Gynaecology and Pathology, the University of Maastricht under supervision of Dr. P. Groothuis, Dr. L.L.H Peters and Prof. Dr. J.L.H. Evers.

On November $15^{\text {th }}, 2004$ she started her PhD-project on the hormoneinduced changes in the coagulation system under supervision of Dr. G. Tans and Prof. Dr. J. Rosing at the department of Biochemistry, the Cardiovascular Research Institute Maastricht (CARIM). In 2005 she obtained her status of article 9-expert according to the Law on Animal Experiments. After taking several courses in the field of cardiovascular research, she received the CARIM PhD-Training Certificate in November 2007. In August 2009, she started as a post-doc at the department of Biochemistry at the University of Maastricht. The result of the research she performed during her PhD-training is described in this thesis. 



\section{Acknowledgments}

The Acknowledgements' chapter is not easy to write, but it is the most pleasant and popular chapter of the thesis. This part is usually read first and sometimes it is the only chapter that one reads.

It is my great pleasure to express my deep gratitude to all people who guided and supported me in my work on the $\mathrm{PhD}$ thesis. Any research is teamwork and a great deal of my thesis I owe to the team of brilliant researchers who participated in the creation of this work.

First of all, I would like to express my sincere gratitude to my promotor Prof. Dr. Rosing for his continuous support over the past five years. Dear Jan, thank you for the opportunity to work in your group, for your continuous interest in the progress of my work as well as non-scientific matters. Your door was always open for me as well as for other PhD students and postdocs; and you were always ready to discuss my problems, share your experience and teach me how to ask questions and how to express my ideas. Thank you for your patience with a gynecologist who was trying hard to become a specialist in Biochemistry. My special thanks to your wife, Sjoukje for her hospitality, it is always my pleasure to talk to her.

Dr. Tans, dear Guido, that were you, who introduced me into the world of Biochemistry and I am really grateful to you for this. Thank you for all your time that you spent teaching me how to design a perfect experiment and how to analyze the data objectively. I will never forget you lessons, at least those that I could follow. I still have those four pages of complicated formulas that you have written as an answer to one of my questions: "Why?" I think I will keep those pages as a remembrance of my "biochemical experience".

My thanks to Prof. Dr. Hackeng, dear Tilman, my example of a scientist who manages to remain always optimistic. This feature I miss sometimes. I appreciate your insightful suggestions and your confidence in my future prospective.

My dear, dear Stella! It is difficult to express in a few sentences how grateful I am to you! How many things you taught me from my first days at the department of Biochemistry till now? Who knows how many thousands samples we measured together, how many peptides tested during these years? Your opinion was always very important for me, independently whether it concerned a design of an experiment or the cover of my $\mathrm{PhD}$ thesis. Besides, you have a real talent of communication with people, your connections inside and outside of the University were often useful for me. And of course you are the best organizer of social activities that I know! Thanks again! 
I am grateful to Dr. Castoldi, better known as Betta for her readiness to answer my questions or help me with calculations of thrombin generation curves; to Henry, who was my teacher in my first animal experiments and did not spare his time to help me in my work with animals; to Menno and Leon who shared their experience of the cell culture work with me; to Berry for his help with my computer, to Dr. Heemskerk, Gerry and René for valuable discussions, to my former and present colleagues: Rory, Kristin, Jeroen, Kenneth, Lisbeth, Wencke, Rudi, Connie, Olivier, Alexandra, Simone, Kristien, Pieter, Dennis, Mahesh, Roy, Sameera, Karin, Jianyfeng, again Lisbeth and all other people who work at the department of Biochemistry. You all contributed to my work in one or another way: some by a useful advice or suggestion, some by practical help or just by the friendly atmosphere that you created in our department. Thank you all and the best of luck in your scientific carriers! It was and is a great pleasure to work with you!

I can not forget our indispensable Trees, thank you very much for you help with all kinds of documents and for your readiness to give a wise advice. You became a real friend of our small family.

I am also greatly indebted to my teachers in the past and people who supported my first steps in the big world of science: Dr. P. Groothuis, Dr. C. Punyadeera, Dr. L.L.H. Peeters, Prof. Dr. J.L.H. Evers and Rick.

For their support in the development of the papers that laid basis to this thesis I would like to acknowledge our collaborators: Prof. Dr. R.M. Bertina, Prof. Dr. F.R. Rosendaal, Prof. Dr. F.M. Helmerhorst, Dr. H.A.A.M. van Vliet, Dr. B.J.M. van Vlijmen, Audrey Cleuren, Dr. K. Fleisher (Leiden University Medical Center), Prof. Dr. P.M. Sandset (Ullevål University Hospital), Prof. Dr. M. Cushman, Dr. J.V. Johnson, Dr. J. Lowell, Dr. G.J. Badger (University of Vermont).

I would like to thank the members of my dissertation committee Prof. Dr. J.G.R. de Mey, Prof. Dr. I. Pabinger, Dr. L.L.H. Peeters, Prof. Dr. M.H. Prins and Prof. Dr. C.D.A. Stehouwer, who have generously given their time and expertise to read my work.

My gratitude to people who are standing behind the company names, enlisted in the page 4: Pieter, Edward, Steffen, Kris, Ann thank you!

I also would like to thank Julian for helping me, an amateur, to design the cover for my thesis.

И пожалуй наиболее важное, я хочу поблагодарить моих родителей. Мама, папа, спасибо Вам огромное за все что Вы для меня сделали, спасибо Вам за то что я такая как есть. Я знаю что Вам иногда тяжело со мной и с моим упрямством, но где-то именно это упрямство помогает мне 
в трудную минуту не сдаться. Я хочу чтобы Вы знали что я Вас очень и очень люблю, берегите себя. Ну что Андрюха, мой любимый и единственный братишка, перевед? Спасибо и тебе что ты у меня есть! Огромное спасибо всей нашей семье за моральную поддержку!

Егор Осипович и Светлана Николаевна, моя вторая семья, низкий поклон и спасибо Вам за то что Вы подарили мне мою вторую половинкумоего любимого Вадима! Мой дорогой супруг! Спасибо тебе огромное за твою поддержку и помощь, за твоё терпение, за то что ты у меня есть! Эта диссертация не только моя, но в равной степени и твоя заслуга.

Спасибо также всем нашим друзьям за их поддержку и готовность помочь в трудную минуту! 
